A 11102 445395

\section{Reference}

NATL INST OF STANDAROS \& TECH R.I.C.

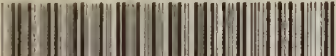

A1 1102445395

1269

NBS

PUBLICATIONS

\title{
Electrical Performance Tests for Audio Distortion Analyzers
}

O.B. Laug, G.N. Stenbakken, and T.F. Leedy

U.S. DEPARTMENT OF COMMERCE

National Bureau of Stanciards

Gaithersburg, MD 20899

Julỵ 1985

Final Report

Issued November 1985

-2.- red for:

- QC - Army Communications Electronics Command Monmouth, New Jersey 07703 

NBSIR $85-3269$

\section{ELECTRICAL PERFORMANCE TESTS FOR AUDIO DISTORTION ANALYZERS}

O.B. Laug, G.N. Stenbakken, and T.F. Leedy

U.S. DEPARTMENT OF COMMERCE

National Bureau of Standards

Gaithersburg, MD 20899

July 1985

Final Report

Issued November 1985

Prepared for:

U.S. Army Communications Electronics Command

Fort Monmouth, New Jersey 07703

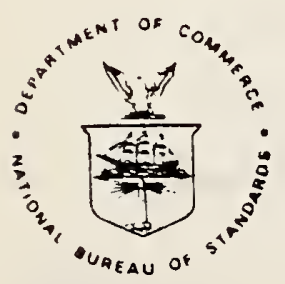

U.S. DEPARTMENT OF COMMERCE, Malcolm Baldrige, Secretary NATIONAL BUREAU OF STANDARDS. Ernest Ambler, Director 

TABLE OF CONTENTS

Page

List of figures....................... iv

List of Tables .................... . . v

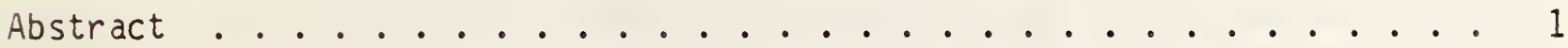

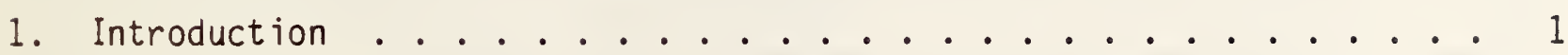

2. Background ................... 2 2

3. Audio Distortion Analyzer Applications \& Principles ....... 3

4. Distortion Analyzer Performance Measurements . . . . . . . . 9

4.1 Input/Output Characteristics ............ 10

4.1.1 Input Impedance . . . . . . . . . . . . . 10

4.1.2 Input Common-Mode Rejection Ratio (CMRR) . . . . . . . 14

4.1.3 Input Protection .............. 19

4.1.4 Monitor Output Impedance . . . . . . . . . . . . 19

4.1.5 Monitor Output Frequency Response . . . . . . . . . . 22

4.1.6 Monitor Output Linearity (Absence of Clipping) . . . . 23

4.2 Voltmeter Mode ................ 23

4.2.1 Voltmeter Accuracy and Range ............ 23

4.2.2 Bandwidth ................ 24

4.3 Distortion Measurements . . . . . . . . . . . 25

4.3.1 Two Sine Wave Test .............. 26

4.3.2 3:1 Crest Factor Signal Test .......... . . 30

4.3.3 SINAD Test ............... . . . 40

4.3.4 Residual Distortion and Noise........... 42

4.4 Filter Characteristics . . . . . . . . . . . 45

4.4.1 High Pass/Low Pass Filter Measurements . . . . . . . . 45

5. References .................... 49

Appendix A . . . . . . . . . . . . . . A-I

Appendix $B$. . . . . . . . . . . . . . . . B-1

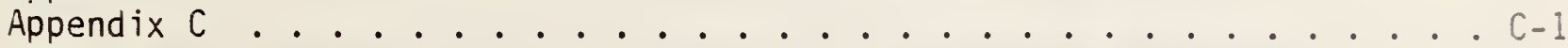

Appendix 0 . . . . . . . . . . . . . . . . . D-1

Appendix E . . . . . . . . . . . . . . . . . . E-1

Appendix $F$ 
Figure 1 Block diagram of a harmonic distortion measurement. The basic distortion anajyzer has a tunable notch filter to remove the fundamental frequency component of the signal and a detector to measure the remaining signal. . . . . . 5

Figure 2 Block diagram of the essential elements contained in a modern audio distortion analyzer.

Figure 3 Equivalent circuit for determing input impedance. . . . . . 11

Figure 4 Test setup for measuring the common-mode rejection ratio of an audio distortion anaiyzer (preferred method). . . . 15

Figure 5 An alternate method of measuring the common-mode rejection ratio of an audio distortion analyzer. ...... 18

Figure 6 Equivalent circuits for determining output resistance. . . . 20

Figure 7 Test setup for measuring distortion accuracy with the sine wave signals. ............. 27

Figure 8 Test setup for measuring distortion accuracy with signals that have a $3: 1$ crest factor. . . . . . . . 29

Figure 9 Waveform of $3: 1$ crest factor signal using 9 th narmonic pulses with amplitudes of 1.86 times the fundamental amplitude.

Figure 10 Waveform of $3: 1$ crest factor signal using 19th harmonic pulses with amplitudes of 0.826 times the fundamental amplitude.

Figure 11 Magnitude spectrum of $3: 1$ crest factor signal using 9 th harmonic pulses.

Figure 12 Magnitude spectrum of $3: 1$ crest factor signal using 19th harmonic pulses.

Figure 13 Test setup for measuuring SINAD accuracy. . . . . . . 39

Figure 14 Test setup for measuring residual distortion and noise. . . 41

Figure 15 Test setup for measuring residual distortion and noise at input levels above 10 volts rms.......... 43

Figure 16 Test setup for measuring the quality of the low-distortion

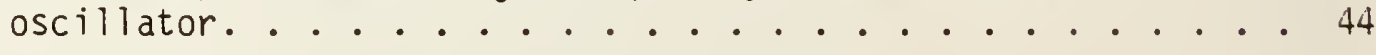

Figure 17 Typical Bode plots of high and low-pass filters. . . . . 46 
List of Tables

Table 1 Typical AC Calibration Accuracy Specification . . . . . . 24

Table 2 Magnitude for the 9th Harmonic Pulse ........... 31

Table 3 Magnitude for the 19th Harmonic Pulse ............ 32

Table 4 Crest Factors Resulting from Various Combinations

of Amplitude and Harmonic Number ........ . . . 32

Table 5 Error Resulting From Using a Limited Number of

Harmonics to Calculate THD .......... 33 


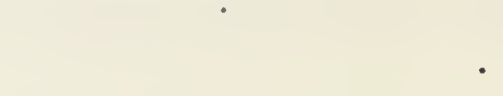


0. B. Laug, G. N. Stenbakken, and T. F. Leedy

Abstract

Electrical performance test procedures for audio distortion analyzers were developed by the National Bureau of Standards for the U. S. Army Communications-Electronics Command. The report provides detailed, step-by-step test procedures that are based on specifications supplied by the Army for purposes of evaluating audio distortion analyzer bid samples. Examples of data sheets and tables are also provided for recording interim and final results.

This report discusses the philosophy of each measurement procedure with a view toward providing an understanding of the basic metrology required to perform the measurements. In addition, the sources of measurement error are discussed. The primary applications and basic principles of modern audio distortion analyzers are also presented.

Key Words: audio distortion analyzer; distortion analyzer; distortion; distortion.specification; and test procedures.

\section{INTRODUCTION}

This report describes test procedures that were developed by the Nationa? Bureau of Standards (NBS) for the U. S. Army Communications-Electronics Command (CECOM) for testing the electrical performance of audio distortion analyzers. The test procedures are based on specifications supplied by CECOM, and will be used by the Army in their Test Measurement and Diagnostic Equipment (TMDE) Modernization Program to evaluate audio distortion anaiyzer bid samples. The report focuses only on the electrical performance test procedures that can be performed without access to the interior of the instrument under test.

The test procedures are based primarily on the Army performance specifications which, for the most part, represent performance levels attainable by modern state-of-the-art commercial audio distortion analyzers. The main objective in developing the test procedures has been to provide measurement techniques which are accurate, repeatable, and simple to perform. Above all, the procedures must be technically sound so as to provide an unbiased and objective evaluation of competitive instruments.

From a cursory inspection, of some of the procedures presented in this report may appear to the reader to be overdesigned in terms of the suggested test equipment. This may seem particularly apparent when only one procedure 
is examined out of context with the entire set of procedures for the distortion analyzers and the entire TMDE bid sample testing program. The reason for specifying instruments which in some cases appear as "overkill" are twofold: first, where possible, most of the tests are designed to provide accurate results without having to resort to special fixtures and techniques, rigorous accounting of errors, or highly skilled test engineers. Second, since the TMDE Modernization Program is relatively new, part of the program objective is to build a laboratory at CECOM with an inventory of modern general purpose test equipment that will serve a wide range of bid sample testing needs. Thus, most of the specific test equipment specified by make and model represent equipment that is a part of, or will become, a part of the CECOM labor atory.

This report is divided into three sections: background, audio distortion analyzer applications and principles, and distortion analyzer performance measurements. The first section gives a brief overview of the Army's TMDE Modernization Program. The second section contains general information on the applications and principles of modern audio distortion analyzers. The third section discusses, in depth, the primary performance measurements with emphas is on a preferred method, some alternate methods, and a discussion of error sources. The information in this last section is intended to provide the theory and analysis to support the actual detailed procedures given in Appendix B. The detailed procedures in this appendix are step-by-step procedures intended to be used by the Army for evaluating bid samples to assure conformance to the set of Army specifications given in Appendix A. Also, included in. Appendix $C$ are samples of appropriate data sheets and tables for recording interim and final results. A program for generating an arbitrary waveform is provided in Appendix $D$. Appendix $E$ shows the design and characteristics of a low-pass filter that is used in some of the procedures, and Appendix F lists all the test equipment and accessories required for the test procedures.

Although the test procedures described in this report were specifically designed for use by the TMDE Modernization Program, many of the tests can be considered generic in nature and perhaps could serve as the basis of some type of industry test standard for audio distortion analyzers.

\section{BACKGROUND}

The Department of the Army has undertaken a Test Measurement and Diagnostic Equipment (TMDE) Modernization Program. The general goal of this program is to provide TMDE for the Army, eliminate the proliferation of numerous types and models of such equipment, and thus reduce the logistical burden. Specifically, the intent of the TMDE Modernization Program is to:

1. Introduce a minimum ensemble of different types and models of up-todate TMDE into the Army inventory,

2. Replace multiple generic types of TMDE with a single new item where feasible and,

3. Continually assess the Army TMDE inventory to identify individual or families of TMDE that require replacement. 
The acquisition of new TMDE items progresses through a two step invitation for bid procedure. The first step begins with letter requests that are released to potential offerors for bid samples. The offeror has a period of 60 days to analyze the solicitation requirement and send bid sample equipment to the Communications-Electronic Command (CECOM), Ft. Monmouth, NJ for testing. Equipment is evaluated for performance, useability, maintainability, workmanship, ease of calibration, military suitability, safety, and environmental capability. After the bid sample testing, only the offerors with test equipment that meets the solicitation requirements are invited to submit bids. The second step occurs when the bids are received, evaluated, and the lowest responsive bidder is awarded the contract. This procedure is believed by the Army to provide reliable and maintainable test equipment with superior performance characteristics for support of weapons systems.

Bid sample equipment evaluation requires an established set of test procedures which can objectively determine conformance to specifications. Unlike some evaluations such as safety and workmanship which are more general and widely applicable, electrical performance test procedures are by necessity specification specific. That is, each particular electrical performance specification must have a procedure. Although some equipment manufacturers provide performance check procedures for purposes of incoming inspection, or readjustment to specifications, there is a lack of generic test methods applicable to various classes of equipment that can be directly and objectively used by the Army.

Therefore, before bid sample testing can proceed, appropriate test procedures must be developed and validated. This report deseribes the test procedures specifically developed by NBS for the Army to perform bid sample testing of audio distortion analyzers.

\section{AUDIO DISTORTION ANALYZER APPLICATIONS \& PRINCIPLES}

Modern audio distortion analyzers are fully automatic, programmable, and can measure Total Harmonic Distortion (THD) levels down to the order of $0.003 \%$ (-90 dB). Also, these analyzers are designed to make Signal, Noise, and Distortion (SINAD) measurements in addition to being versatile enough to be used as a high sensitivity autoranging voltmeter, frequency counter, or even as a low-noise amplifier. Distortion and SINAD measurements have, in the past, required a great deal of operator control and interaction but microprocessor control for the automatic tuning and amplitude leveling has removed this burden from the classic audio distortion analyzer.

The term "audio" generally means frequencies within the range of human hearing, (about $20 \mathrm{~Hz}$ to $20 \mathrm{kHz}$ ) although frequencies on either side of this range are often loosely termed as "audio." Most audio distortion analyzers have a range of operation that typically covers a frequency range from $20 \mathrm{~Hz}$ to $100 \mathrm{kHz}$. Because of their wide bandwidth, most analyzers include filters which allow bandwidth limiting, hum rejection, and weighted measurements of noise. 
The primary application areas for distortion analyzers are general audio testing and transceiver testing. In audio testing, a distortion analyzer can be used to measure the frequency response and distortion characteristics of filters, amplifiers, and high-fidelity audio systems. The most common measurements for transceiver testing are SINAD for FM receivers and Signal-to-Noise $(S / N)$ ratio for AM receivers. The above mentioned types of testing all require a low-distortion, low noise signal source. Consequently, some distortion analyzers also contain a built-in low-distortion source, making the unit a complete, self-contained audio measurement system.

Distortion of electrical signals takes many forms. The basic causes of distortion are nonlinearity in amplitude response and nonuniformity of phase response. Distortion may be grouped into the following commonly encountered types: [1]

1. Harmonic distortion is due to nonlinearities in the amplitude transfer characteristics. It causes a dispersion of energy that is distributed in integer multiples of the fundamental frequency.

2. Intermodulation distortion is also due to nonlinearities in amplitude transfer characteristics and causes a spurious output resulting from the mixing of two or more signals at different frequencies. The spurious output occurs at the sum or difference in integer multiples of the original frequencies.

3. Phase distortion is a deviation from a constant slope of the output phase versus. frequency response of a device. This deviation produces echo responses in the output that precede and/or follow the main response.

There are other specific types of distortion which are classified according to their causes such as cross-over distortion or transient distortion. These distortions, as well as other types, manifest themselves in one or 211 of the above listed distortion types. Most audio distortion analyzers are designed mainly to measure THD and SINAD. Intermodulation distortion measurements $c$ an also be made with some audio analyzers provided they contain the appropriate filters to give a weighted response that conforms to a particular industry standard. However, most audio distortion analyzers do not provide an intermodulation measurement capability.

THD is defined as the ratio of the total rms voltage in all significant harmonics to the rms voltage of the fundamental. The ratio is usualiy expressed as a percentage or in decibel units. A spectrum analyzer can be used to make a THD measurement of a signal by measuring the magnitude of all the harmonics and the fundamental. Then the ratio of the rms sum of all the harmonics to the rms level of the fundamental is computed to obtain the THD. The spectrum analyzer method, however, requires a costly instrument and is tedious to perform. On the other hand, a distortion analyzer can quickly make an accurate distortion measurement by removing the fundamental of the signal being investigated and measuring the remainder relative to the signal. Figure 1 shows the basic block diagram of a harmonic distortion analyzer measurement. A distortion measurement made this way also includes effects from noise and hum. Thus, the term (THD $+N$ ) has been recommended by the Institute of High Fidelity [2] to distinguish distortion measurements made 


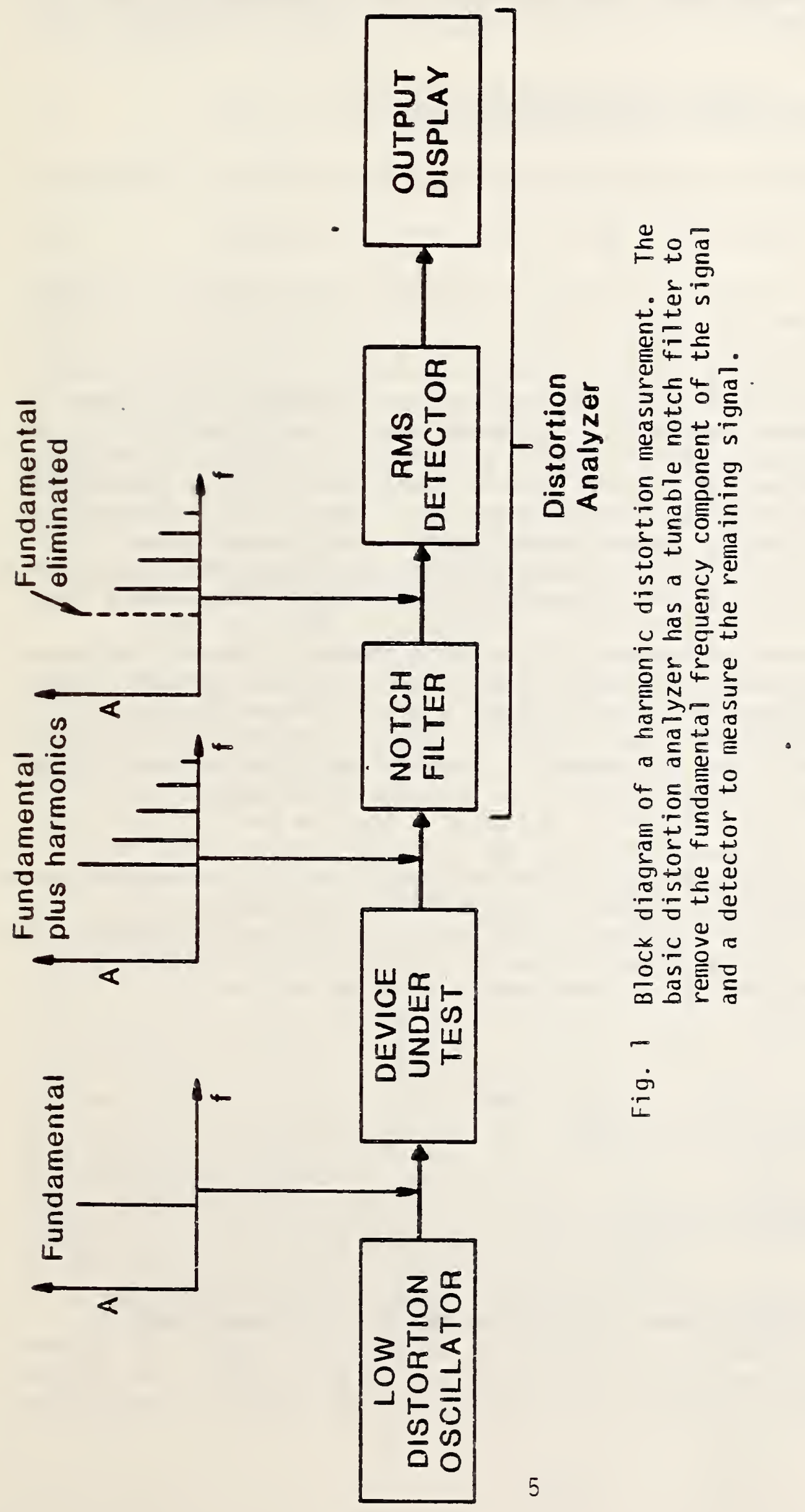


with a distortion analyzer from those made with a spectrum analyzer. An audio distortion analyzer, therefore, measures distortion $D$ according to the following relationship:

$$
D=\frac{\text { noise + distortion }}{\text { fundamental }+ \text { noise }+ \text { distortion }} .
$$

The distortion is usually converted and displayed as

$$
\text { Percent units }=D \times 100 \text {, }
$$

or

$$
d B \text { units }=20 \log D \text {. }
$$

When using a distortion analyzer which makes a distortion measurement according to the above expression, it is important to know that the measurement is not exactly "total harmonic distortion" as defined when using the spectrum analyzer method. The difference comes about for two reasons. First, since the distortion analyzer measures, exclusive of the fundamental, all harmonic signals, noise, and extraneous non-harmonic signals, the indicated level of distortion may be considerably higher than that contributed only by the harmonics. In order to separate certain extraneous signals such as power line hum or out-of-band noise, selectable filters are usually available to reject such extraneous signals. The second difference, al though small for low distortion, results because the distortion analyzer references the total distortion (numerator) to the input signal (fundamental + distortion) - the denominator - as opposed to referencing the total distortion to only the magnitude of the fundamental. In other words, a distorted signal level is not quite the same as the level of the signal fundamental. An example will perhaps best illustrate this point. Suppose that a given signal has a one volt ac (rms)fundamental level and a 0.2 volt ac (rms) sum of all harmonics. The THD of this signal would simply be 20 percent or one fifth the fundamental. The same signal measured with a distortion analyzer will indicate a slightly lower value because the distortion analyzer references the harmonic level [0.2 volts ac (rms)] to the rms level of the "signal" (i.e., fundamental + harmonics) which in this example would be

$$
\left|(1)^{2}+(0.2)^{2}\right|^{1 / 2}=.1 .02 \vee \text { ac (rms). }
$$

Thus, the indicated distortion becomes

$$
\frac{0.2 V(\mathrm{rms})}{1.02 V(\mathrm{rms})}=0.196 \text { or } 19.6 \% \text {. }
$$

The difference here amounts to only 2 percent below the actual THD, but it is clear that the difference becomes significant at very high levels of distortion. 
Most distortion analyzers are equiped to measured SINAD. The SINAD measurement is essentially the reciprocal of the distortion measurement. Thus, a SINAD measurement is made according to the following relationship:

$$
\text { SINAD }=\frac{\text { fundamental }+ \text { noise }+ \text { distortion }}{\text { noise }+ \text { distortion }}
$$

The SINAD is usually converted and displayed as

$$
d B \text { units }=20 \log (\text { SINAD). }
$$

SINAD is a widely accepted method of specifying receiver sensitivity. Receiver sensitivity is defined as the RF level that, when modulated with a pure audio tone, produces a certain SINAD at the receiver's audio output. The "usable sensitivity" is generally defined as 12-dB SINAD which serves as a reference level where a tone can just be discerned in the noise [3]. Usually the SINAD measurement is more heavily filtered than the distortion measurement in order to smooth the noisy signals encountered in receiver testing. Sometimes a psophometric filter is required in the receiver sensitivity measurement. The psophmetric filter weights the frequency response of the distortion analyzer with a bandpass characteristic that approximates the response of human hearing. If a distortion analyzer employs such a filter it is characteristics are specified by the C.C.I.T.T [4].

Figure 2 shows a block diagram of the essential elements contained in a modern automatic distortion analyzer. The particular architecture shown may not necessarily conform to an actual instrument but rather is intended to illustrate the basic principles involved. Specific details of control, whether done directly in hardware or through the central processing unit, (CPU) are not within the scope of this discussion.

The input stage is designed to accept the test signal in differential form and convert it to a single-ended signal (referred to ground). The differential input configuration helps to reject common-mode signals. The input stage also contains appropriate attenuation networks for high level signals and overload protection circuitry to protect the input circuits. The signal is further amplified by a programmable gain amplifier which is set to keep the signal level at the input detector within a narrow range to optimize the detection accuracy. The input detector converts the rms level of the signal to a dc voltage. The dc output level of the input detector is used to set the gain of the first programmable amplifier and becomes the denominator of the distortion measurement or the numerator of the SINAO measurement. A high-pass or psophometric filter can be inserted in the signal path betiveen the programmable amplifier and the notch filter. A $400 \mathrm{~Hz}$ high-pass filter is often used to suppress power line hum or squelch tones used in some mobile receivers. As mentioned previousiy, a psophometric filter can be switched in at this point for certain receiver measurements.

In the distortion or SINAD measurement, the fundamental of the signal is removed by a notch filter which is automatically tuned to the fundamental of the signal. Auto-tuning of the notch filter is accomplished by several methods which involve the CPU to control the internal analog tuning circuitry. 


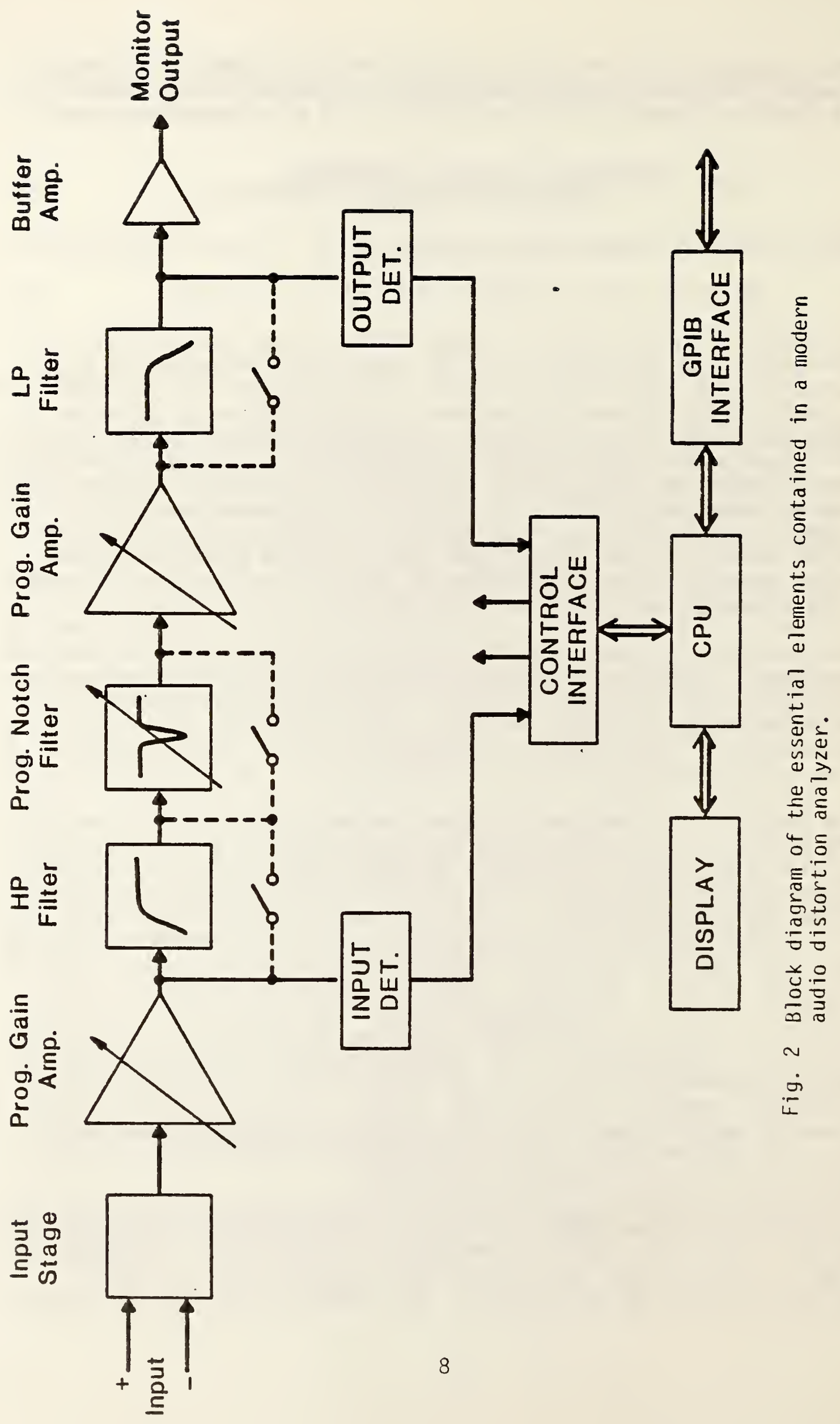


Large amounts of noise may prevent the automatic tuning circuits from locking onto the fundamental during SINAD measurements. Thus, most distortion analyzers require some manual tuning to bring the locking frequency within approximately 5 percent of the source frequency in order for the system to lock onto the fundamental.

A programmable gain amplifier following the notch filter is used to amplify the low-level noise and distortion signals. The signal levels are adjusted to within a narrow range by the programmable gain amplifier to optimize the output detector accuracy. If desired, a series of low-pass filters can be switched in to remove high-frequency noise components in low frequency distortion measurements. The two filters most commonly used are 30 $\mathrm{kHz}$ and $80 \mathrm{kHz}$ low-pass filters with at least a $60 \mathrm{~dB}$ per decade rolioff.

The output detector converts the rms level of the signal to a dc voltage which becomes the numerator in the distortion measurement and the demoninator. in the SINAD measurement. Rms detection is the most often used detection method because it is proportional to the power of a signal. However, some distortion analyzers employ the option of "average" detection which was more popular in early designs.

The output from the second programmable amplifier drives a buffer amplifier which provides an output signal that can be used to monitor the processed signals with another instrument such as an oscilloscope.

If the distortion analyzer is to be used as a voltmeter, the notch filter is switched out and the output level from the output detector is displayed. Appropriate scaling is managed by the CPU's control of the programmable amplifiers. Also, some distortion analyzers provide a display of the frequency of the fundamental signal. Thus, the versatility of the instrument is extended since it may be used as a general purpose frequency counter.

The audio distortion analyzer outlined in figure 2 is a very versatile instrument. Its measurement flexibility comes from the CPU's ability to process and display various measurements, and the measurement can be completely controlled through the General Purpose Interface Bus (GPIB).

\section{DISTORTION ANALYZER PERFORMANCE MEASUREMENTS}

This section discusses the philosophy of the measurements employed in the test procedures provided in Appendix B. The information in this section is intended to provide an understanding of the measurements and some of the details which must be considered. It is important that there be an understanding of the basic metrology required to perform the measurements because no matter how detailed a particular procedure is prescribed and followed, there are invariably situations that may require slight deviations or modifications to a procedure. The format of this section is divided into 
four groups of measurements: Input/Output Characteristics, Voltmeter Mode, Distortion Mode, and Filter Characteristics. Under each of these groups, particular measurements are discussed, with emphasis on a preferred method, some alternate methods if applicable, and a discussion of error sources.

\subsection{Input/Output Characteristics}

The characteristics of the audio distortion analyzer signal input port which are generally specified are: the input impedance, the common-mode rejection ratio (for differential inputs), maximum input voltage, and input over-voltage protection. A monitor output port is usually provided to permit external instrumentation to monitor the processed signal. The output impedance of the monitor output is usually specified. Other input-output specifications such as physical configuration and location of connections do not require a measurement.

\subsubsection{Input Impedance}

The input impedance specification relates to the loading that an instrument presents to a circuit or device under test. Input impedance is often stated in terms of a dc resistance and a shunt capacitance. The user is interested in this parameter to determine the effect that the instrument may have upon the circuit under test. Since capacitive reactance varies with frequency, in order for the input impedance specification to have the most practical meaning, it is usually expressed in terms of a resistance and a parallel capacitance rather than an impedance at a given frequency. In some applications, a low input impedance could upset the operation of the circuit which is being measured. Most often, though, it is the finite input impedance which interacts with an equivalent source resistance to cause a measurement loading error.

For example, the input impedance of typical audio distortion analyzers may be specified to be 100 kohms, accurate to \pm 2 percent, shunted by less than 300 picofarads. The effect of this input resistance and capacitance on the accuracy of voltage measurements may be calculated by considering the circuit shown in figure 3 . 


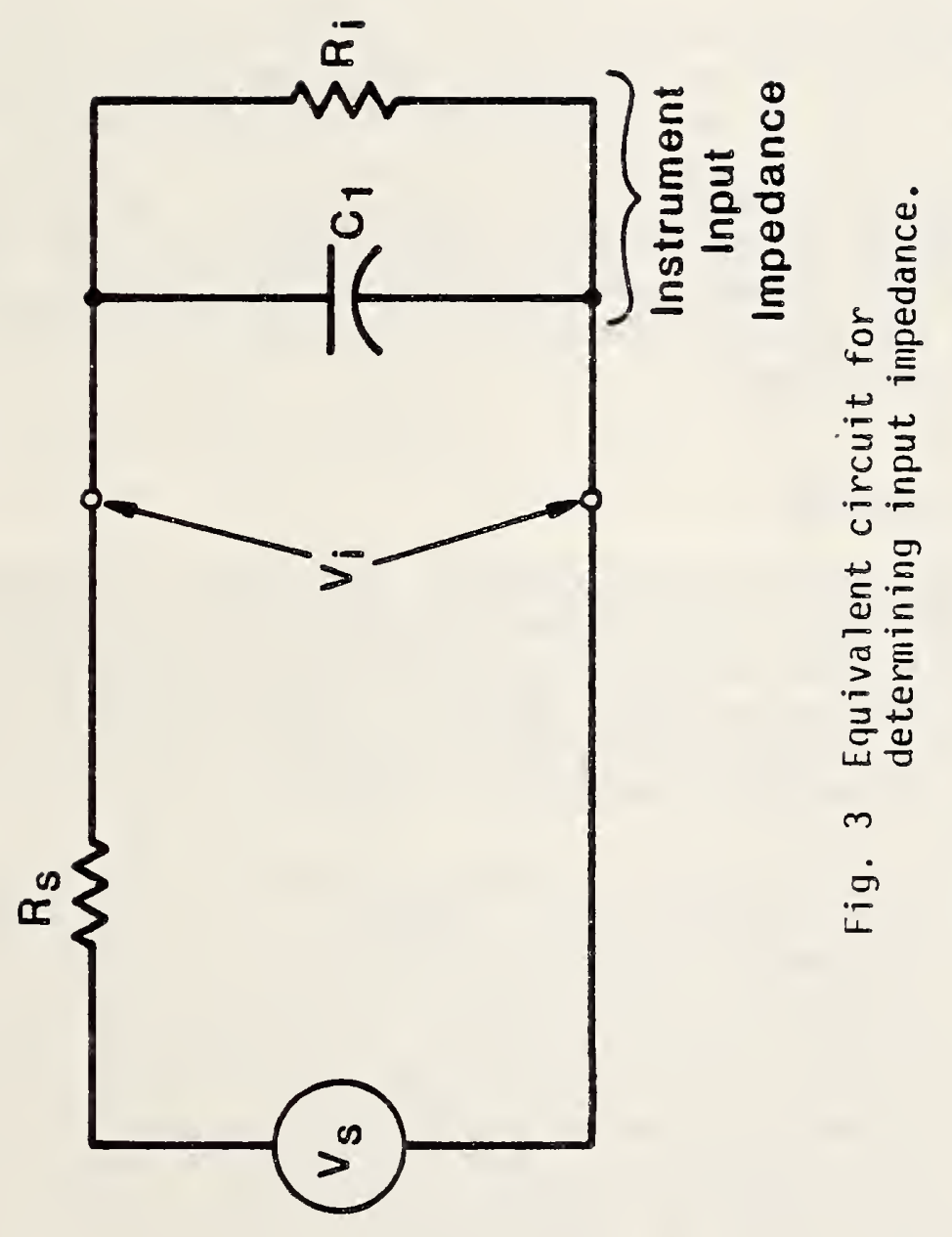


In this circuit, $R_{S}$ is the equivalent circuit or device source resistance in series with the source voltage $V_{S}$ being measured, $R_{j}$ is the instrument input resistance, and $\mathrm{Ci}$ is the instrument input shunt capacitance. The fractional loading error, $E$ may be expressed as

$$
E=1-\left(V_{i} / V_{s}\right)=1-\frac{R_{i}}{\left[\left(R_{i}+R_{s}\right)^{2}+\left(2 \pi f R_{s} R_{i} C_{i}\right)^{2}\right]^{1 / 2}},
$$

where $f$ is the frequency:

From this equation, and the values given above for $R_{i}$ and $C_{i}$, it is possible to determine the amount of error introduced by the loading effects of the input impedance of the distortion analyzer when used in the voltmeter mode. For example, if the user wishes to measure a voltage to within two percent, even at low frequencies (less than $100 \mathrm{~Hz}$ ) where the effects of the shunt capacitance (second term of equation 8) may be considered negligible, then the impedance of the voltage source must not exceed approximately 2000 ohms. On the other hand, for the same $2000 \mathrm{ohm}$ source resistance, the total loading error increases to almost four percent at $50 \mathrm{kHz}$ due, in part, to the $300 \mathrm{pF}$ input capacitance.

Measurement Technique

Two methods can be used to measure the input impedance of the audio distortion analyzer. The first method uses a direct-reading LCR meter to measure the resistive and capacitive components of the input impedance. The second method uses an external resistor in series with the input to obtain a voltage division between the resistor and the input such that the input resistance and capacitance may be calculated.

The preferred method is to use a commercial digital LCR meter to directly measure the input resistance and capacitance. Such instruments may be broadly categorized, according to the technique used, into the bridge, voltage/ current, and $Q$ methods. In the bridge technique, circuit conditioning required to achieve a balance or null condition is processed to indicate the measured values of the resistance and shunt capacitance. The voltage/current method essentially uses Ohm's law in that a constant voltage or current is applied to the unknown and the converse current or voltage is indicative of the unknown impedance. The $Q$ method utilizes the unique characteristics of a resonant circuit to determine $Q$, and indirectly $L, C$, and $R$.

When the LCR method is used, the measurement port of a voltage/current type LCR meter is placed directly across the input port of the distortion analyzer under test which should be energized. The input resistance and capacitance may be read directly in terms of ohms and picofarads. Two precautions are necessary to assure that proper measurements are made. First, it is necessary that either the instrument under test or the LCR meter be isolated from power-line ground. 
The circuit configuration of the LCR meter is such that if the "low" measuring terminal is grounded to the chassis, the LCR meter will not measure correctly. Functionally, the LCR meter's "low" terminal is at virtual ground but cannot be directly shorted to ground. When the measuring terminals of the LCR meter are connected to the input terminals of the distortion analyzer, the LCR "low" terminal will be grounded through the distortion analyzers $60 \mathrm{~Hz}$ power-safety ground circuit.

The suggested method of breaking the ground circuit is to "float" the chassis of the distortion analyzer which is powered through an isolation transformer. "Floating" (disabling the power safety ground circuit) without an isolation transformer is not recommended for safety reasons. It is not necessary to use the isolation transformer when measuring the input impedance of a differential input, since neither input is grounded. If the LCR "low" terminal is grounded, a resistance and capacitance value will be displayed which is far above or below the expected value.

The second precaution in using the LCR meter is to assure that the distortion analyzer does not change ranges in response to the applied voltage from the LCR meter. Range changes can cause the apparent input impedance of the analyzer to change momentarily, forcing a range change in the LCR meter. This in turn causes the voltage output of the LCR meter to also change. Such range changing is manifested by a system oscillation wherein neither the LCR meter nor the distortion analyzer obtains the proper range. The presence of oscillating range changes is obvious by the unstable display of the LCR meter.

A second method that can be used to determine the input impedance is by measuring the loading error expressed in equation 8 with a given source resistance. The method involves two steps. The first step is to obtain the value of the input resistance, and the second step is to obtain the capacitance. Determing input resistance consists of applying an ac voltage from an oscillator through an external adjustable source resistance to the input of the distortion analyzer which is set to the voltmeter mode. The frequency of the oscillator is set to $100 \mathrm{~Hz}$, and the amplitude is set to approximately $2.0 \mathrm{~V}$ ac ( $\mathrm{rms}$ ). The external source resistance is set to zero and the voltage displayed on the voltmeter is read and recorded. The external resistance is then increased to a value such that the display is exactly one-half the recorded value. At this point, the measured external source resistance is equal to the input resistance. Note that the source resistance of the oscillator must also be accounted for as part of the total source resistance. To obtain the input capacitance, the frequency of the oscillator is increased to a frequency, $f$, of approximately $100 \mathrm{kHz}$. The external source resistance is set to zero, and the analyzer input voltage is read and noted as $V_{1}$. Then an external source resistance equal to the input resistance previously determined is inserted between the oscillator output and analyzer input and the voltage recorded as $V_{2}$. The input capacitance, $C_{i n}$, may be calculated as

$$
c_{i n}=\frac{\left[\left(V_{1} / V_{2}\right)^{2}-4\right]^{1 / 2}}{2 \pi f R_{i}}
$$

where $R_{i}$ is the value of the input resistance determined in step 1 . 
The errors associated with using the direct-reading LCR meter are attributable to uncertainties asSociated with the calibration accuracy of the LCR meter and the uncertainties of the cable capacitance connecting the LCR meter to the audio distortion analyzer under test. The basic calibration accuracy of the LCR meter used in the procedure described in Appendix $B$ is specified by the manufacturer to be 0.2 percent of reading plus one digit for capacitance measurements and 0.2 percent of reading plus two digits for resistance measurements. The total worst case rms errors associated with the LCR meter, considering the ranges used and the number of digits displayed, are $\pm 1.6 \mathrm{pF}$ and 50 ohms for the measurement of parallel capacitance and resistance, respectively.

The sources of error in using the second method are numerous, requiring an independent measurement of external source resistance which must include the source resistance of the test oscillator. The method also depends on the linearity of the voltage measurement of the analyzer. Also, for low input capacitances, the accuracy drops off rapidly as the measurement of the $V_{1} / V_{2}$ ratio of equation (9) approaches a value of two. Because of the many sources of possible error with this technique, the direct-reading LCR meter technique is preferred.

\subsubsection{Input Common-Mode Rejection Ratio (CMRR)}

The input configuration of some audio distorition analyzers provides two input ports for differential voltage measurements and rejection of common-mode signals. In many applications, especially where the signal source is located an appreciable distance from the analyzer, undesired ground loop signals can arise, particularly from the ac power source. These undesired signals appear simultaneously on both input terminals; hence, they are referred to as common-mode signals. The common-mode gain is a measure of the amplification of such a signal and should be as small as possible. The common-mode rejection ratio (CMRR) is the ratio of the desired differential gain to the undesired common-mode gain and should be as large as possible. CMRR is often expressed in $d B$ as 20 times the logarithm of the direct ratio.

Measurement Technique

A test method is described that will measure the CMRR of the differential input over given ranges of differential gain, common-mode amplitudes, and frequencies. The method is especially designed for instruments that have an autoranging capability that cannot be manually overridden. The measurement is made with a center-tapped (CT) audio-frequency transformer which permits coupling a common-mode signal with a balanced source impedance to both inputs 


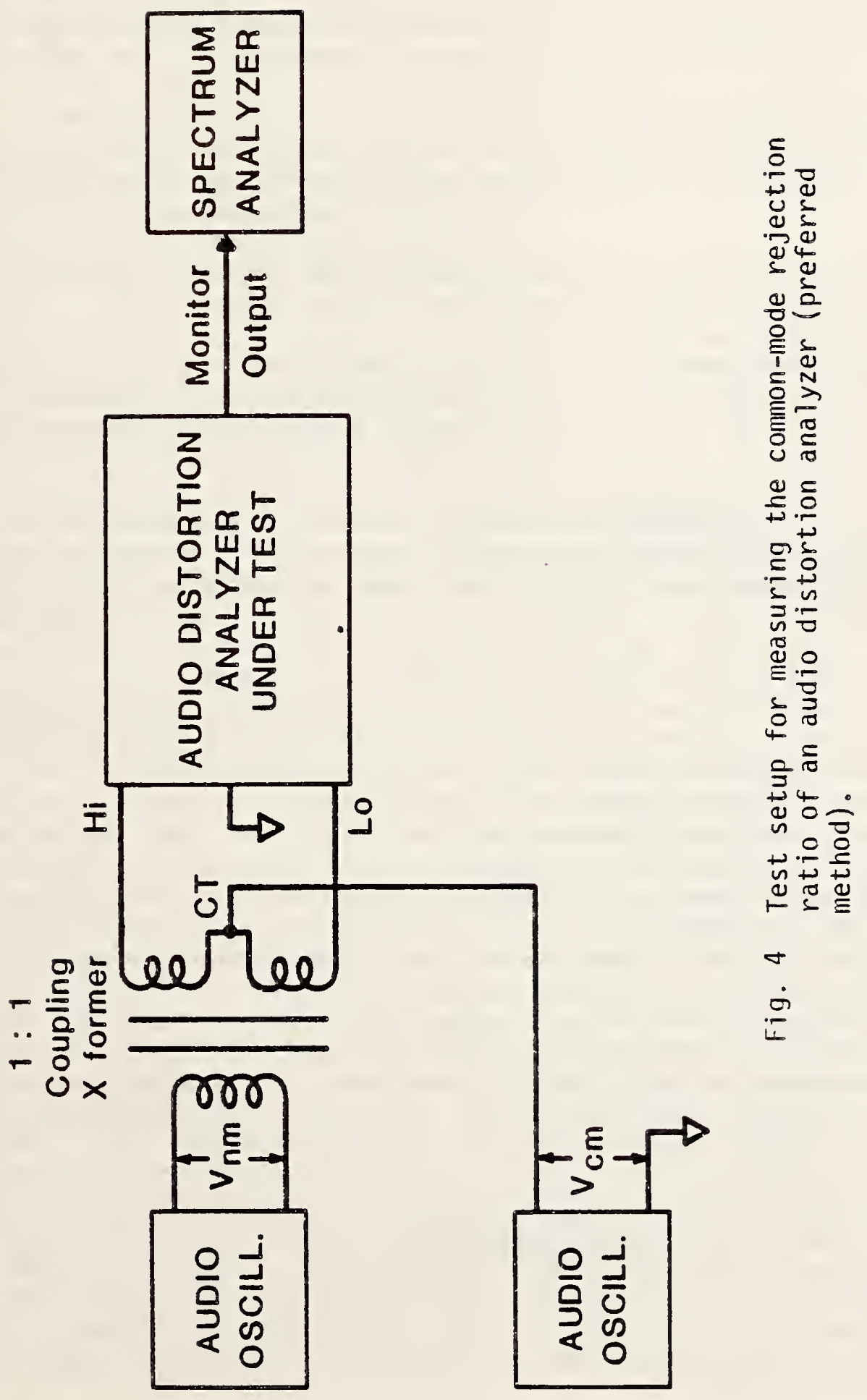


while simultaneously applying a given normal-mode signal. The test setup is shown in figure 4 . Applying a normal-mode signal simultaneously with a common-mode signal forces the instrument's autoranging system to settle at one particular range independent of the common-mode level. A spectrum analyzer is used to measure the respective normal and common-mode signals appearing at the monitor output terminals of the distortion analyzer. The equipment required for this test and its essential characteristics are:

1. Audio Oscillators -

2. Spectrum Analyzer -

3. Coupling Transformer -
Frequency and amplitude coverage over range of interest.

Frequency coverage over range of interest. Sufficient dynamic range to measure the common-mode input and output level. A dynamic range of at least $10 \mathrm{~dB}$ greater than the measured CMRR.

Line to line type, 1:1 overall turns ratio, primary 600 ohms, secondary 600 ohms CT, frequency response $100 \mathrm{~Hz}$ to $10 \mathrm{kHz}, \pm 3 \mathrm{~dB}$.

The controls of the distortion analyzer are set to operate in the voltmeter mode with all filters turned off. The frequency of the oscillator which supplies the normal-mode signal is set near the mid-band frequency of the distortion analyzer which is usually in the range of 1 to $5 \mathrm{kHz}$. The amplitude of the normal-mode oscillator is set to the desired normal-mode level at which a CMRR is to be made. Different normal-mode levels will cause the programmable amplifiers within the distortion analyzer to shift ranges which may change the normal-mode differential gain which in turn affects the CMRR. The actual normal-mode level must be measured and recorded. It is suggested that the spectrum analyzer be used to measure all levels even though the distortion analyzer itself can be used to measure the input normal-mode level. The frequency of the audio oscillator which supplies the common-mode signal is set to the frequency of interest (usually the power line frequency or harmonics of the line frequency). The level of the common-mode signal is set to the desired level which must be with in the maximum common-mode amplitude specification of the distortion analyzer. An ac calibrator can be used in place of an oscillator for the common-mode signal to obviate the need to separately measure the input common-mode amplitude. The spectrum analyzer is then used to measure the amplitudes of the normal and common-mode signals at the distortion analyzer monitor output. The CMRR is calculated as

$$
\text { CMRR }=20 \log \frac{\left(V_{\text {onm }}\right)\left(V_{\text {icm }}\right)}{\left(V_{\text {inm }}\right)\left(V_{\text {ocm }}\right)},
$$


where $V_{\text {onm }}$ is the measured output normal-mode amplitude,

$V_{\text {inm }}$ is the measured input normal-mode amplitude,

$V_{\text {ocm }}$ is the measured output common-mode amplitude, and

$V_{i c m}$ is the measured input common-mode amplitude.

An alternate and somewhat simpler method for determining the CMRR is described. It is the method most often suggested by manufacturers in their description of performance tests. The alternate method, however, must be a approached with some caution, especially if the distortion analyzer has an autoranging capability. It is recommended that all autoranging systems be overridden and measurements made at fixed gain settings. Some distortion analyzers have both a preamplifier and post-notch filter autoranging capability. The manual control of ranges may have to be set via the GPIB in some distortion analyzers.

The test setup for the alternate method of measuring the CMRR is shown in figure 5. The common-mode voltage source is connected between the common ground of the audio distortion analyzer and the two input terminals (high and low, + or -$)$ which are jumpered together. A digital multimeter measures ac voltage from the common-mode input source at the monitor output terminal. The ratio of the monitor output voltage to the input common-mode amplitude establishes the common-mode gain. The normal-mode internal gain from the input to the monitor output can either be measured directly or the gain factor can be determined from the manufacturer's specification. If the normal-mode gain is to be measured, then $a 11$ autoranging functions must be overridden and manually set. The errors associated with this measurement are the same as in the preferred method.

Sources of Measurement Error

The principle source of error arises from the uncertainties of the amplitude of input and output normal and common-mode amplitudes with the spectrum analyzer. $A \pm 10$ percent error in the measurement of the normal-mode gain and the common-mode gain can produce a maximum error of $=1.74 \mathrm{~dB}$ in the CMRR. Likewise, a \pm 1 percent error in the two gain measurements will produce a $\pm 0.174 \mathrm{~dB}$ error. The characteristics of the coupling transformer contribute negligible error to the CMRR measurement since it serves primarily as a means of providing a balanced normal-mode signal for the differential input to the distortion analyzer. If the secondary center-tap is unbalanced, this will cause an unbalance in the reflected source impedance of the normal-mode generator. This in turn unbalances the effective source impedance of the common-mode generator as seen by the differential inputs of the distortion analyzer. The common-mode imput impedance of most differential amplifiers is high but not infinite, and thus, an unequal source impedance will produce an unequal attenuation at each input which is amplified by the differential amplifier. The result is a lower measured CMRR than that which is inherent in the amplifier itself. Some specifications specify a given source impedance unbalance which is a much more difficult CMRR specification to meet, since in order to maintain a high CMRR under this condition, requires very high common-mode impedances. By connecting the common-mode signal generator to the 


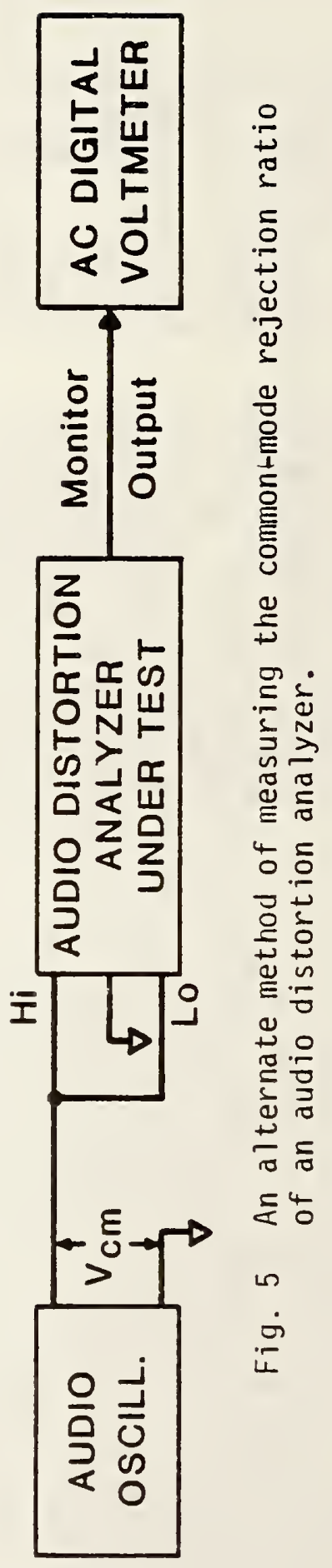


transformer secondary center-tap, the CMRR measurement is made with a balanced source impedance. An imbalance of \pm 10 percent of the secondary center-tap will cause a negligible change in the CMRR measurement, considering a nominal normal and common-mode source resistance of 600 ohms, a typical common-mode input impedance of 100 kohms, and a $40 \mathrm{~dB}$ CMRR specification. The effect of a common-mode source impedance imbalance can be greatly diminished by making the source impedance of the normal-mode generator very small.

\subsubsection{Input Protection}

The audio distortion analyzer should be protected from excessive voltages applied at the input terminals. This protection is important from the standpoint of reliability and safety. Overvoltage protection is usually specified to be automatic in the sense that the user does not need to perform a manual reset or replace fuses in the event of an application of excessive voltage. The input circuitry must be able to respond rapidly to large overvoltage signals (within specification) without degrading the performance and without causing a safety hazard to the user.

\section{Measurement Technique}

Testing for input protection is a fairly simple and straightfor'ward procedure. The test requires a source of voltage equal to the specified overvoltage specification limit. Specifying an overvoltage in rms volts without specifying the type of waveform can be ambiguous since such a specification fails to define the peak amplitude. Generally, the automatic protection circuitry is designed to respond to the peak amplitude; the rms level may be useful for determining the maximum power dissipated in the input circuitry without degradation. The input protection test procedure should be done prior to all other performance tests as a means of ensuring that a given overvoltage has not degraded the overall performance. The procedure is to apply the specified overvoltage to the input terminals of the distortion analyzer for a period of at least two minutes while observing for any obvious signs of component overstress such as smoke or sparks. If there are no obvious faults, then the overvoltage is removed and all other test procedures are performed.

\subsubsection{Monitor Output Impedance}

The output impedance specification is a measure of the internal resistance of the audio distortion analyzer as presented at the output monitor connector. This output is provided to permit external instrumentation, such as voltmeters and oscilloscopes, to measure the signals after they are processed by the circuitry of the distortion analyzer. The output signal present at the output connector depends on the mode in which the distortion analyzer is used. For example, if the analyzer is in the distortion mode, the signal present at the output connector provides a scaled presentation of the 


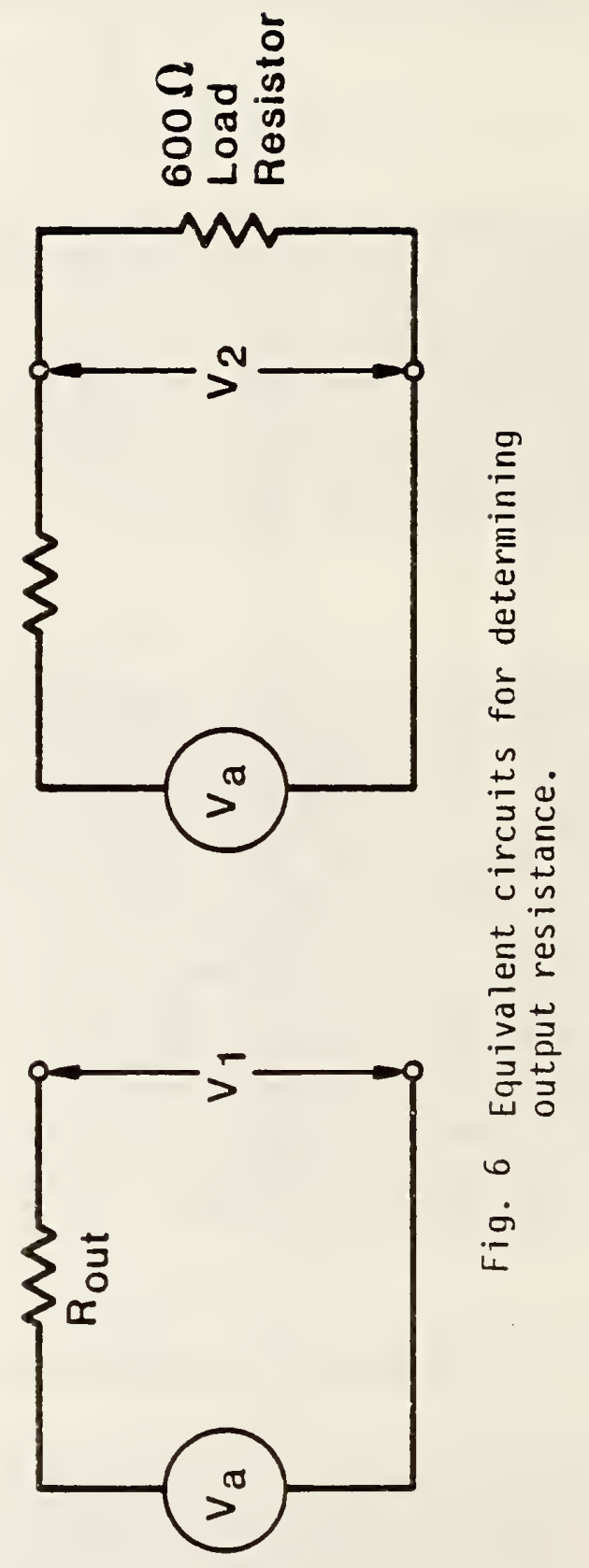


input signal with the fundamental frequency removed. For example, the user may wish to connect a frequency spectrum analyzer to this port to determine the relative amplitudes of the harmonics contained in the input signal.

It is desirable for the output impedance to be as low as possible. This permits external instrumentation to be connected to the distortion analyzer with a minimum of "loading" or reduction in signal amplitude at the output connecter when an external impedance is attached.

\section{ileasurement Technique}

The measurement of the output impedance is done in two steps. The first step consists of setting the controls of the distortion analyzer such that the filters are removed and that the signal at the output of the distortion analyzer is a scaled presentation of the input signal. A $1 \mathrm{kHz}$ signal from an audio oscillator is then applied to the input of the distortion analyzer and the voltage at the output connector is measured with a high input impedance (nominally 1 megohm) ac digital voltmeter. The amplitude of the voltage from the audio oscillator is adjusted to obtain a reading on the digital voltmeter of approximately $1 \mathrm{~V}$ ac ( $\mathrm{rms})$. The exact value of the open circuit, or "unloaded," voltage at the output connector is recorded as $V_{1}$.

The second step consists of placing a resistance equal to the expected olitput resistance across the output connector of the distortion analyzer and remeasuring the amplitude of the voltage at the output connector. The resultant voltage is recorded as $V_{2}$. Figure 6 shows the equivalent circuit from which an expected internal output resistance, Rout, of 600 onms can be calculated from $V_{1}, V_{2}$, and a $600 \mathrm{ohm}$ load resistor. The output resistance is calculated by the equation

$$
R_{\text {out }}=600\left(V_{1} / V_{2}-1\right) .
$$

\section{Sources of Measurement Error}

The measurements errors for this procedure arise from two sources. First, the 600-ohm load resistor may deviate slightly from its prescribed tolerance value. Second, the internal impedance of the voltmeter loads the circuit slightly and results in lower voltages being recorded than are actually present without the voltmeter being connected.

Choosing a load resistance approximately equal to the value of the expected output resistance represents the best compromise in making an accurate measurement of output impedance. Under such conditions, the tolerance of the output resistance is equal to the tolerance of the load resistance and the voltage ratio $V_{1} / V_{2}$ is easily measured with a digital voltmeter.

The effects of voltmeter loading in the measurement of output resistance in the $600 \mathrm{ohm}$ range can be neglected since most digital voltmeters have at least a one megohm input impedance. Usually the monitor output impecance 
specification of the distortion analyzer places a loose tolerance on the actual value for purposes of specifying a nominal value. Highly accurate determinations of output impedance for a monitor output port are generally not necessary since it is used primarily for monitoring and does not affect the basic accuracy of distortion measurements.

\subsubsection{Monitor Output Frequency Response}

The monitor output signal connector on the audio distortion analyzer provides a convenient way of examining the effects on the signal processed by the input scaling circuitry and the notch filter. In the voltmeter mode, the monitor output signal is a scaled version of the input signal with a scale factor inversely proportional to the range setting. In the distortion mode, this signal is obtained after the notch filter such that, in addition to scaling, the fundarnental frequency has been filtered out of the signal. Many of the distortion analyzers amplify the signal after the notch filter. Thus, the scale factor may not be the same in the distortion mode as in the voltmeter mode.

It may be difficult to determine the scale factor for those distortion analyzers that do not have provision for manual setting of the input sensitivity range. For those instruments that provide only automatic ranging capability, the frequency response may be checked using a fixed input voltage at various selected frequencies such that the audio distortion analyzer does not change range.

\section{Measurement Technique}

The frequency response of the signal provided by the monitor output is checked by applying an accurately known ac signal at several frequencies to the input, and measuring the monitor output signal with an ac voltmeter. For analyzers which can be manually ranged, a range should be chosen such that the signal at the monitor output is maximum without overloading. For instruments which can only autorange, care must be taken to watch for range changes during the test. If range changes occur, then the test must be rerun at a slightly higher or lower voltage such that no range changes take place. An amplifier will need to be employed to boost the test signal levels above the maximum output voltage of the test generator. The data taken at $1 \mathrm{kHz}$ is used as the reference value. The scale factor at the other frequencies must be within the specific tolerance of this value.

\section{Sources of Measurement Error}

The main sources of error are the flatness of the frequency responses of the ac calibrator, power amplifier, and the ac voltmeter. This can be checked by directly connecting the calibrator to the ac voltmeter and making the same set of measurements. The errors in this case should be about 10 times lower than the tolerance for the test. If this is not the case, then the data must be corrected using this calibration. 


\subsubsection{Monitor Output Linearity (Absence of Clipping)}

The distortion analyzer must accurately measure the distortion of signals containing waveform abberations such as spikes. If the input circuitry clips these spikes then the distortion reading will be in error. Clipping $c$ an be detected by comparing the input signal with the signal from the monitor output connector using a dual channel oscilloscope with variable gain. The two signals can be placed at the same location on the screen. Clipping will be indicated by the presence of the signal overlap everywhere except at the peaks.

Measurement Technique

The test signal used for this test is the same as that described in 4.3 .2 (3:1 crest factor signals). Refer to that section for a detailed description of the signal. For distortion analyzers whose ranges $c$ an be manually set, each range should be checked by applying an input signal with an appropriate crest factor and an rms amplitude equal to the full-scale voltage of that range. For analyzers which can only autorange, this test can be performed at selected voltages.

Sources of Measurement Error

The main error source is any nonlinear amplitude response of the ocilloscope to the two signals, which may have significantly different amplitudes. Most oscilloscopes will perform satisfactorily for this test since only gross peak limiting is being checked.

\subsection{VOLTMETER MODE}

\subsubsection{Voltmeter Accuracy and Range}

Since all of the essential elements of an ac voltmeter are contained in an audio distortion analyzer, the versatility of the instrument is enhanced by being able to use it as an ac voltmeter. Ideally, an ac voltmeter should have a uniform response over a specified frequency range, should be capable of making measurements to a predetermined accuracy, and should present stable readings with changes in environmental factors such as time, temperature, and line voltage.

Measurement Technique

The accuracy of the voltmeter contained in the distortion analyzer can be verified by applying various ac voltages over a range of frequencies to the voltmeter from a precision ac source. The voltages and frequencies chosen are commensurate with the range of the voltmeter contained in the distortion analyzer under test. Such a test is easily accomplished by connecting the distortion analyzer (set to the voltmeter mode) to an ac source or meter 
calibrator with sufficient accuracy to assure that errors in the readings are due to voltmeter errors and not due to errors in the source itself. The readings obtained on the voltmeter are then compared to the limits of accuracy given in the specifications. Those readings which exceed the limits of specified accuracy fail the test.

\section{Sources of Measurement Error}

The specified amplitude accuracy of most calibrators is a function of both output voitage and frequency. The following table summarizes the accuracy of one particular calibrator which is used in the procedure outlined in Appendix B.

Table 1 Typical AC Calibration Accuracy Specifications

\begin{tabular}{|l|l|l|}
\hline Frequency & $\begin{array}{c}\text { Accuracy } \\
\text { to } 100 \mathrm{mV} \\
\text { Range }\end{array}$ & $\begin{array}{c}\text { Accuracy } \\
\text { to } 100 \mathrm{~V} \\
\text { Range }\end{array}$ \\
\hline $10 \mathrm{~Hz}$ to $30 \mathrm{~Hz}$ & $\pm(0.1 \%+10 \mu \mathrm{V})$ & $\pm(0.1 \%+0.005 \mathrm{~V})$ \\
$30 \mathrm{~Hz}$ to $20 \mathrm{kHz}$ & $\pm(0.02 \%+10 \mu \mathrm{V})$ & $\pm(0.02 \%+0.002 \mathrm{~V})$ \\
$20 \mathrm{kHz}$ to $50 \mathrm{kHz}$ & $\pm(0.05 \%+20 \mu \mathrm{V})$ & $\pm(0.05 \%+0.005 \mathrm{~V})$ \\
$50 \mathrm{kHz}$ to $100 \mathrm{kHz}$ & $\pm(0.05 \%+20 \mu \mathrm{V})$ & $\pm(0.05 \%+0.005 \mathrm{~V})$ \\
\hline
\end{tabular}

The greatest uncertainties of the output voltage of the meter calibrator occur when the calibrator is used to generate a $1 \mathrm{mV}$ signal at the lowest frequency $(10 \mathrm{~Hz})$. Since the specifications call for a few percent accuracy over the entire range it is clear that the accuracies shown in Table 1 above are sufficient to calibrate the distortion analyzer in the voltmeter mode.

\subsubsection{Bandwidth}

\section{Significance}

The bandwidth of most audio distortion analyzers spans a frequency from a few hertz to several hundred kilohertz. Strictly speaking, the bandwidth is the difference between the upper and lower limiting frequencies, but often is simply specified as a minimum upper limiting frequency. The commonly defined limiting or cutoff frequency is the point where the response is three dB less than a reference level (usually the mid-band level). Bandwidth measurements 
should be made over the entire amplitude range or, at least, at the lower and upper ranges. A measurement at the lowest amplitude range forces the system to operate at maximum gain while a measurement at the upper range ensures that the internal attenuators are not limiting the bandwidth.

\section{Measurement Technique}

Measurement of the bandwidth, or more specifically the upper cutoff frequency limit, is a straightforward procedure requiring only a source which has a flat frequency response from midband (one $\mathrm{kHz}$ ) to the upper cutoff frequency $(300 \mathrm{kHz})$. The most convenient source for this frequency $r$ ange is a precision ac calibrator and high voltage power amplifier system. An audio oscillator can also be used but the flatness of the frequency response must be verified. The measurement is made using the distortion analyzer in the voltmeter mode to display the input voltage amplitude in $\mathrm{dB}$. All filters must be switched out of the signal path. The test source is connected to the distortion analyzer input and the frequency of the calibrator is set to about one $\mathrm{kHz}$; then the level displayed is referenced to zero $\mathrm{dB}$. The frequency is changed to the specified minimum and maximum bandwidth frequencies and the levels displayed at both frequencies are noted.

\section{Sources of Measurement Error}

The primary source of error in this measurement is the flatness of the amplitude versus frequency of the source. If the source does not have a - specified amplitude/frequency accuracy, it must be determined by independent means. High level measurements require special purpose precision amplifiers whose bandwidth should exceed the minimum specified bandwidth by at least a factor of three in order to keep the measurement error within five percent.

\subsection{DISTORTION MEASUREMENTS}

As described in section 3., the distortion of a signal is defined as the ratio of the rms amplitude of the harmonics, noise, and nonharmonic signals to the rms amplitude of the total signal which includes the fundamental, its harmonics, noise, and nonharmonic signals. The SINAD of a signal is the reciprocal of this ratio. All the distortion performance tests described in this report use the method of stimulating the distortion analyzer under test with a signal whose distortion has been determined by independent means. Three types of signals are used to fully measure the range and accuracy of the distortion analyzer in the distortion and SINAD mode. The first type of signal stimulus contains a single harmonic, either the second or the third. This signal is created by two independent sine wave sources that are added together. This type of signal is used for the "two sine wave test." The second type of signal stimulus is one that has a high crest factor and a broad spectrum of harmonics. This signal consists of a distorted sine wave that has a defined pulse at the crest of the wave. The high crest factor signa? serves two purposes; it tests the autoranging circuits' ability to pass such a signal without clipping, and it also tests the ability of the instrument to measure a 
signal with a broad spectrum of harmonics. Testing with this type of signal is called the "3:1 crest factor signal test." The third type of performance measurement uses a sine wave at the fundamental frequency in the presence of noise. The test with this type of signal is called the "SINAD test." For all of the above types of signals, a range of amplitudes, fundamental frequencies, and distortion levels are used to determine the accuracy of the audio distortion analyzer. The following list gives the test instrumentation and associated essential specifications required for making distortion measurements good to an uncertainty of

$\pm 0.1 \mathrm{~dB}:$

1. Audio Oscillator - Frequency and amplitude coverage over the range of interest. Output impedance 600 ohms or use series resistor. Switched attenuator with range sufficient to drop output by more than $40 \mathrm{~dB}$ without changing output impedance.

2. Low Distortion Oscillator - Frequency and amplitude coverage over range of interest. Output impedance 600 ohms or use series resistor.

Switched attenuator with range sufficient to drop output more than $20 \mathrm{~dB}$ below the lowest distortion level being tested. Distortion of output signal at least $10 \mathrm{~dB}$ less than lowest distortion level being tested.

3. AC Voltmeter - Frequency and amplitude coverage over range of interest. Uncertainty less than 0.5 percent.

4. Power Amplifier - Frequency and amplitude coverage over high voltage range of interest. Distortion level of output at least $10 \mathrm{~dB}$ below lowest distortion level to be tested.

5. Spectrum Analyzer - Must cover frequency range from $20 \mathrm{~Hz}$ to $300 \mathrm{kHz}$, and amplitudes from $30 \mu \mathrm{V}$ to $130 \mathrm{~V}$ ac (rms). (Note: an external attenuator probe may be needed to cover the high voltages). Absolute accuracy over these ranges must be $\pm 1 \mathrm{~dB}$ or better. Stability must allow special calibrations of limited frequency ranges to achieve an accuracy of better than $\pm 0.1 \mathrm{~dB}$.

6. Noise Generator - Flat noise spectrum from $20 \mathrm{~Hz}$ to $100 \mathrm{kHz}$ within $\pm 3 \mathrm{~dB}$. Attenuator switch settings over $40 \mathrm{~dB}$. Stability over one hour of better than $0.1 \mathrm{~dB}$ when measured with a broadband ac voltmeter.

\subsubsection{Two Sine Wave Test}

One very common form of distortion is harmonic distortion, where one or more harmonics of the fundamental are present with the fundamental. This type of distortion is simulated in this test by combining two signals which are harmonically related ( $i . e$. , the fundamental and one harmonic). Combining the two signals must be done in a manner which does not introduce any additional unknown distortion into the two signals. Accurate knowledge of the amplitudes of the two signals then determines the simulated distortion level. 


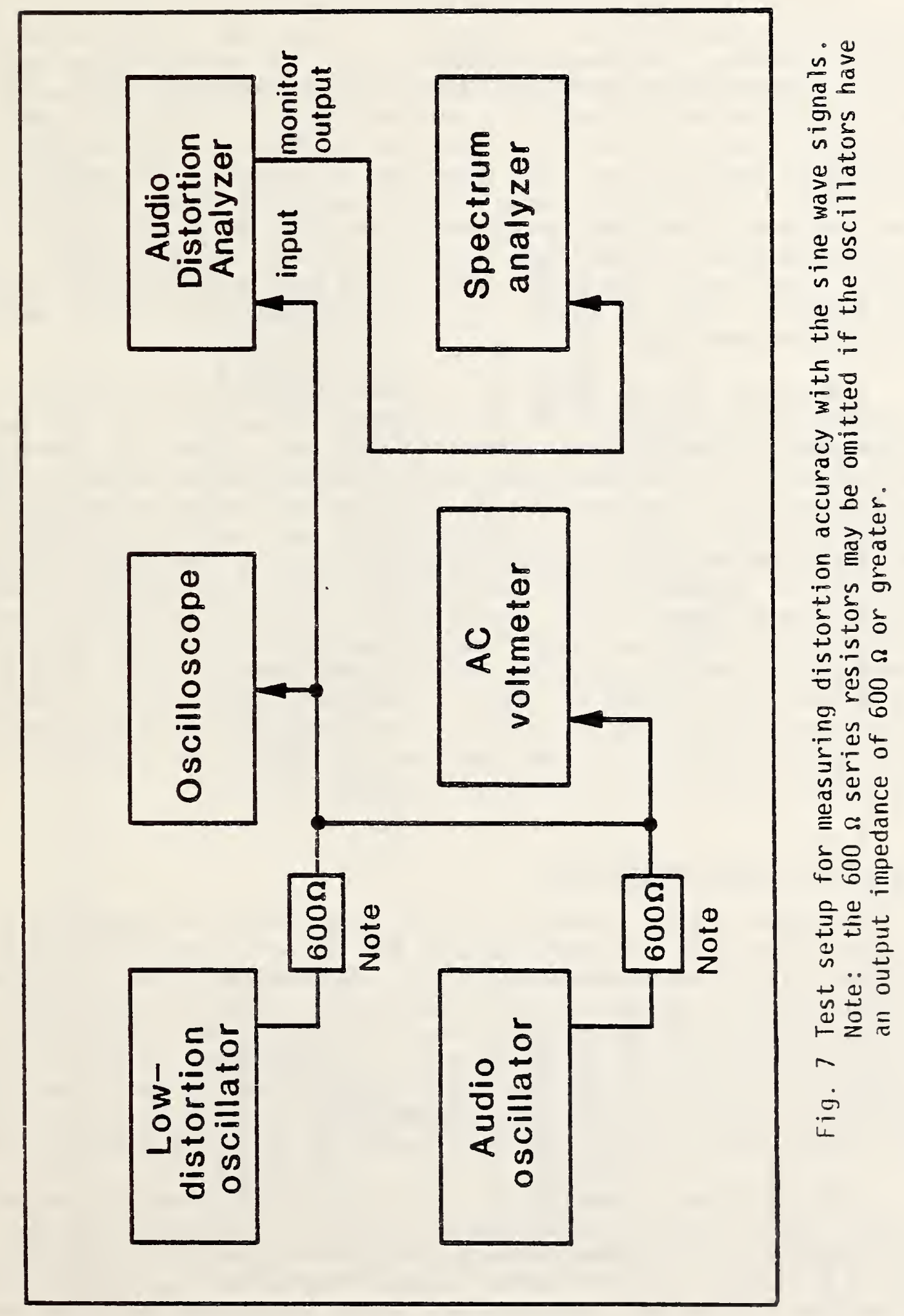


For low voltages, one easy method of combining the signals is to use a resistive divider as shown in figure 7 . If the two oscillators have a high output impedance ( $600 \mathrm{ohms}$ or greater), then the two oscillator outputs can be directly connected in parallel. If they have low output impedances, then nominally equal valued resistors must be placed in series with each output before the two oscillators are connected together. This will result in output voltages of about one half the open circuit voltages. The amplitude of each oscillator is measured by an ac voltmeter with the other oscillator set to a very low level. For each measurement, the other oscillator must be set to at least $20 \mathrm{~dB}$ below the amplitude of the oscillator being measured. In no case should either oscillator be disconnected or switched off during these measurements, since the change in circuit loading will cause a large error in the measured amplitude.

The use of 600 ohm external resistors to sum the two signals is appropriate for amplitudes of $10 \mathrm{~V}$ ac (rms) and below. One watt resistors are recommended to minimize resistance changes due to a resistor temperature coefficient. A resistance value of 600 ohms was chosen because a number of oscillators are commercially available with this output impedance. For low voltage levels, a $600 \mathrm{ohm}$ resistance allows easy addition of signals without drawing large amounts of power. Also, 600 ohms is low enough that the input impedance of voltmeter, oscilloscopes, and distortion analyzers, which are typically one megohm, do not significantly disturb the circuit. For testing distortion at higher voltages, a power amplifier is used to amplify the combined two sine wave signal. However, the power amplifier must exhibit low distartion. The distortion level of the power amplifier will limit the range of distortions that can be applied to the distortion analyzer under test. The distortion contributed by the power amplifier should be at least $10 \mathrm{~dB}$ below the lowest distortion level that is to be measured.

Sources of Measurement Error

The main sources of error for this measurement are dependent on the accuracy with which the amplitudes of the two sine waves can be measured, the inherent distortion of the oscillators, and any distortion introduced by the circuit used to combine the two signals. The voltmeter specified for the test should have an accuracy of better then 0.5 percent which will result in an error of less than $0.05 \mathrm{~dB}$ in the measured distortion. The error caused by the contribution of the one oscillator signal which is set to only $20 \mathrm{~dB}$ below the level of the oscillator level being measured is about 0.5 percent. This also translates to an error of less than $0.05 \mathrm{~dB}$ in the measured distortion.

The distortion caused by the resistive divider used to combine the signals and by the high voltage amplifier used in the high voltage measurements $c$ an be checked with a spectrum analyzer. The spectrum analyzer should be used to look for harmonics and interharmonics, (sum and difference of the two frequencies) for each oscillator signal when both are present. The oscillator that provides the larger fundamental signal must be a 


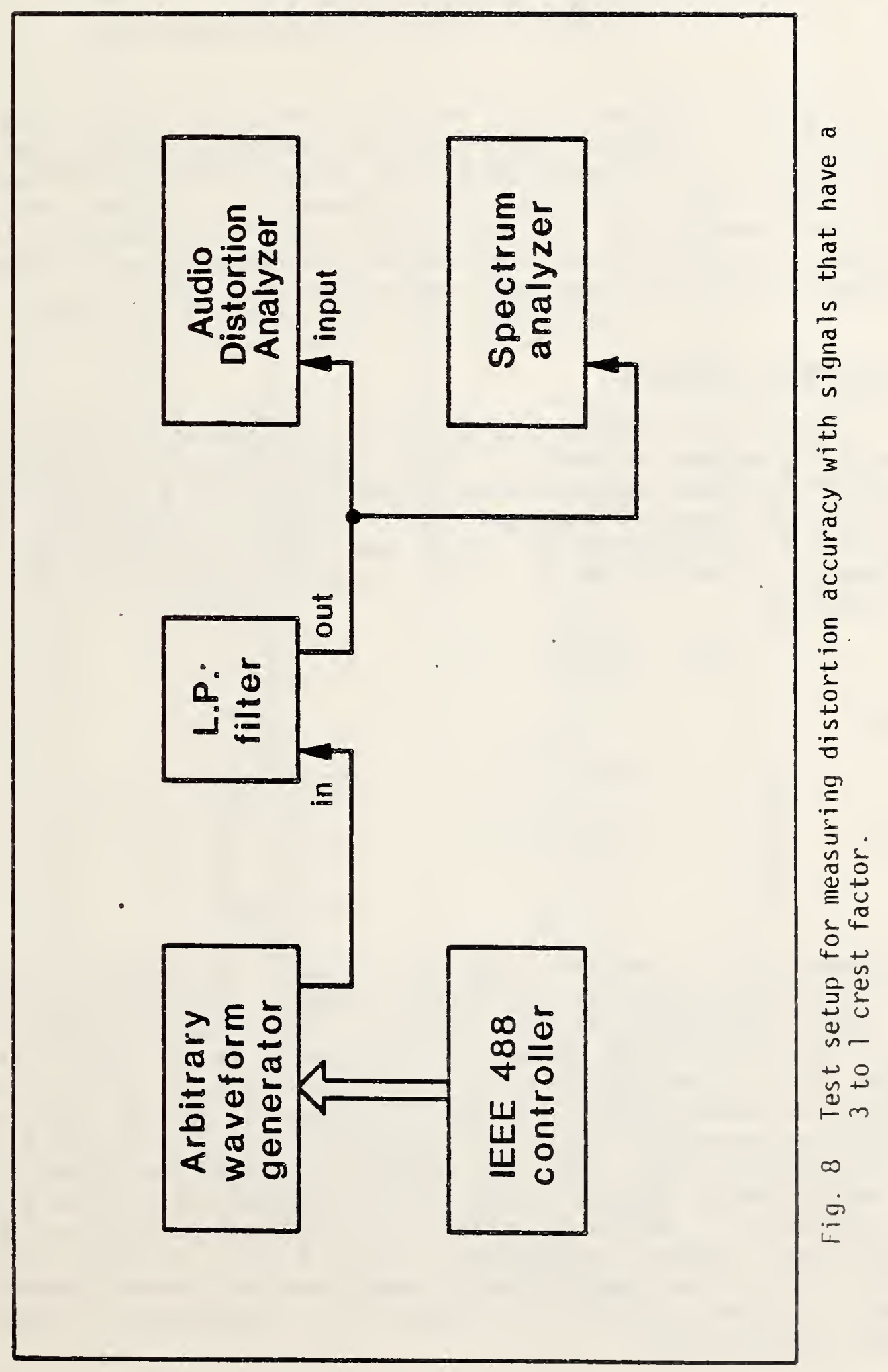


low-distortion oscillator since its distortion limits the range of distortion levels that this test can cover. The distortion of the other oscillator is not as critical.

\subsubsection{3:1 Crest Factor Signal Test}

High crest factor signals are used to measure the tolerance of instruments to clipping. Generally the autoranging circuits and overload indication circuits respond to the rms value of an applied signal. When a full scale signal is applied to an instrument, for a given range, that instrument should still not clip signals which have moderately high crest factors. The crest factor of a waveform is the ratio of its crest (peak, maximum) value to its root-mean-square (rms) value [5].

\section{Measurement Technique}

The 3:1 crest factor test waveform is generated using an arbitrary waveform generator in the test setup shown in figure 8 . The program for the waveform is loaded into the waveform generator from a desk-top computer via the IEEE 488 standard interface bus. A listing of the program is given in Appendix $D$. The waveform is a sine wave with a single cycle of a higher harmonic superimposed on the peaks. An analytic expression for this waveform is given by

$$
V(t)=\sin (\omega t)+P(t)
$$

where

$$
P(t)= \begin{cases}A\left(1+\cos \left(H \omega t-\frac{H \pi}{2}\right)\right), & \text { for } \frac{\pi}{2}-\frac{\pi}{H}<\omega t<\frac{\pi}{2}+\frac{\pi}{H} \\ -A\left(1+\cos \left(H \omega t-\frac{3 H \pi}{2}\right)\right), & \text { for } \frac{3 \pi}{2}-\frac{\pi}{H}<\omega t<\frac{3 \pi}{2}+\frac{\pi}{H} \\ 0, & \text { otherwise }\end{cases}
$$

and where $\omega$ is the angular frequency in radians per second, $A$ is the amplitude of the harmonic, and $H$ is the harmonic number. Figures 9 and 10 are examples of signals which have $3: 1$ crest factors. The signal represented in figure 9 uses a pulse of the 9th harmonic with an amplitude of 1.86 and the one in figure 10 uses the 19th harmonic with an amplitude of 0.826 . The frequency spectra for these signals are shown in figures 11 and 12 . The harmonics for the 9th harmonic pulse start out higher than those for the 19th harmonic but decrease more rapidly. The test procedure calls for measuring all the harmonics greater than two percent of the fundamental or less than $34 \mathrm{~dB}$ below the fundamental. Tables 2 and 3 give the harmonic amplitudes for the 9 th and 19 th harmonic pulses, respectively. Table 4 gives the crest factors that will result from various combinations of amplitude and harmonic numbers. It $c$ an be used as a guide in selecting the appropriate amplitude and harmonic combination desired. 
Table 2 Magnitude for the 9th Harmonic Pulse

\begin{tabular}{|c|c|c|}
\hline COEF & FREQUENCY $\mathrm{kHz}$ & MAGNITUDE $(\mathrm{dB})$ \\
\hline $\begin{array}{r}1 \\
3 \\
5 \\
7 \\
9 \\
11 \\
13 \\
15 \\
17 \\
19 \\
21 \\
23 \\
25 \\
27 \\
29 \\
31 \\
33 \\
35 \\
37 \\
39\end{array}$ & $\begin{array}{r}1.953 \\
5.859 \\
9.766 \\
13.672 \\
17.578 \\
21.484 \\
25.391 \\
29.297 \\
33.203 \\
37.109 \\
41.016 \\
44.922 \\
48.828 \\
52.734 \\
56.641 \\
60.547 \\
64.453 \\
68.359 \\
72.266 \\
76.172\end{array}$ & $\begin{array}{r}-.92 \\
-8.30 \\
-9.44 \\
-11.21 \\
-13.69 \\
-17.07 \\
-21.66 \\
-28.30 \\
-40.65 \\
-44.20 \\
-39.18 \\
-40.76 \\
-46.87 \\
-127.68 \\
-51.06 \\
-49.21 \\
-52.05 \\
-61.73 \\
-63.24 \\
-56.60\end{array}$ \\
\hline
\end{tabular}


Table 3 Magnitude for the 19th Harmonic Pulse

\begin{tabular}{|r|r|r|}
\hline COEF & FREQUENCY kHz & MAGNITUDE (dB) \\
\hline & 1.953 & -4.63 \\
3 & 5.859 & -21.35 \\
5 & 9.766 & -21.60 \\
7 & 13.672 & -21.98 \\
9 & 17.578 & -22.49 \\
11 & 21.484 & -23.13 \\
13 & 25.391 & -23.92 \\
15 & 29.297 & -24.86 \\
17 & 33.203 & -25.96 \\
19 & 37.109 & -27.24 \\
21 & 41.016 & -28.71 \\
23 & 44.922 & -30.41 \\
25 & 48.828 & -32.37 \\
27 & 52.734 & -34.65 \\
29 & 56.641 & -37.33 \\
31 & 60.547 & -40.59 \\
33 & 64.453 & -44.71 \\
35 & 68.359 & -50.49 \\
37 & 72.266 & -61.54 \\
39 & 76.172 & -63.21 \\
& & \\
\hline
\end{tabular}

Table 4 Crest Factors Resulting From Various Combinations of Amplitude and Harmonic Number

\begin{tabular}{|c|c|c|c|c|c|c|}
\hline Harmonic & & \multicolumn{5}{|c|}{ Amp litude } \\
Number & 0.75 & 1 & 1.5 & 2.0 & 2.5 & 3.0 \\
\hline \multirow{2}{*}{9} & 2.48 & 2.66 & 2.89 & 3.03 & 3.13 & 3.19 \\
11 & 2.60 & 2.82 & 3.11 & 3.29 & 3.40 & 3.48 \\
13 & 2.69 & 2.95 & 3.29 & 3.50 & 3.64 & 3.74 \\
15 & 2.77 & 3.05 & 3.44 & 3.69 & 3.86 & 3.98 \\
17 & 2.84 & 3.14 & 3.58 & 3.86 & 4.05 & 4.19 \\
19 & 2.89 & 3.22 & 3.70 & 4.01 & 4.23 & 4.38 \\
21 & 2.94 & 3.29 & 3.80 & 4.15 & 4.39 & 4.56 \\
& & & & & & \\
\hline
\end{tabular}


One source of error in measuring crest factor is neglecting to measure all the harmonics present in the signal. Tables 2 and 3 show that for the 9 th harmonic pulse waveform, the amplitudes of 7 harmonics out to the 15 th harmonic must be measured, whereas for the 19th harmonic pulse, 13 harmonic amplitudes are needed out to the 27 th harmonic. The error associated with ignoring the higher harmonics is $0.005 \mathrm{~dB}$ for the 9 th harmonic pulse and 0.057 $\mathrm{dB}$ for the 19th harmonic pulse. The errors that result from a limited number of harmonics are shown below in Table 5 .

Table 5 Error Resulting From Using a Limited Number of Harmonics to Calculate THD

\begin{tabular}{|c|c|c|c|}
\hline $\begin{array}{c}\text { Number of } \\
\text { Harmonics }\end{array}$ & $\begin{array}{c}\text { Highest } \\
\text { Harmonic }\end{array}$ & $\begin{array}{c}\text { 9th Harmonic PuTse } \\
\text { Error (dB) }\end{array}$ & $\begin{array}{c}\text { 19th Harmonic Pulse } \\
\text { Error (dB) }\end{array}$ \\
\hline & 3 & 6.8 & 15.1 \\
1 & 5 & 2.8 & 9.5 \\
4 & 9 & 0.42 & 4.5 \\
6 & 13 & 0.27 & 2.15 \\
7 & 15 & 0.005 & 1.46 \\
8 & 17 & 0.004 & 0.96 \\
10 & 21 & 0.002 & 0.37 \\
12 & 25 & 0.000 & 0.11 \\
13 & 27 & & 0.057 \\
14 & 29 & & 0.025 \\
15 & 31 & & 0.012 \\
16 & 33 & & 0.006 \\
18 & 37 & & 0.005 \\
\hline
\end{tabular}

Another error source is the inaccuracy of the harmonic amplitude measurements. Spectrum analyzers typicaliy specify the accuracy of a single frequency measurement but usually do not specify the relative accuracy. The important error parameter for distortion measurements is the accuracy with which the harmonics are measured relative to the accuracy of the fundamental measurement. As long as these ratios are measured accurately, the distortion measurement is accurate. The spectrum analyzer should be checked for this 


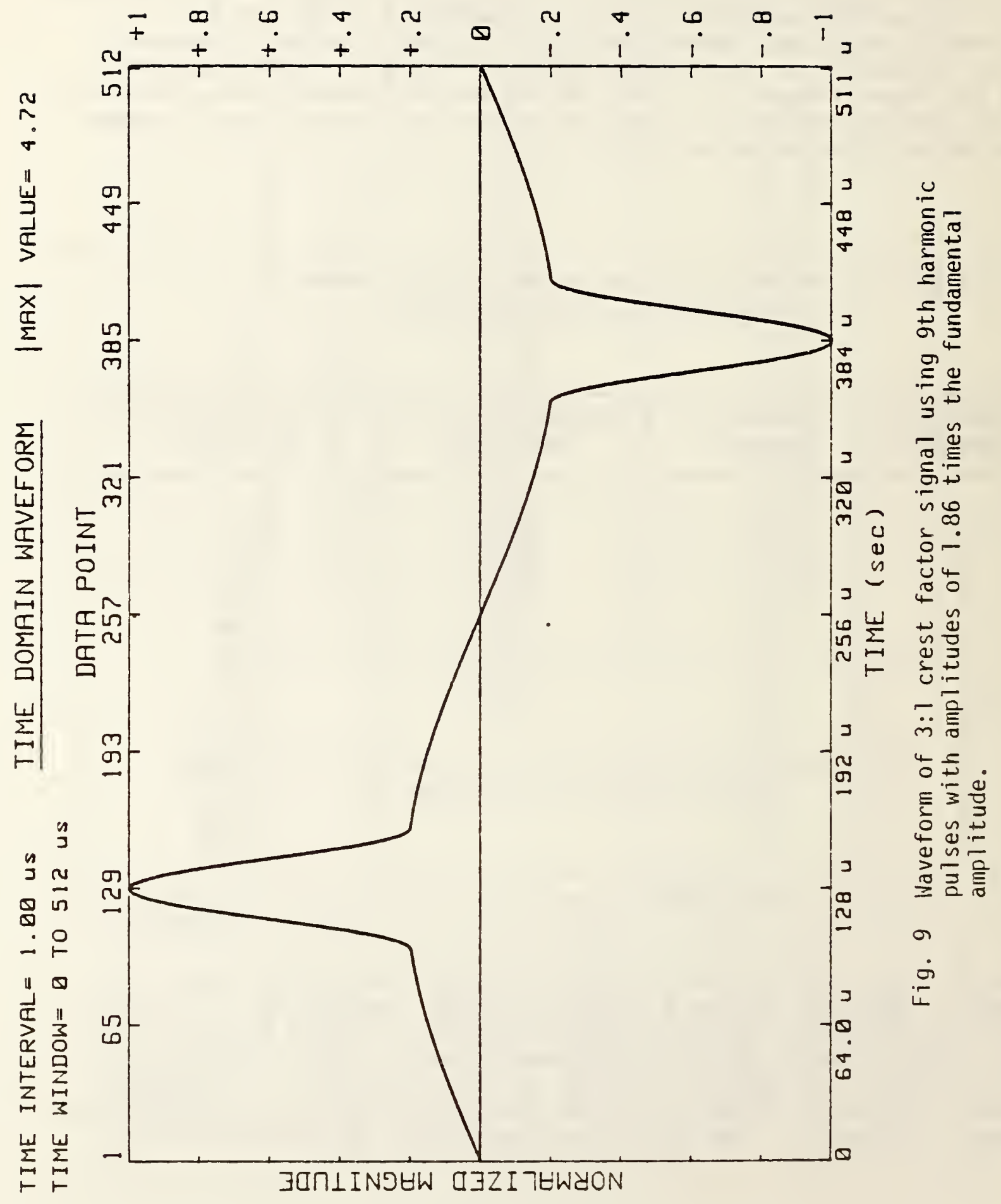




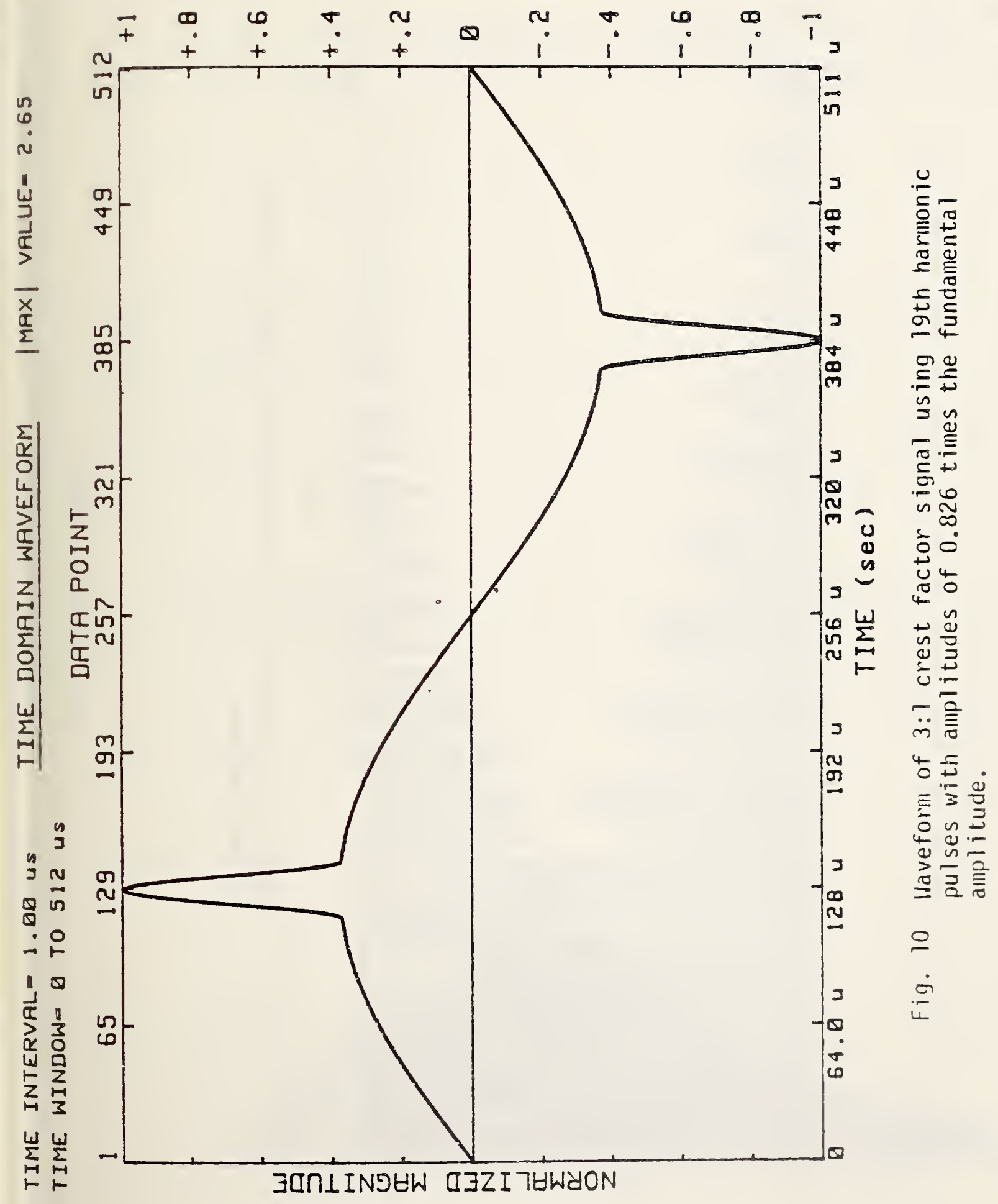




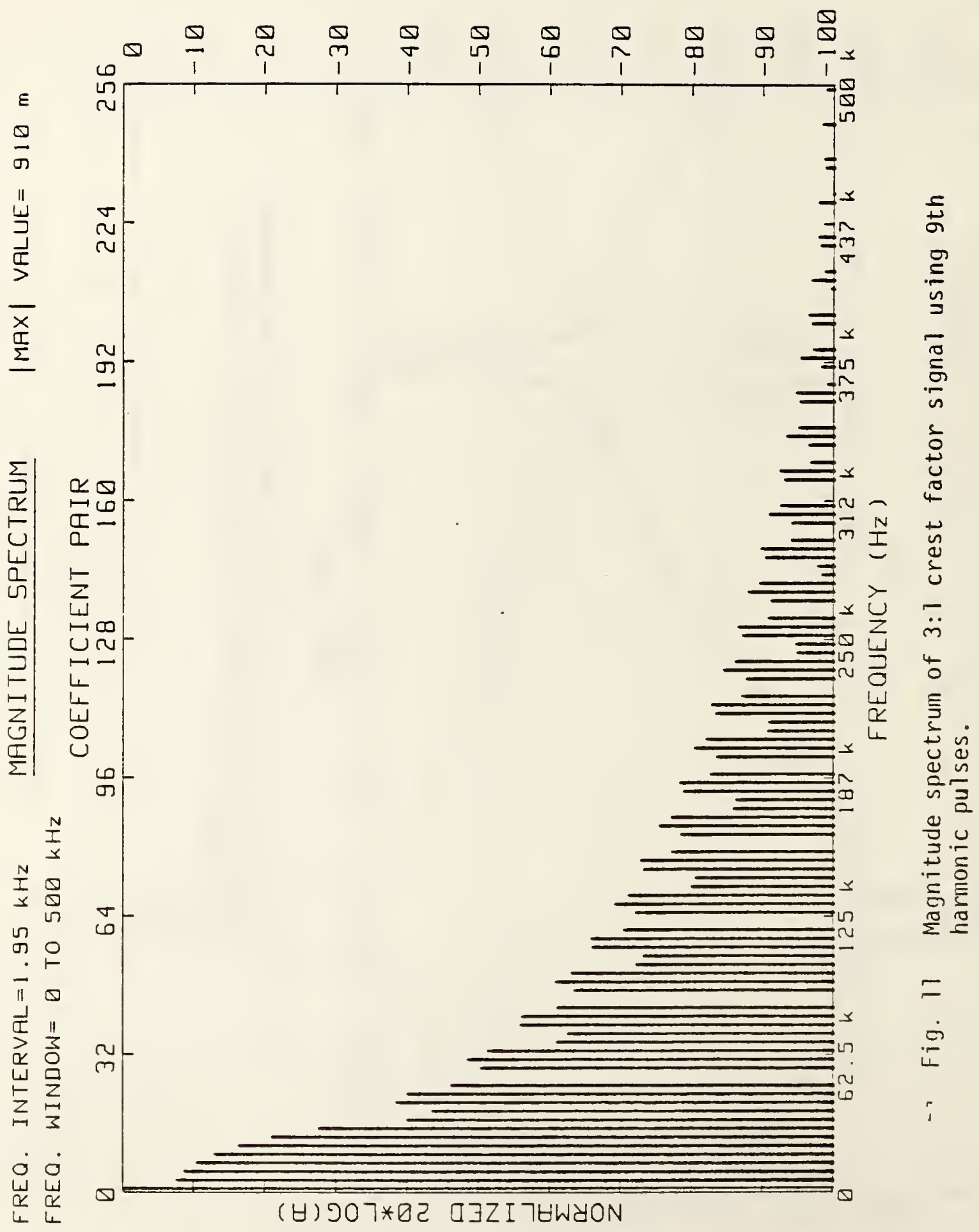




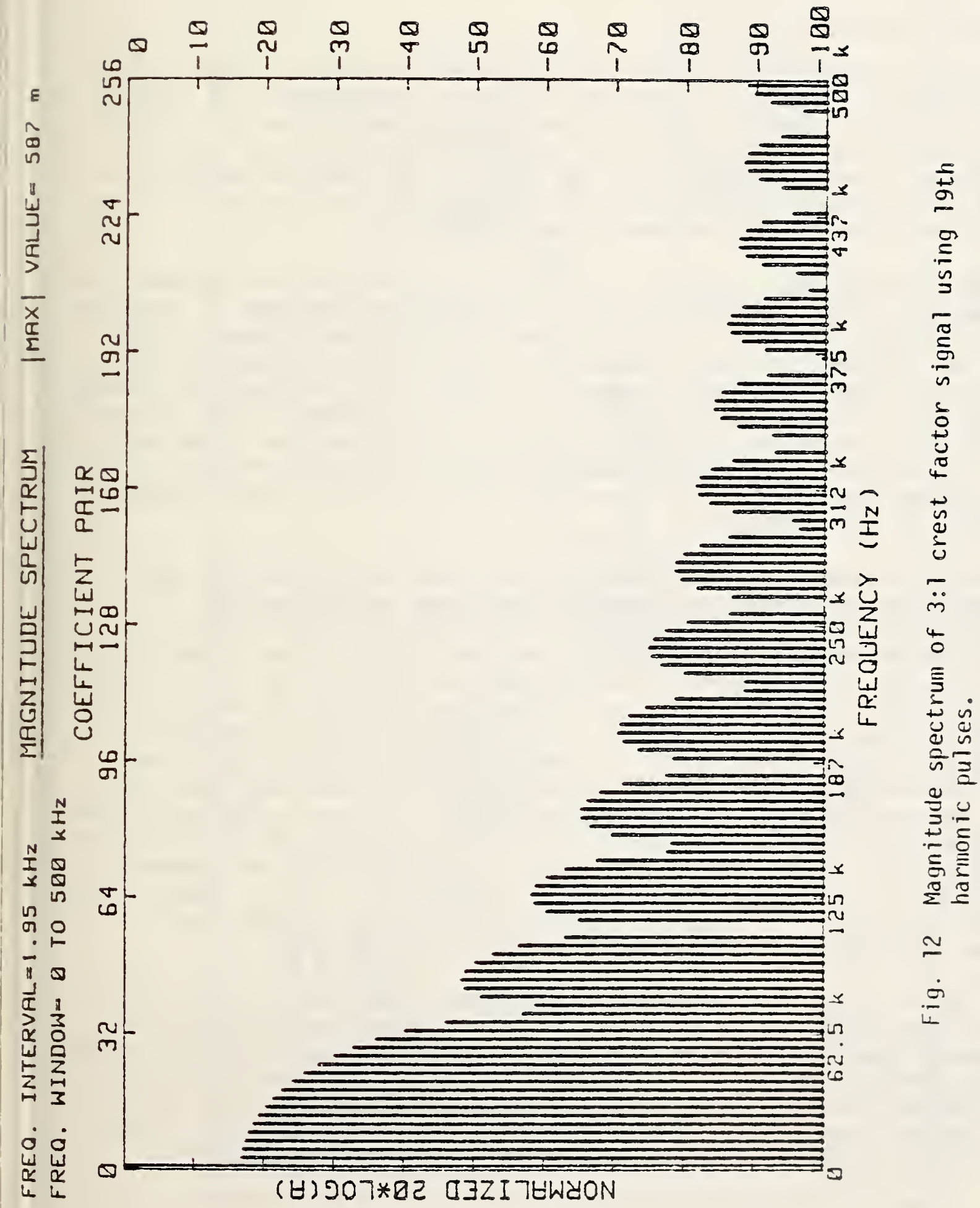


relative accuracy at the frequencies and amplitudes at which distortion measurements will be made. The procedure for doing this is given below.

\section{Calibrating the Spectrum Analyzer}

The spectrum analyzer is calibrated by applying accurate ac signals of the same frequency and amplitude as the fundamental and harmonics of the 3:1 crest factor signal. These signals are applied and measured one at a time. The known signals can be obtained either from an ac calibrator or from a signal generator and measured by an ac voltmeter. The spectrum analyzer is set manually such that the range does not change between making the fundamental measurement and the harmonic measurements.

The approximate amplitudes used for calibrating the spectrum analyzer can be obtained from Table 2 or 3 or by making a spectral measurement of the high crest factor signal that will be used. First set the ac calibrator to the amplitude and frequency of the fundamental. Manually set the $r$ ange of the spectrum analyzer so this signal is near full scale. Set the sweep to a range that will cover all harmonics, and as in the 3:1 test procedure, set the sweep rate to two steps below the automatic setting. Set the vertical range to 5 $\mathrm{dB} /$ div. Then without changing the spectrum analyzer settings, record the amplitude of the fundamental and, after resetting the ac calibrator frequency, the amplitude of each harmonic.

To determine the relative accuracy of the spectrum analyzer, one must compare the ratio of the measured harmonic amplitude to the measured fundamental amplitude, with the expected ratio based on the ac calibrator settings. The percentage of error in the measured ratio is then calculated for each harmonic. If the errors are less than two percent then no correction will be necessary, since this error will cause less than $0.1 \mathrm{~dB}$ error in the distortion reading. For 1 arger errors, the readings should be corrected. If the errors are biased in one direction, then it may be possible to correct only the fundamental reading to get all the remaining errors less than two percent. The correction to use for the fundamental is the weighted average of the harmonic ratio errors. Each error should be weighted by the square of the harmonic amplitude ratio. If the errors are not biased, then each harmonic measurement must be corrected individually. Without much loss in accuracy the corrections can be made to only the larger harmomics, say to those whose amplitudes are greater than half the largest harmonic amplitude.

Some of the distortion measurements are made at amplitude levels which exceed the input level of the spectrum analyzer. Under this condition the test procedure specifies an attenuator probe. It is important that the probe is properly compensated for a flat frequency response when connected to the spectrum analyzer input. The probe $c$ an be checked by connecting the tip to the spectrum analyzer's tracking generator while adjusting the probe for the best flatness in frequency response particularly over the bandwidth of interest. 


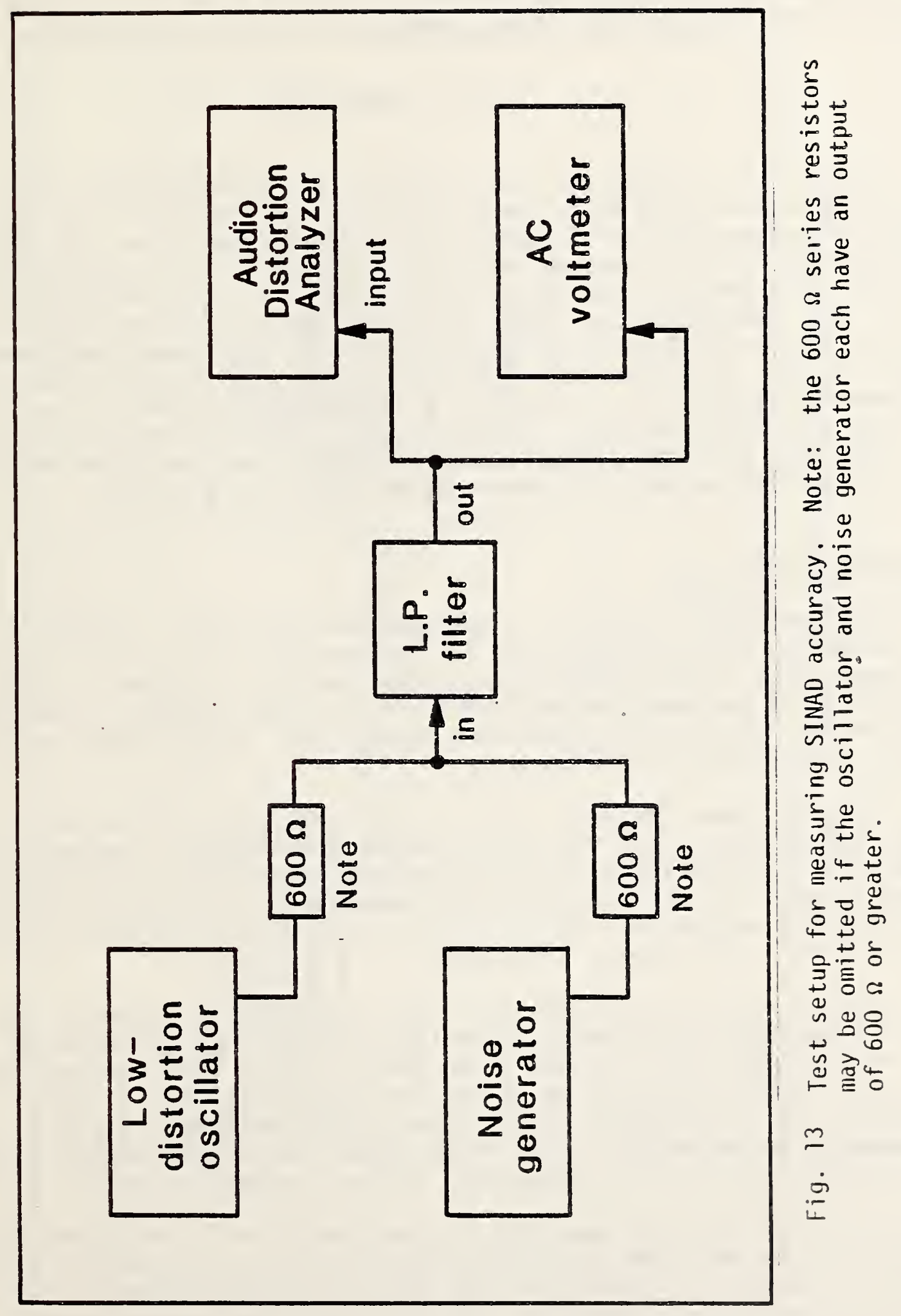


The above test and calibration of the spectrum analyzer is repeated for each fundamental amplitude and frequency that will be used to measure the distortion of the $3: 1$ crest factor signal.

\subsubsection{SINAD TEST}

The SINAD of a signal is the reciprocal of its distortion. For measurements in $\mathrm{dB}$ this means changing the sign of the value. Thus, $-50 \mathrm{~dB}$ of distortion becomes $+50 \mathrm{~dB}$ of SINAD. Although both distortion and SINAD measurements can determine the ratio of a fundamental to noise and harmonics, traditionally SINAD is used where the predominant interfering signal is noise rather than harmonics. Some distortion analyzers incorporate some special features in the SINAD mode which enhance its ability to make measurements of noisy signals. These features may include a narrower search $r$ ange for the fundamental frequency which requires an approximate frequency to be entered into the distortion analyzer. Alternatively, a locking feature may be used that maintains the notch filter at one frequency even though the amplitude of the signal being measured is reduced close to the noise level.

\section{Measurement Technique}

The SINAD test is similar to the two sine wave test. The signal from a low distortion oscillator provides the fundamental signal and is combined with the signal from a noise generator. A $600 \Omega$ resistor is placed in series with each generator and then the generators are connected together in parallel. As discussed in 4.3.1, if the generators already have a high output impedance, the $600 \Omega$ resistors are not used.

Figure 13 shows the test setup for the SINAD test. The setup is similar to the two sine wave test setup but with the addition of a low-pass filter between the generators and the distortion analyzer and the ac voltmeter. The low pass filter is needed to match the bandwidth of the distortion analyzer to that of the ac voltmeter. The filter limits the high frequency noise to below the bandwidth limit of both instruments.

The amplitudes of both the oscillator and the noise generator are measured sequentially by the ac voltmeter with the other generator set to as near zero as possible. For each measurement, the one generator must be at least $20 \mathrm{~dB}$ below the amplitude of the other generator that is being measured. In no case during the test can one of the generators be disconnected or turned off. This would change the circuit loading between the two generators and cause a large error in the measured amplitude.

As with the two sine wave test, a power amplifier is necessary to provide signals with an amplitude greater than $10 \mathrm{~V}$ ac ( $r \mathrm{~ms})$. This must be a low distortion amplifier, since it will be amplifying the fundamental signal. The distortion level of this amplifier places a lower limit on the $r$ ange of distortion that can be measured. A low-pass filter must be placed on the output side of the amplifier to limit out-of-band noise contributed by the amplifier. The filter must be designed to handle the power levels present at this location. Appendix $E$ gives the details of an appropriate filter for this application. 


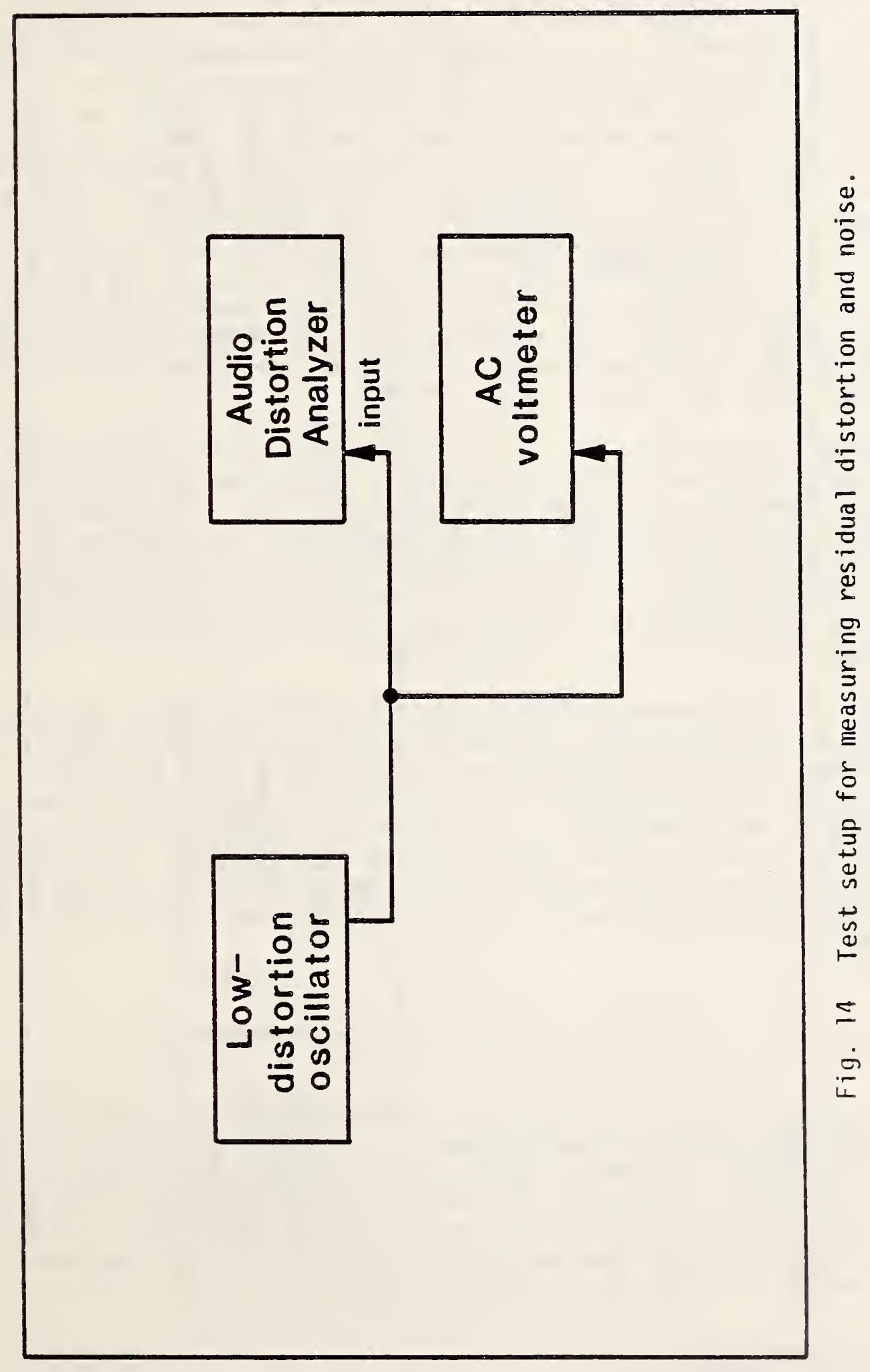


One potentially significant error source for SINAD measurements is the failure of the low-pass filter to properly limit the high-frequency noise. In general, the bandwidth of the ac voltmeter will be significantly greater than that of the distortion analyzer. The cutoff frequency for the low pass filter must be significantly below the bandwidth of the distortion analyzer. One method of checking the adequacy of the filter is to compare the noise amplitude measurements of the ac voltmeter to those of the distortion analyzer. This is done by setting the distortion analyzer to the ac voltage mode and the low distortion oscillator to its lowest level. Then, for a series of noise amplitudes, compare the readings of the distortion analyzer to those of the ac voltmeter. The readings should be within \pm 3 percent of each other. If this is not the case, a filter with a lower cutoff frequency should be used. Reading differences of \pm 3 percent will produce a SINAD measurement error of $\pm 0.25 \mathrm{~dB}$, whereas reading differences of \pm 1 percent will produce errors less than $\pm 0.1 \mathrm{~dB}$.

Another error source is the noise and distortion caused by the power amplifier. The value of distortion may be determined by using the distortion analyzer to measure the distortion of the amplifier. The measurement is made by setting the noise generator to its lowest level and setting the low distortion oscillator to one of the amplitudes that are to be used in the test. Then the distortion analyzer is set to the distortion mode and the distortion level is noted. The indicated level must be at least $10 \mathrm{~dB}$ below the lowest distortion level to be measured.

Finally, the presence of the signal from one generator while measuring the level of the other wi $1^{\circ} 1$ contribute an error. As stated above, the level of the generator not being measured should be more than $20 \mathrm{~dB}$ below the level of the signal being measured. At a ratio of $20 \mathrm{~dB}$ this will cause the level of the signal being measured to be one percent high, which will contribute an error of less than $0.1 \mathrm{~dB}$ to the calculated SINAD level. If the ratio of the signal levels cannot be kept at greater than a $20 \mathrm{~dB}$ difference, then a correction should be applied to account for this additional signal during the measurement.

\subsubsection{Residual Distortion and Noise}

The lowest distortion level that the distortion analyzer can measure is limited by the ability of the analyzer to lock onto and notch out (filter) the fundamental signal frequency, and by the residual noise and distortion of the internal circuitry. This test measures the latter two properties by presenting a sine wave with low distortion to the distortion analyzer. The distortion of the signal used in this test must be at least $10 \mathrm{~dB}$ below the level to which the distortion analyzer is being qualified.

\section{Measurement Technique}

The residual distortion and noise test is very straightforward; figure 14 shows the test setup. The oscillator level is set with an ac voltmeter and 


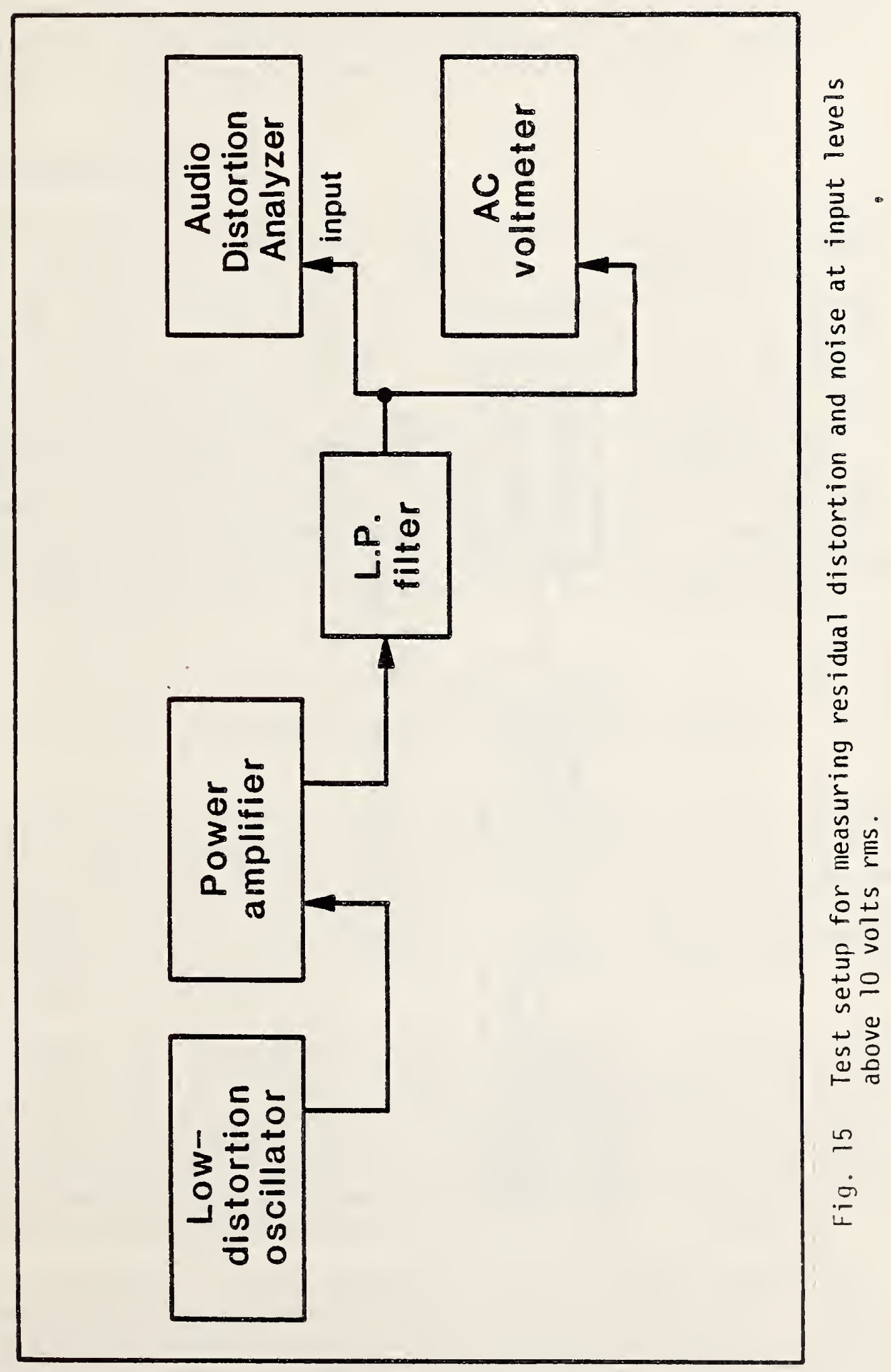




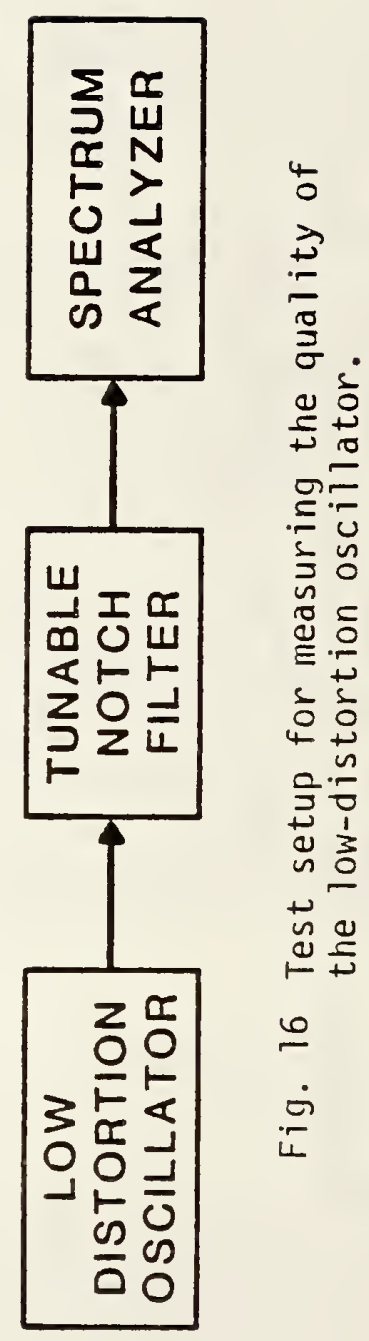


the attendant distortion is read from the distortion analyzer. For higher signal levels above $10 \mathrm{~V}$ rms, the power amplifier must be used as shown in figure 15. For these tests a low pass filter is usually added to reduce the higher frequency noise components contributed by the power amplifier. The test for these voltage levels is the same as for the lower level.

\section{Sources of Measurement Error}

The main error sources are the characteristics of the low distortion oscillator and the power amplifier. These devices must have the required low distortion levels. If there is some question as to whether they are operating properly, the distortion of these units can be measured. This requires a tunable notch filter, such as a Tektronix calibration fixture 067-0938-00, and a spectrum analyzer. The test setup is shown in figure 16. The notch filter is adjusted to remove as much of the fundamental as possible. The amplitudes of the harmonics and the background noise level are then measured with the spectrum analyzer. From the known amplitude of the fundamental, the distortion of the oscillator or of the amplifier can be determiried. The noise floor of the spectrum analyzer must be taken into account as a limiting factor in determining the distortion and noise characteristics of the source. The spectrum analyzer should have a noise floor at least $10 \mathrm{~dB}$ below the specified residual distortion and noise of the distortion analyzer under test.

\subsection{FILTER CHARACTERISTICS}

\subsubsection{High Pass/Low Pass Filter Measurements}

Audio distortion analyzers contain several sets of filters that are selectable by front panel controls. A high-pass filter can be used to reject low-frequency components of the waveform presented to the audio analyzer. Also, a choice of low pass filters is available to reject the high-frequency components. These filters, used singly or in combination, may be used to reduce unwanted signals and the effects of noise in the measurements nade by the audio distortion analyzer.

Filters are generally characterized by two parameters: the "corner frequency" and the "rolloff" $r$ ate at which the signal is attenuated as a function of frequency. The frequency response of a filter is conventionally represented by a Bode plot. The absolute vaiue of the voltage gain (or loss) measured at the output of the filter is plotted in $\mathrm{dB}$ versus the logarithm of the frequency of the voltage source applied to the input of the filter. Typicai Bode plots of a high-and a low-pass filter are shown in figure 17.

The "corner frequency" is usually defined as that frequency where the attenuation of the power is twice $(-3 d B)$ its midband value [6]. Such a definition agrees closely with the corner frequency as shown in figure 17. In this figure, the corner frequency is defined as the intersection of the straight-line extrapolation of the attenuated portion of the filter characteristic with the extrapolated midband value. 


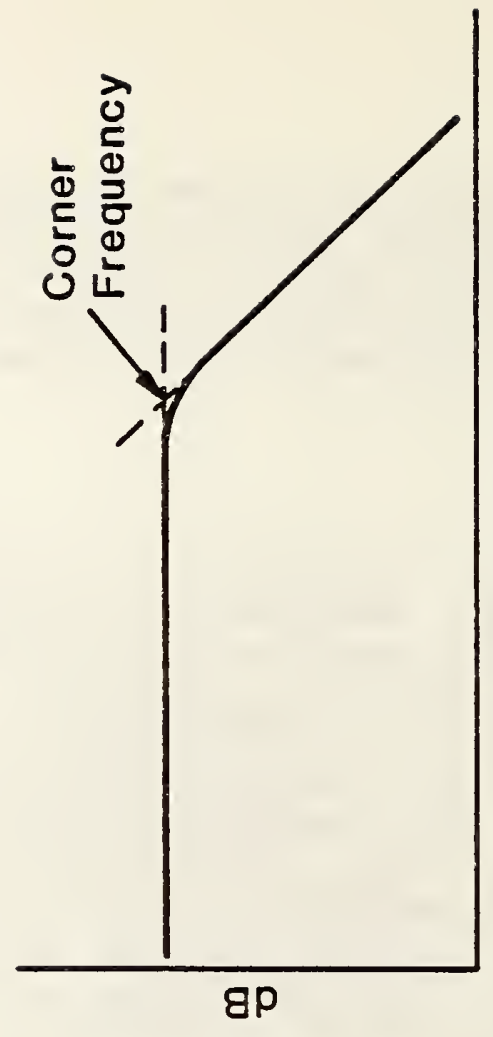

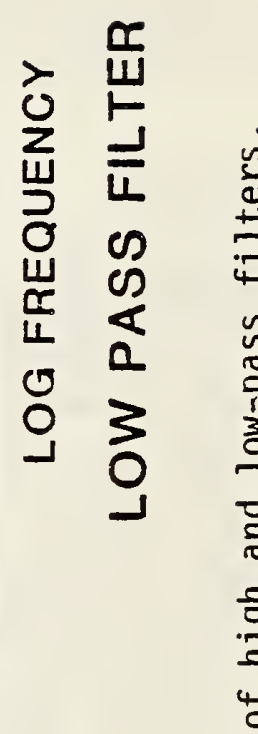

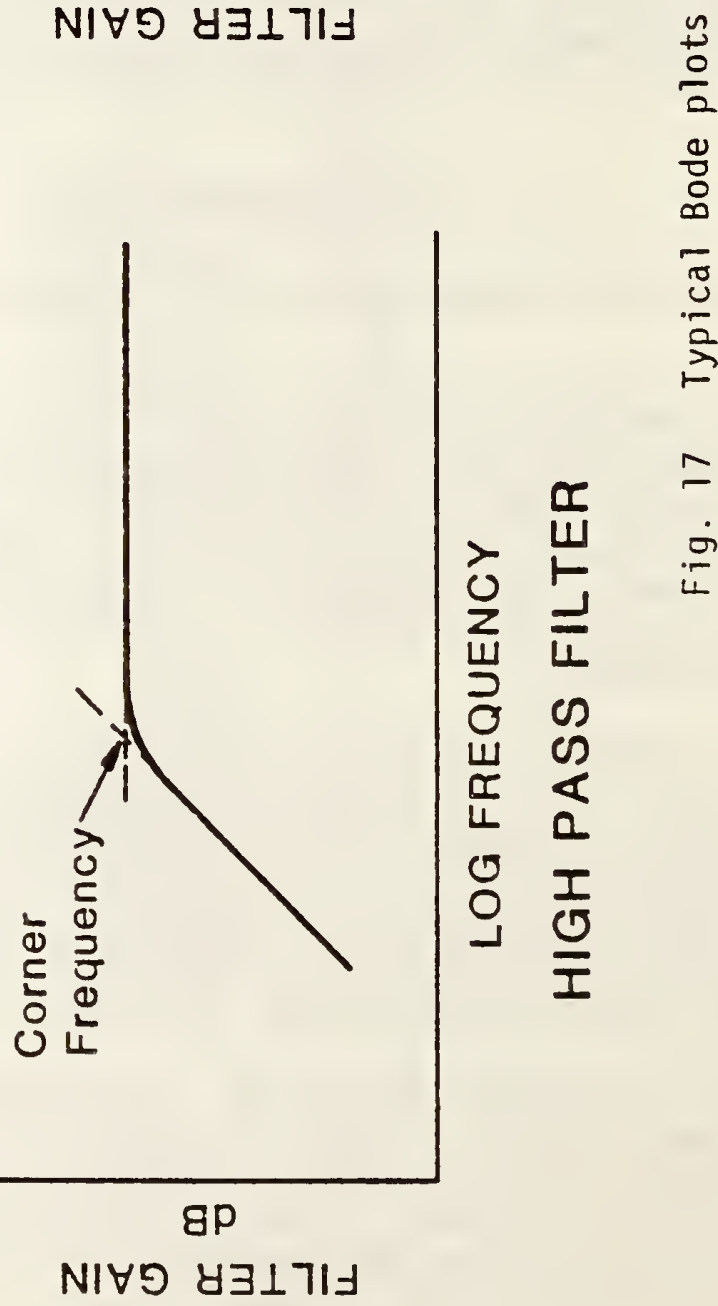


It is important that the frequency response of the filters be defined for measurement instruments such as an audio distortion analyzer. The filter parameters, such as corner frequency and rolloff, determine the bandwidth of the instrument when the filters are used.

Most audio distortion analyzers investigated had at least three switch-selectable filters. A 400-Hz high-pass filter can be inserted in the input path of the ac signal before the notch filter to reject $60 \mathrm{~Hz}$ interference that may be present on the signal to be measured. This $60 \mathrm{~Hz}$ interference is often a result of ground loops. In addition, two low-pass filters are provided which limit the high-frequency response of the system to $30 \mathrm{kHz}$ and $80 \mathrm{kHz}$, respectively. These filters are provided to remove the high-frequency noise components in low-frequency distortion and signal-to-noise measurements.

\section{Measurement Technique}

The same measurement method is used to characterize both the high-and low-pass frequency filters. The method consists of applying a nominal one $V$ ac (rins) signal to the input of the audio distortion analyzer from an oscillator set to the specified corner frequency of the filter under investigation. The switches controlling the filters are set such that all filters are out of the signal path. The amplitude of the signal is then measured by the audio distortion analyzer and this amplitude is referenced to be zero $d B$. To test the filter response at the minus three $d B$ corner frequency, the filter is then switched on. The frequency of the input signal is adjusted so that the amplitude of the signal, as measured by the audio distortion analyzer, decreases by exactly three $d B$. The frequency of the signal is then measured and recorded.

The slope of the filter characteristic, or rolloff, is measured in a similar manner. The filters are switched off and the amplitude of the input signal is set to zero $d B$. The frequency of the input signal is changed by one decade from the measured three $d B$ corner frequency and the amplitude of the signal, as measured by the audio analyzer in decibels, is measured and recorded. $A$ digital multimeter is used to measure the amplitude of the input signal at both frequencies and the amplitude is adjusted, if necessary, to assure that equal signal levels were applied to the audio distortion analyzer at both frequencies. To determine characteristics of the low-pass filter, the measurement of rolloff requires that the input signal frequency be increased by one decade, or a factor of ten. Conversely, the signal frequency is decreased by a factor of ten to determine the rolloff characteristics of the high-pass filter. In either case, the change in output amplitude cf the filter is measured over a decade change in input frequency, referenced to the corner frequency.

\section{Sources of Measurement Error}

Possible sources of error in determining the filter characteristics include errors in measuring the input signal frequency and amplitude, errors in the measurement of the output amplitude of the filter by the audio distortion analyzer, and measurement of signals outside the specified bandwidth of the instrument. 
The amplitude of the input signal is nominally set to $1.0 \mathrm{vac}$ (rms). This amplitude can be measured by a digital multimeter with a worse-case accuracy of \pm 3.5 percent. This worse-case accuracy occurs when the digital multimeter reads a voltage between 0.3 and $10 \mathrm{~V}$ ac ( $\mathrm{rms}$ ) at frequencies from $500 \mathrm{kHz}$ to 1 $\mathrm{MHz}$. This worse-case error is encountered in performing the $80 \mathrm{kHz}$ low-pass filter test $(10.2 .6 .2)$. The \pm 3.5 percent error of applied voltage is equivalent to $a \pm 0.299 \mathrm{~dB}$ error in the determination of the filter slope characteristic.

The frequency of the input signal is measured with a frequency counter. Typically, frequency counters demonstrate the largest percentage error at low frequencies, since their accuracy is determined by an uncertainty of plus or minus one count in the least significant digit. The lowest frequency measured in these procedures is encountered in determining the high-pass filter slope characteristic. This procedure requires the frequency measurement of a $40 \mathrm{~Hz}$ signal. The least significant digit for the $40 \mathrm{~Hz}$ measurement is $0.1 \mathrm{~Hz}$. Thus, the frequency error from the one digit ambiguity is one part in 400 or \pm 0.25 percent. The uncertainity of the ampitude of the output of the filter is directly proportional to the frequency error; thus, the uncertainity of the measured amplitude is

$$
\begin{aligned}
\text { Amplitude Uncertainity } & =60 \mathrm{~dB} / \text { decade } \times 0.0025 \\
& =0.15 \mathrm{~dB} / \mathrm{dec} \text { ade } .
\end{aligned}
$$

The measurement of the output signal from the filters is made by the distortion analyzer in the amplitude measurement mode. Typically, distortion analyzers display the amplitude of the input signal in either linear units (volts ac rms) or logarithmic units ( $d B$ ) relative to a signal level. In either case, the specified amplitude accuracy of the distortion analyzer should be considered as a possible source of error in characterizing the filters.

A further source of possible error is the measurement procedure. Some audio distortion analyzers have a bandwidth of approximately $100 \mathrm{kHz}$. The test procedure for the $80 \mathrm{kHz}$ low-pass filter requires that an $300 \mathrm{kHz}$ signal be applied to the input of such analyzers in order to characterize the filter slope over a one decade frequency change. Since the inherent bandwidth of the distortion analyzer should attenuate such high-frequency input signals, it was deemed that this test is valid. However, users of this test should be aware that it may require operation of the audio distortion analyzer at frequencies in excess of the required performance specifications. 
[1] Fink, Donald D., Electronics Engineers Handbook, McGraw-Hill Book Co., New York, NY, First Ed. 1970, p. 13-6.

[2] The Institute of High Fidelity, Inc., Stand. Metnods of measurement for Audio Amplifiers, The Institute of High Fidelity, Inc., NY (1978) p. 9.

[3] Fink, Donald, D., Electronics Engineers Handbook, McGraw-Hill Book Co., New York, NY, 1st Ed. 1970, p. 22-67.

[4] The International Telegraph and Telephone Consultative Committee (C.C.I.T.T.) Fifth Plenary Assembly, 1972 Telephone Transmission Quality, The International Telecommunication Union (1973), pp. 87-91.

[5] IEEE Standard Dictionary of Electrical and Electronics Terms, John Wiley \& Sons, Inc. 2nd Ed.

[6] Hunter, Lloyd P., Handbook of Semiconductor Electronics, McGraw-Hil1 Book Co., Inc., New York, NY 3rd Ed. 1970, pp. 12-24. 


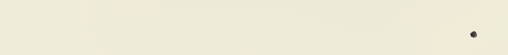


APPENDIX A

\section{PEFORMANCE SPECIFICATION FOR \\ TS- 4084 ( ) /G \\ OISTORTION ANALYZER}

Note:

These specifications were written by the U.S. Army Communications Electronic Command (CECOM) and have been reprinted exactly as presented to NBS by the Army. 


\section{A. PEOUIREP.ENTS}

1. Safety. Unless otherwise specified herein, the equipment shall camply with the Type II safety requirrments specified in MIL-T-28800C.

1.1 Personnel Hazardr. Personnel hazards shall be kept to a minimum. The criteria of MIL-T-28800C, : ihall be made applicable for tasks and efforts such as the selection of parts, the complete manufacturing and assembly process, and any product baseline conficuration changes that may be implemented during the course of the contract. Verification that compliance with this requirement has been achieved shall be thrugh a visual inspection (see 1.5).

1.2 Edge Rounding Exposed. Exposed edges and corners shall be rouncied sufíiciently to minimize laceration/puncture hazards, the design goal being a minimum radius of 0.04 inch $(1 \mathrm{~mm})$ for edges and a minimum of 0.5 inch $(12.7 \mathrm{~mm})$ for corners.

1.3 Radioactive Mater:ials. Radioactive materials shall not be used (e.g., luminous dials/markings, electron tubes, surge arrestors and lenses).

1.4 Weight Caution Label. All equipments over 35 pounds shall have a weight caution ląbel for Two-pirson lift centered at the top surface. The format and color code shall be in accordance with American National Standarus Institute (ANSI) Standard 235.?-1972. Label size shall be appropriate for high visibility and legibility. Marking requirements shall conform to NiLL-M-13231. The weight caution label shoul' read, for example:

\section{CAUTION}

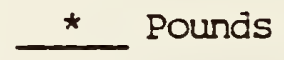

TWO-PERSON LIFT

* Weight of Distortion Analyzer

1.5 System Safety Engineering Inspection. A visual inspection shall be performed in the presence of a government safety representative to determine that all requirements of $1,1.1,1.2,1.3$ and 1.4 have been incorporated in the equipment. Inability to meet these requirements shall constitute a failure of the test. Result of this insp:ction shall be included in the Safety Assessment Report (DI-H-7049) if required in the contract.

2. Design and Construction. Unless otherwise specified herein, the equipment shall comply with the Type II, Class 5, Style $E$, Color R, design and construction requirements of MIL-T-28800C. All requirements which are automatically invoked by MIL-T-28800C to all types, and specifically to Type II, apply.

2.1 Front Handles. Front handles or a front panel cover shall be provided on the equipment which can be used for carrying the equipment and will offer a degree of protection to the front panel controls. 
L.2 Racknount. Rackilounting capability shall be available.

2.3 Mainframe Plug-II Concept. Equipment utilizing externally accessible, removeable subassenblies (inainframe plug-in concept) coes not meet the requirements of this specification if more than one plug-in is used.

2.4 Controls. All orntrols required to operate the equigment throughout its specified performance range shall be located on the front panel.

3. Parts, Materials, and rocesses. Unless otherwise specified herein, the equipment shall comply with Type II parts, materials, and processes reouirements of MIL-T-28800C.

3.1 Restricted Material. Equipment shall camply with the restricted material requirements of MIL-T. $28800 \mathrm{C}$ including the requirement for radicactive deterioration of any material sontained in the equipment due to effects of outgassing.

3.2 Interchangeability. Unless otherwise specified herein, the equipment shall comply with Type II interchangeability requirements of MII-T-28800C.

3.2.1 Marking. All replaceable assemblies, subassemblies, modules anco printed circuit card assemblie's shall be indelibly marked with the contractor's Federal Supply Coce for Manufacturers (FSC.1) and the contractor's part number.

4. Marking and Identification. Unless otherwise specified herein, tine equipment shall comply with Type II marking and icentification requirements of MIL-T-28800C.

4.1 Supplemental Ineptification Plate. The supplemental identification plate specified in MIL-T-28800C shall contain the following data:
a. Nomenclature
b. Contract ivumber
c. Serial Number
d. National stock number
e. US

4.2 Information Plate. An information plate affixed to each deliverable equipment shall contain the following data:

a. Warranty termination date.

b. Brief statement of warranty limitations (for example: opening a cover voids warranty; calibration adjustments may be made without voiding warranty; defective modules may be returned for warranty service; etc.).

4.3 Battery Warning Label. Equipment containing batteries shall provide a battery warning label in accordance with MII-T-288000, para 3.8.3.1.3. 
b. Electrical Power Sourc ss. Unless otherwise specified herein, the equipment shall comply with the Type II electrical power sources and connections requirements of MIL-T-28800C. The equipment shall operate from a nominal 115 $\mathrm{VAC}$, single phase 50,60 and $40 \mathrm{HIz}$ and $230 \mathrm{VAC}, 50$ and $60 \mathrm{~Hz}$ power source.

5.1 Fuses and Circuit Breakers. Fuses or circuit breakers shall be in accordance with MII-T-28800C. Either common or separate fuseholders may be provided. If only one fuseholder is used (comon), the equipment shall be provided with the 115 VAC fuse installes: and the 230 VAC fuse shall be provided with the accessories.

5.2 Electrical Power Connections. The equipment shall be delivered connected for $115 \mathrm{VAC} 60 \mathrm{~Hz}$ op ration.

6. Accessories. The foll owing accessories shall be supplied with each equipment:

\section{a. Power Cable}

b. Fuses (See Para 5.1)

c. One operator's manual tional check.

d. All cables and adi ptors necessary for initial turn on or preopera-

e. Other standard acressories, if any, that are offered camercially.

7. Preconditionina Requi-ement (Burn-In). Each deliverable equipment shall be subjected to a minimul 48 hours on-time burn-in period, prior to Acceptance Testing. During the last 24 hours of on-time burn-in, the equipment must operate failure free. Up until this time, equipment will be allowed to accumilate failures. Each equipment which fails during the final 24-hour period shall be repaired and returned to test until it successfully survives a 24-hour period without failure. Failures which occur during the burn-in test shall be noted and reported, but shall not count toward the establishment of equipment MTBF. Prior to burn-in, the Satisfactory Operation Test (SOT) shall be conducted. Daily Satisfactory Oprration Checks $(S O C)$ shall be conducted. For the last 24-hour failure-free periud, a complete satisfactory operation test shall be conducted prior to and after the period. The SOC and SOT are defineci by MIL-T-28800C, Paras 6.3.2.24 and 6.3.2.25. Thile under burn-in the equipment shall be subjected to the following conditions:

Ambient temperature: $40^{\circ} \mathrm{C}+5^{\circ} \mathrm{C}-0^{\circ} \mathrm{C}$

Input Voltage: Nominal specified voltage $+58-28$

Equipment on-off cycling: Equipment on for 8 hours and off for 4 hours. This cycle shall continue until a minimum 48 hours on time is accumulated, with the last 24 hours of on time, failure free.

8. Environmental Requirenents. Unless otherwise specified herein, the equipment shall comply with the Class 5 environmental requirenents of MIL-T-28800C. 
8.1 Vibration. The iquipment shall comply with Class 5 vibration requirements of MIL-T-28800C, ixcept that the equipment is not required to be operatir.g during the vibration test.

8.2 Electromagnetic Interference (E.II). EMI requirements shall be as specified in 1:IL-T-28800C and 1 IL-STD-461A Notice 4 (EL) except as noted below. The equipment shall comply with the following emission and susceptibility requirenients when tested as sprcified in Para 8.3.

\begin{tabular}{|c|c|}
\hline CE02 & $\mathrm{CSO} 2$ \\
\hline CEO4 & CS06 \\
\hline
\end{tabular}

8.2.1 Radiated Emissıon RE02.1. The narrow band cmissions level shall be 3.5 specified in MIL-STD-46la Notice 4 (EL) over the $14 \mathrm{kHz}$ to $1 \mathrm{GHz}$ frequency range.

8.2.2 Radiated Suscentibility RS03. The susceptibility shall be $1 \mathrm{~V} / \mathrm{m}$ over the $14 \mathrm{kHz}$ to $1 \mathrm{GHz}$ frequincy range. The susceptibility limit shall be met for both horizontally and vertically polarized fields.

8.3 EMI Testing. EMT testing shall be in accordance with MIL-T-28800C and MIL-STD-462 Notice 3 (EL).

\section{RA11 Requirements.}

9.1 Reliability Requirements. The equipment shall camply with the Thpe II Reliability Requirements of liIL-T-28800C, (Para 3.10.12 ana Para 4.5.8.1.2). . The contractor shill demonstrate his equigment MITEF (00) as stated in his bid data submission. The stated value shall be equal to or greater than a $\operatorname{MTBF}(00)$ of 1500 hours. Reliability tests shall be perforned on the first prociuction lot only.

9.2 Calibration. Calibration interval shall meet or exceed 240 cays with 85 of items still within tolerance at the end of the period.

9.3 Maintainability Requirements. The contractor shall demonstrate his equipment mean-time-to-repsir (MTR) (Ho in NII-STD-471), as stated in his bid data sulmission. The stated value shall be less than or equal to MTTR (Ho) of 300 minutes. The maximum tolerable MTR (HI of I.IL-STD-471) shall be 360 minutes. The MTIR shall incluje all the time required to troubleshoot, fault isolate, repair and test the rquipment for any malfunction down to the lowest circuit card or module level c:t the ecuipment, but does not include calibration time. In equipments, sections of equipments or plug-ins (see para 2.3) not utilizing a modular concept, MTI shall inclucie all time required to troubleshoot, fault isolate, repair and test the equipment for any malfunction down to the lowest discrete component (resistor, switch, transistor, integrated circuit, nonrepairable assembly, and so forth) of the equiument, but does not incluae calibration time.

10. Performance. Unless otherwise noted, the following performance requirements apply to the basic equimment after one hour wanm-up for performarce across the full specified bandwicth and voltage range. 
10.1 Operation. In measuring level and in measuring distortion in which the distortion is pure harmonic distortion, and when the input signal to noise and distortion ratio is greater than 20 ds the equipment shall have full automatic operation. There shall be no manual operations in locating the fundamental frequency, nulling the fundamental frequency and in locating the level. For distortion measurements in which the input signal to noise and distortion ratios is less than $20 \mathrm{~dB}$, down to $6 \mathrm{~dB}$, the following is allowable: setting the frequency of the distortion analyzer to within $\pm 10 \%$ of the frequency of the fundamental component of the input signal so that the analyzer can lock onto and null the fundmental camponent of the input signal and remain locked down to $6 \mathrm{~dB}$; or by inputing to the analyzer a signal in which the input signal to noise and distortion ratio is greater than $20 \mathrm{~dB}$ so that the distortion analyzer can lock onto and null the fundamental component of the input signal and remain locked down to $6 \mathrm{~dB}$.

10.1.1 Distortion Measurement. The distortion analyzer shall measure total hamonic distortion and noise (herein called distortion) by dividing the distortion plus noise over the input signal.

10.2 Distortion/Noltmeter/SINAD Mode. The following specifications apply to the equipment in the distortion, voltmeter and SINAD mode.

\subsubsection{Disolav. The display shall be a $3 \frac{1}{2}$ digit electronic digital} display, calibrated to measure level in dam, ms volts and millivolts, distortion in $\mathrm{dB}$ and 8 , and sinad in $\mathrm{dB}$.

10.2.1.1 Display Resolution. The resolution of the display in measuring level in $\overline{\mathrm{ABm}}$, distortion in dB and 8 , and sinad in dB sharl be 0.1 units or less. For measuring level in millivolts and volts display shall display at least 100 counts.

10.2.2 Input Connector. The input to the equipment shall be capable of providing a differential input for signals less than 1 volt ms. For signals greater than 1 volt $\mathrm{ms}$ the input connector may be a full differential input or single ended. The equipment must be protected, such that no internal camponents need be replaced (i.e.., the cover of equipment shall not be removed), to the range specified in 10.4.1 for any improper connection to the equipment. Input connector may be BNC female coaxial connector or dual bananna. If dual bananna, a BNC to dual bananna adapter must be provided with each equipment.

10.2.3 Monitor Outout Connector. There shall be an output connector located on the front panel which when the equipment is in the A.C. volumeter mode provides a scaled output of the input signai and in the distortion and SINAD mode provides a scaled output of the input signal with the fundamentai removed. The output level shall be greater than 50 millivolts rms accurate to within \pm 108 and less than 5 volts rms, accurate to within \pm 108 . The output signal shall not be clipped for imput signals with crest factors fram 1:1 to $3: 1$.

10.2.3.1 Output Impedance. The output impedance for the output connector shall be 600 ohms accurate to within \pm 58 .

10.2.4 Detection. The analyzer shall be capable of detecting input signals by true Ims detection (distortion, SINAD and voltmeter mode) on signals with crest factor fram $1: 1$ to $3: 1$ and also shall be able to detect signals by average detection (distortion and SINAD mode). Type of detection shall be selectable by either a pushbutton or dial located on the front panel. 
10.2.5 Response Time. The response time over the entire specified performance range of the equipmert shall be less than 10 seconds to obtain a reading within the accuracies as stated in para 10.3.4 and 10.4.2 and stable to within \pm 3 counts of the 0.1 digit.

10.2.6 Filters. There shall be 3 internal filters selectable by controls on the front panel.

10.2.6.1 Low Pass Filter. $3 \mathrm{~dB}$ at $30 \mathrm{kHz}$ accurate to within $\pm 2 \mathrm{kHz}$ and a rolloff of at least $60 \mathrm{~dB} /$ decade $\left(18 \mathrm{~dB} / \alpha_{\text {ctave }) .}\right.$

10.2.6.2 Low Pass Filter. $3 \mathrm{~dB}$ at $80 \mathrm{kHz}$ accurate to within $\pm 4 \mathrm{KHz}$ and a rolloff of at least $60 \mathrm{~dB} /$ decade $(18 \mathrm{~dB} / \mathrm{Octave}$.

10.2.6.3 High Pass Filter. $3 \mathrm{~dB}$ at $400 \mathrm{~Hz}$ accurate to within $\pm 40 \mathrm{~Hz}$ and a rolloff of at least $60 \mathrm{~dB} /$ decade ( $18 \mathrm{~dB} /$ octave). $^{\circ}$

10.2.6.3.1 Line Frequency Rejection. The high pass filter shall reject line frequency interference by at least $40 \mathrm{~dB}$.

10.2.7 Mode Selection. The front panel shall include controls to select mode of operation (distortion, SINAD or voltmeter).

10.2.8 Common Mode Rejection Ratio (CMRR). For a common mode signal of $\leq 1$ volt rms, the common mode rejection ratio in the frequency range fron 50 $\mathrm{Hz}$ to $800 \mathrm{~Hz}$, shall be greater than $40 \mathrm{~dB}$.

10.2.9 Overload Protection. The instrument sharl be protected to at least a ms value of 175 volts and shall be capable of performing to all specifications after being subjected to an overload voltage up to 175 volts ms.

10.2.10 Relative $\mathrm{AB}$ Reference. The equipment shall be capable of setting a measurement made in $d B$ and $d B m$ as a zero reference. The control to set the $d B$ reference shall be located on the front panel.

10.2.11 Bandwidth. The $3 \mathrm{~dB}$ bandwidth of the equipment shall be at least $300 \mathrm{kHz}$.

10.2.12 Input Impedance. The input impedance shall be $100 \mathrm{~K}$ ohms accurate to within \pm 28 shunted by less than 300 picofarads.

10.2.13 Fundamental Frequency Locking. There shall be an indication on the front panel as to when the distortion analyzer is locked on the fundamental component of the input signal.

10.3 Distortion/SINAD Mode. The following specifications apply to the equipment operating in the distortion and SINAD mode.

10.3.1 Fundamental Frequency Range. The equipment shall cover the fundamental frequency range fram $20.0 \mathrm{~Hz}$ to $100.0 \mathrm{kHz}$.

10.3.2 Input Level Range. The minimm input level range for distortion and SINAD measurements shall be from 100.0 millivolts ims to 130.0 volts riss. 
10.3.3 Distortion Measurement Range. The equipments distortion measurement range shall cover, within specified accuracy, the range from 0.18 $(-60 \mathrm{~dB})$ to $508(-6 \mathrm{~dB})$.

10.3.4 Distortion Measurement Accuracy. The accuracy of the distormeasurement across the full bandwidth and voltage range shall be within the following:

\section{Fundamental Frequency Range Accuracy}

$$
\begin{array}{ll}
20 \mathrm{~Hz}-20 \mathrm{KHz} & \pm 1 \mathrm{~dB} \\
20 \mathrm{KHz}=50 \mathrm{KHz} & \pm 2 \mathrm{~dB} \\
50 \mathrm{KHz}-100 \mathrm{KHz} & +3 \mathrm{~dB},-4 \mathrm{~dB}
\end{array}
$$

10.3.5 SINAD Measurement. Using average detection, the equipment shall be capable of measuring and displaying SINAD over the entire frequency and voltage rangeas specified herein, in the range from $6 \mathrm{~dB}$ to $60 \mathrm{~dB}$.

10.3.6 SINAD Measurement ACcuracy. The accuracy of the SINAD measurement shall be within the same accuracy as specified in para 10.3.4.

10.3.7 Fundamental Rejection. The distortion analyzer shall reject the fundamental component of the input signal by at least $10 \mathrm{CB}$ below the total harmonic distortion and noise level.

10.3.8 Measurement Mode. The equipment shall display distortion in $d B$ and $\delta$ and sinad in $d B$. Measurement mode shall be selectable by front panel control.

10.3.9 Residual Distortion and Noise. Without using any filters, for both $\mathrm{ms}$ and average response, the total harmonic distortion + noise introduced by the equipment across the entire voltage range shall be less than $-65 \mathrm{~dB}$ $(.056 \%)$ across the entire bandwidth of the equipment.

10.3.10 Level Underrange/Overrange Indication. There shall be on the front panel an indication to indicate when the input signal is not within the accuracies as specified in para 10.3.4.

10.4 Voltmeter. The following specifications apply to the equipment operating in the A.C. voltmeter mode.

10.4.1 Voltage Range. The minimun range of the A.C. voltmeter shall be from 100 millivolts true $\mathrm{ms}$ to 130 volts true $\mathrm{ms}$.

10.4.2 Voltmeter Accuracy. The A.C. voltmeter shall be accurate, over the entire range as specified in para 10.4 .1 , to within \pm 28 of the reading in the fundamental frequency range of $20 \mathrm{~Hz}$ to $20 \mathrm{kHz}$, and within \pm 48 of the reading in the fundamental frequency range from $20 \mathrm{KHz}$ to $100 \mathrm{KHz}$.

10.4.3 Measurement Mode. The equipment shall display level in ms volts, millivolts, and dBm (into $600 \mathrm{ohms}$ ). Measurement mode shall be selectable by front panel control. 
10.4.4 Level Overrange Indication. There shall be on the front panel an indication to indicate when the input signal is not within the accuracies as specified in para 10.4.2.

11. Digital Interface. An IEEE STANDARD 488-1978 interface shall be provided. The interface shall provide talk and listen for all equipment functions required by this specification with the exception of line power on and off. The interface shall be furnished with address selections fran 00 to 30 and interface functions SHl, AHI, SRl, RLl, PPO, DCl, DTO, $C$ and one of Tl, 2, 5, 6 and one of Ll, 2, 3, 4. Mating connector to be in accordance with IEEE STD 488-1978, Chapter 4, without the use of removeable adapter or converters. 



\section{APPENDIX B}

\section{TEST PROCEDURES}

for

\section{SPECIFICATION PARAGRAPHS}

\section{1 through 10.4 .4}

The data sheets and tables referred to in this Appendix are located in Appendix $C$.

\section{Note:}

The procedures described in this document are valid only if used with test equipment that is maintained within the normal Army calibration procedures. Certain commercial equipment is identified in this document. This identification does not imply endorsement by the National Bureau of Standards nor does it imply that the equipment identified is necessarily the best available for the purpose. Also, each specification description included itith these procedures have been copied without modification from the specification paragraphs in Appendix A. 


\subsection{OPERATION}

\section{Specification:}

In measuring level and in measuring distortion in which the distortion is pure harmonic distortion, and when the input signal to noise and distortion ratio is greater than $20 \mathrm{~dB}$, the equipment shall have full automatic operation. There shall be no manual operations in locating the fundamental frequency, nulling the fundamental frequency and in locating the level. For distortion measurements in which.the input signal to noise and distortion ratios is less than $20 \mathrm{~dB}$, down to $6 \mathrm{~dB}$, the following is allowable: setting the frequency of the distortion analyzer to within $=10 \%$ of the frequency of the fundamental component of the input signal so that the analyzer can lock onto and null the fundamental component of the input signal and remain locked down to $6 \mathrm{~dB}$; or by inputing to the analyzer a signal in which the input signal to noise and distortion ratio is greater than $20 \mathrm{~dB}$ so that the distortion analyzer can lock onto and null the fundamental component of the input signal and remain locked down to $6 \mathrm{~dB}$.

Equipment:

Manufacturer's manual for unit under test (UUT)

Procedure:

1. Read the manuals for the UUT and note whether or not any manual operations are required to. locate the fundamental frequency or signal level during any of the tests covered by this test procedure. 


\section{Specification:}

The distortion analyzer shall measure total harmonic distortion and noise (herein called distortion) by dividing the distortion pius noise over the input signal.

\section{Equipment:}

Manufacturer's manual for UUT

\section{Procedure:}

1. Read the manual for the UUT and assure that the equipment measures total harmonic distortion by dividing the distortion plus noise over the input signal. Note on the data sheet whether or not this condition is met. 


\subsubsection{DISPLAY}

Specification:

The display shall be $31 / 2$ digit electronic digital display, calibrated to measure level in $\mathrm{dBm}$, rms volts and millivolts, distortion in $\mathrm{dB}$ and $\%$, and SINAD in $\mathrm{dB}$.

\section{Equipment:}

Manufacturer's manual for UUT

\section{Procedure:}

1. Read the manual for the UUT. Assure that the UUT contains a $31 / 2$ digit digital display calibrated to display level in $\mathrm{dBm}$, rms volts and millivolts, distortion in $\mathrm{dB}$ and $\%$, and SINAD in $\mathrm{dB}$. 


\subsubsection{DISPLAY RESOLUTION}

\section{Specification:}

The resolution of the display in measuring level in $\mathrm{dBm}$, distortion in $\mathrm{AB}$ and $\%$, and SINAD in $d B$ shall be 0.1 units or less. For measuring level in millivolts and volts display shall display at least 100 counts.

\section{Procedure:}

1. Set the controls on the UUT such that the instrument measures input level in $\mathrm{dBm}$. Turn the autoranging feature of the UUT to the OFF position.

2. Set the range of the UUT to each range possible.

3. Note and record the minimum resolution indicated on the display of the UUT on the data sheet.

4. Set the controls on the UUT such that the instrument measures input level in volts. Turn the autoranging feature of the UUT to the OFF position.

5. Set the range of the UUT to each range possible.

6. Note and record the minimum number of counts indicated on the display of the UUT on the data sheet.

7. Set the controls on the UUT such that the instrument measures distortion in $d B$. Turn the autoranging feature of the UUT to the OFF position.

8. Set the range of the UUT to each range possible.

9. Note and record the minimum resolution indicated on the display of the UUT on the data sheet.

10. Set the controls on the UUT such that the instrument measures distortion in percent. Turn the autoranging feature of the UUT to the OFF position.

11. Set the range of the UUT to each range possible.

12. Note and record the minimum resolution indicated on the display of the UUT on the data sheet. 


\subsubsection{INPUT CONNECTOR}

Specification:

The input to the equipment shall be capable of providing a differential input for signals less than 1 volt rms. For signals greater than 1 volt rms the input connector may be a full differential input or single ended. The equipment must be protected, such that no internal components need be replaced (i.e., the cover of the equipment shall not be removed), to the range specified in 10.4.1 for any improper connection to the equipment. Input connector may be BNC female coaxial connector or dual banana. If dual banana, a BNC to dual banana adapter must be provided with each equipment.

\section{Procedure:}

1. Assure that the UUT is capable of providing a differential input for signals less than $1 \mathrm{~V}$ ac ( $\mathrm{rms}$ ) by performing measurements required in paragraph 10.2.8. Note on data sheet if this condition is met.

2. Assure that the UUT is protected, such that no internal components need be replaced (i.e., the cover of the equipment shall not be removed), to the range specified in 10.3.2 for any improper connection in paragraph 10.2.9. Note on data sheet if this condition is met.

3. Visually inspect the UUT to determine if the input connector is a BNC female coaxial connector or dual banana connector. Note on data sheet which connector is present. Note on data sheet if a BNC to dual banana adapter is provided if the input connector is a dual banana. 


\subsubsection{MONITOR OUTPUT CONNECTOR}

\section{Specification:}

There shall be an output connector located on the front panel which when the equipment is in the $A C$ voltmeter mode provides a scaled output of the input signal and in the distortion and SINAD mode provides a scaled output of the input signal with the fundamental removed. The output level shall be greater than 50 millivolts rms accurate to within $\pm 10 \%$ and less than 5 volts $\mathrm{rms}$, accurate to within $\pm 10 \%$. The output signal shall not be clipped for input signals with crest factors from $1: 1$ to $3: 1$.

\subsubsection{Part 1. Sine Wave Test Signals}

\section{Equipment:}

Items

AC Calibrator

Power Amplifier

AC Voltmeter
Range

$100 \mathrm{mV}$ to $100 \mathrm{~V}$ ac $100 \mathrm{~V}$ to $175 \mathrm{~V}$ ac $10 \mathrm{mV}$ to $175 \mathrm{~V}$ ac
Mode 1

Fluke $5200 \mathrm{~A}$ or equivalent Fluke $5205 \mathrm{~A}$ or equivalent Fluke $8506 \mathrm{~A}$ or equivalent

Procedure:

1. Connect the equipment as shown below

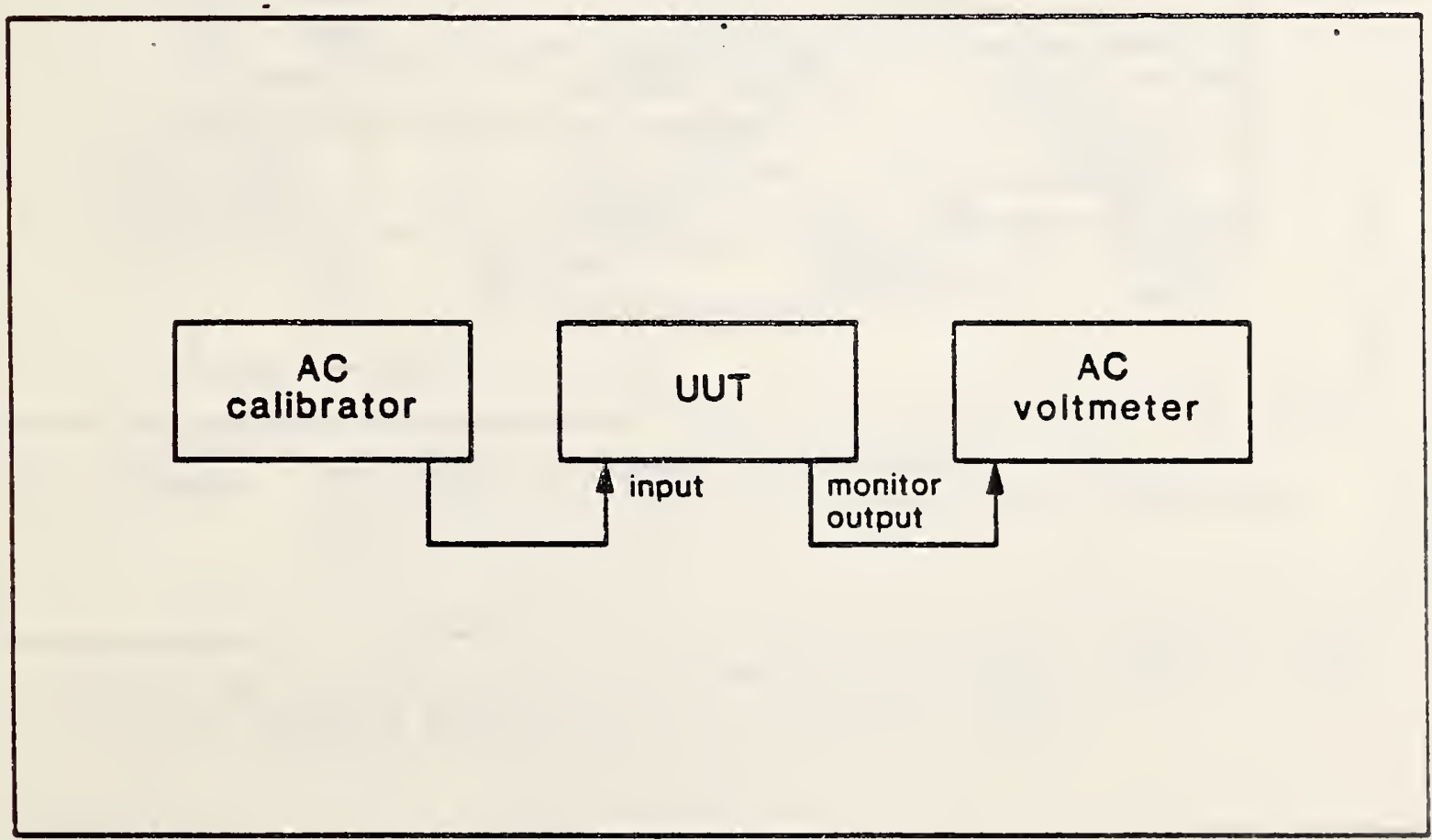

Fig. 10.2.3A. Test setup for measuring the accuracy of the monitor output for sine wave signals. 
2. Set the UUT controls as follows:

On/Off switch

Function

Filters (all)

Range Mode

ON

AC LEVEL MODE

OFF

AUTORANGE

3. Set the voltmeter controls as follows:
Function
AC VOLTS
Mode
HIGH ACCURACY
Range
AUTO

4. Refer to data sheet table 10.2.3A for setting AC calibrator frequency and amplitude levels.

5. Read and record the $A C$ voltmeter reading for each line of data. Note that for calibrator amplitude levels greater than 100 volts the equipment is to be reconnected as shown below.

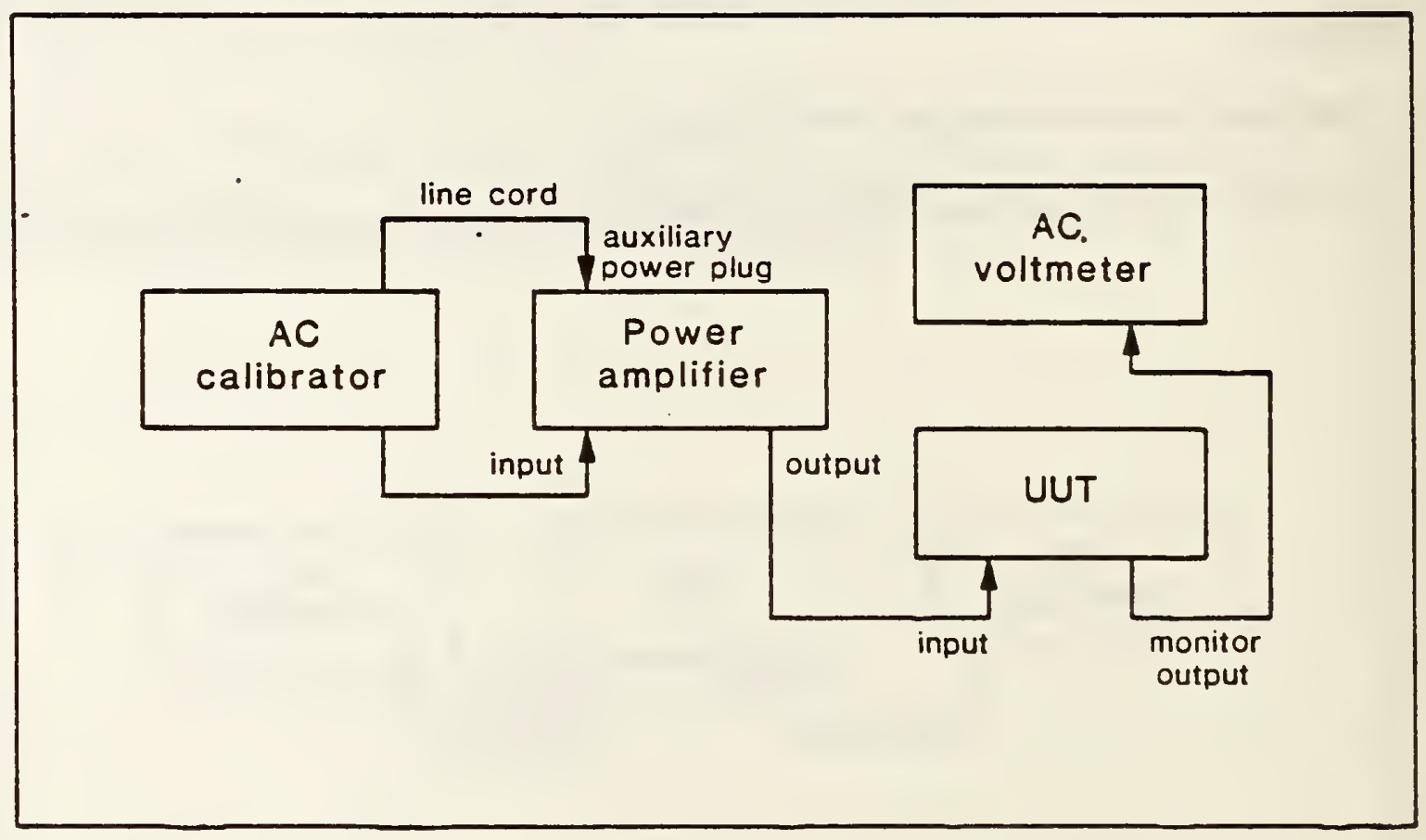

Fig. 10.2.3B. Test setup for measuring the accuracy of the monitor output for high voltage sine wave signals.

6. Calculate the deviation in percent for each line of data using the $1 \mathrm{kHz}$ ac voltmeter indication for each group of three measurements at the same amplitude as the reference level. 
10.2.3 Part 2. 3:1 Crest Factor Test Signals

Equipment:

Items

AC Voltmeter

Arbitrary Waveform Generator 488 Controller

Oscilloscope

Power Amplifier
Range

$10 \mathrm{mV}$ to $175 \mathrm{~V} \mathrm{ac}$

$20 \mathrm{~Hz}$ to $20 \mathrm{kHz}$

-

$20 \mathrm{~Hz}$ to $300 \mathrm{kHz}$

$100 \mathrm{~V}$ to $130 \mathrm{~V}$ ac
Mode

Fluke $8506 \mathrm{~A}$ or equivalent Wavetek 275 or equivalent HP 9836 or equivalent.

Tektronix 2445 or equivalent Fluke $5205 \mathrm{~A}$ or equivalent

\section{Procedure:}

1. Connect the equipment to the UUT as shown below

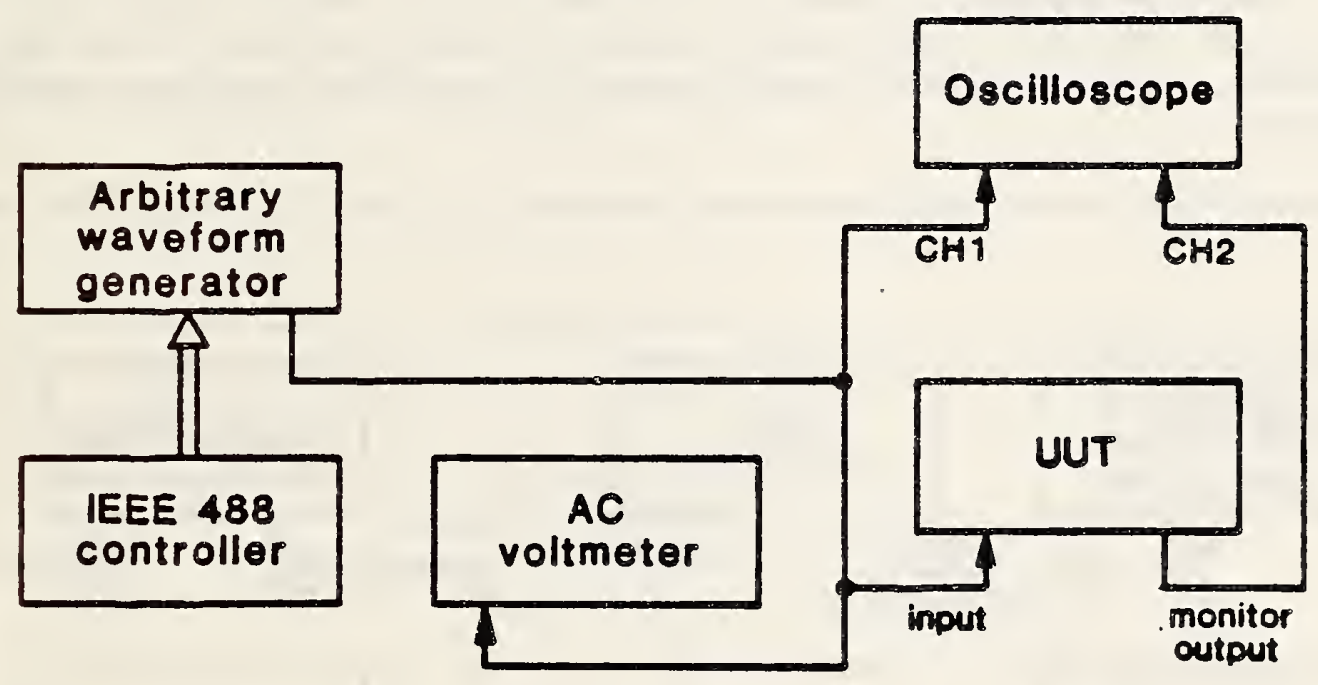

Fig. 10.2.3C. Test setup for measuring the monitor response to signals with a $3: 1$ crest factor and peak amplitudes less than 10 volts.

2. Set the UUT Controls as follows:

Function

Filters (all)

Range Mode
AC LEVEL MODE

OFF

AUTORANGE 
3. Set the controls on the voltmeter as follows:

$\begin{array}{ll}\text { Function } & \text { AC VOLTS } \\ \text { Mode } & \text { HIGH ACCURACY } \\ \text { Range } & \text { AUTO }\end{array}$

4. Set the frequency of the arbitrary waveform generator to $20 \mathrm{~Hz}$ and set its amplitude off.

5. Set the amplitude of the arbitrary waveform generator to indicate $100 \mathrm{mV}$ on the ac voltmeter.

6. Adjust gains and appropriate sweep settings on the oscilloscope so that the trace of the input and monitor output signal can be compared.

7. Observe if there is any clipping on the monitor output signal and note on data sheet Table 10.2.38.

8. Repeat steps 5 through 7 for input levels to the UUT of $1 \mathrm{~V}, 10 \mathrm{~V}, 100 \mathrm{~V}$, and 130V. The ac voltmeter is used to set the input levels. Note that when the peak-to-peak, voltage requirement exceeds 10 volts reconnect the equipment as shown below. NOTE: Extreme caution must be used when the power amplifier is operational.

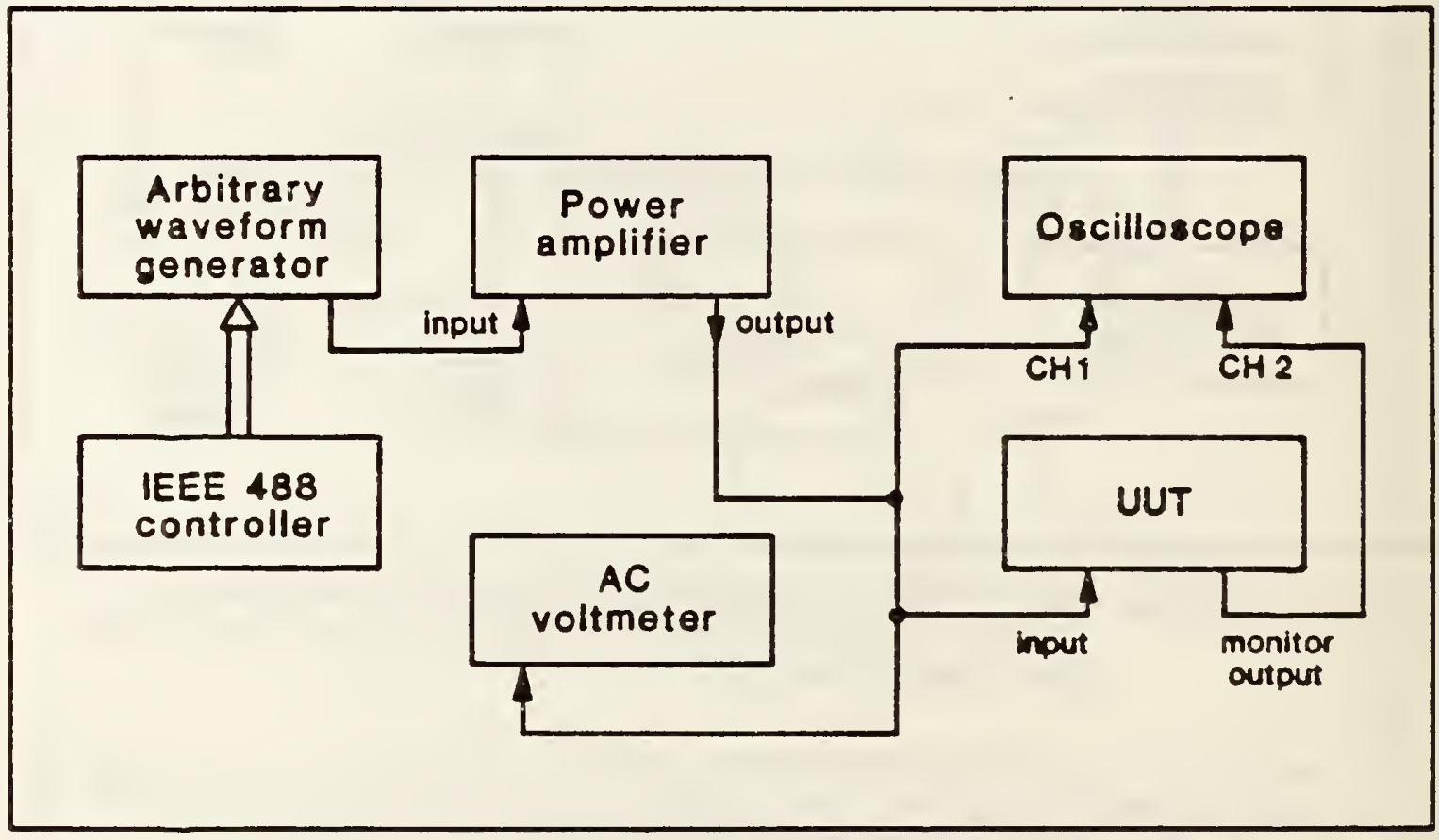

Fig. 10.2.30. Test setup for measuring the monitor response to signals with a $3: 1$ crest factor and peak amplitudes greater than 10 volts.

9. Set the frequency of the arbitrary waveform generator to $20 \mathrm{kHz}$ and repeat steps 5 through 8 inclusive. 


\subsubsection{OUTPUT IMPEDANCE}

\section{Specification:}

The output impedance for the output connector shall be 600 ohms accurate to within $\pm 5 \%$

\section{Equipment:}

\section{Items}

Audio Oscillator

$A C$ voltmeter

600 ohm Feedthrough Termination, $\pm 1 \%$

\section{Procedure:}

1. Connect the equipment as shown below
Model

TEK FG504T, or equivalent Fluke $8506 \mathrm{~A}$, or equivalent TEK 011-0092-00, or equivalent

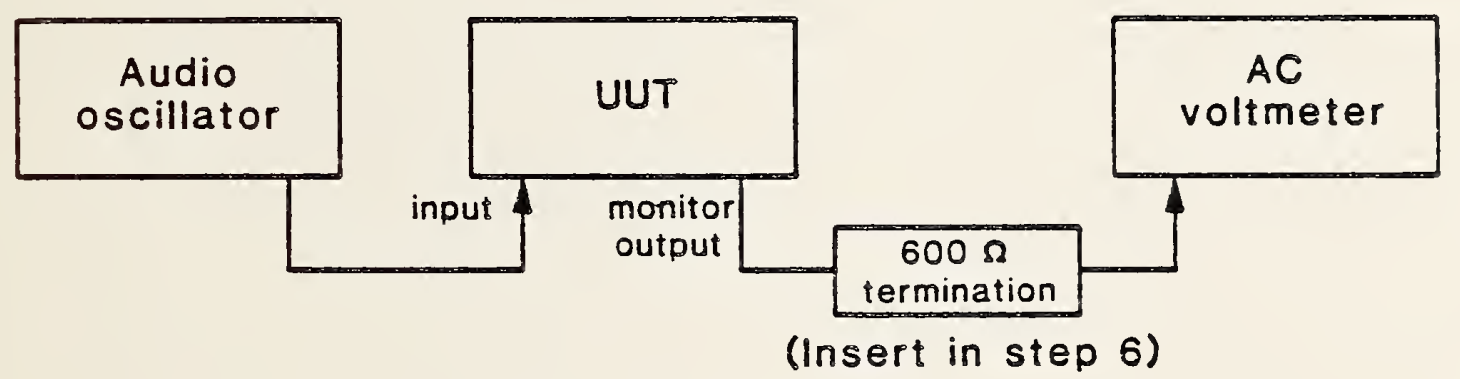

Fig. 10.2.3.1. Test setup for measuring the monitor output impedance.

2. Set the controls on the UUT as follows:

Function

Filters (all)

Range

AC LEVEL MODE

OFF

AUTORANGE 
3. Set the Voltmeter controls as follows:

$\begin{array}{ll}\text { Function } & \text { AC VOLTS } \\ \text { Mode } & \text { HIGH ACCURACY } \\ \text { Range } & \text { AUTO }\end{array}$

4. Set the frequency of the audio oscillator to approximately $1000 \mathrm{~Hz}$ as indicated by the dial setting. Adjust the amplitude of the audio oscillator such that the voltmeter indicates a nominal value of $1.0 \mathrm{~V}$ ac ( $\mathrm{rms}$ ).

5. Measure and record the voltage indicated on the $A C$ voltmeter as VI.

6. Disconnect the cable from the voltmeter to the UUT at the output connector of the UUT. Connect the feedthrough termination to the output connector. Reconnect the cable to the voltmeter to the feedthrough termination.

7. Measure and record the voltage indicated on the digital voltmeter as V2.

8. Calculate the output impedance by the following formula:

$$
R_{\text {out }}=(600 \mathrm{~V} 1 / \mathrm{V} 2)-600 \text {. }
$$

9. Record the value of $R_{\text {out }}$ on the data sheet. 


\section{Specification:}

The analyzer shall be capable of detecting input signals by true rms detection (distortion, SINAD and voltmeter mode) on signals with crest factor from $1: 1$ to $3: 1$ and also shall be able to detect signals by average detection (distortion and SINAD mode). Type of detection shall be selectable by either a pushbutton or dial located on the front panel.

\section{Equipment:}

Manufacturer's manual for UUT.

\section{Procedure:}

1. Read the manual for the UUT and note what type of detection (average or rms) is used for each mode. Assure that both modes of detection are seiectable from the front panel. Record on the data sheet the modes of detection. 


\subsubsection{RESPONSE TIME}

Specification:

The response time over the entire specified performance range of the equipment shall be less than 10 seconds to obtain a reading within the accuracies as stated in para. 10.3.4 and 10.4.2 and stable to within \pm 3 counts of the 0.1 digit.

\section{Procedure:}

1. The response time in the voltmeter mode is checked at the $20 \mathrm{~Hz}, 0.1$ volt level in steps 28 through 30 of the procedure in 10.4.2.

2. The response time in the distortion mode is checked at the $20 \mathrm{~Hz}$, 0.1 volt, $60 \mathrm{~dB}$ level in steps 12 through 15 of the procedure in 10.3.4.

3. In each of the response time tests record the time required to obtain a reading that is stable within \pm 3 counts at the 0.1 digit. 


\subsubsection{FILTERS}

Specification:

There shall be 3 internal filters selectable by controls on the front panel. Procedure:

Assure that the UUT has at least 3 internal filters which are selectable by controls on the front panel. Note on data sheet if this condition is met. 


\subsubsection{LOW PASS FILTER}

Specification:

$3 \mathrm{~dB}$ at $30 \mathrm{kHz}$ accurate to within $\pm 2 \mathrm{kHz}$ and a rolloff at least $60 \mathrm{~dB} / \mathrm{dec}$ ade (18dB/octave).

Equipment:

Items

Audio Oscillator

AC Voltmeter

Frequency Counter

600 ohm Feedthrough Termination, $\pm 1 \%$

\section{Procedure:}

1. Connect the equipment as shown below

\section{Connect the equipment as shown below}

Mode 1

Tek FG504T, or equivalent Fluke $8506 \mathrm{~A}$, or equivalent HP 5316A, or equivalent TEK 011-0092-00, or equivalent

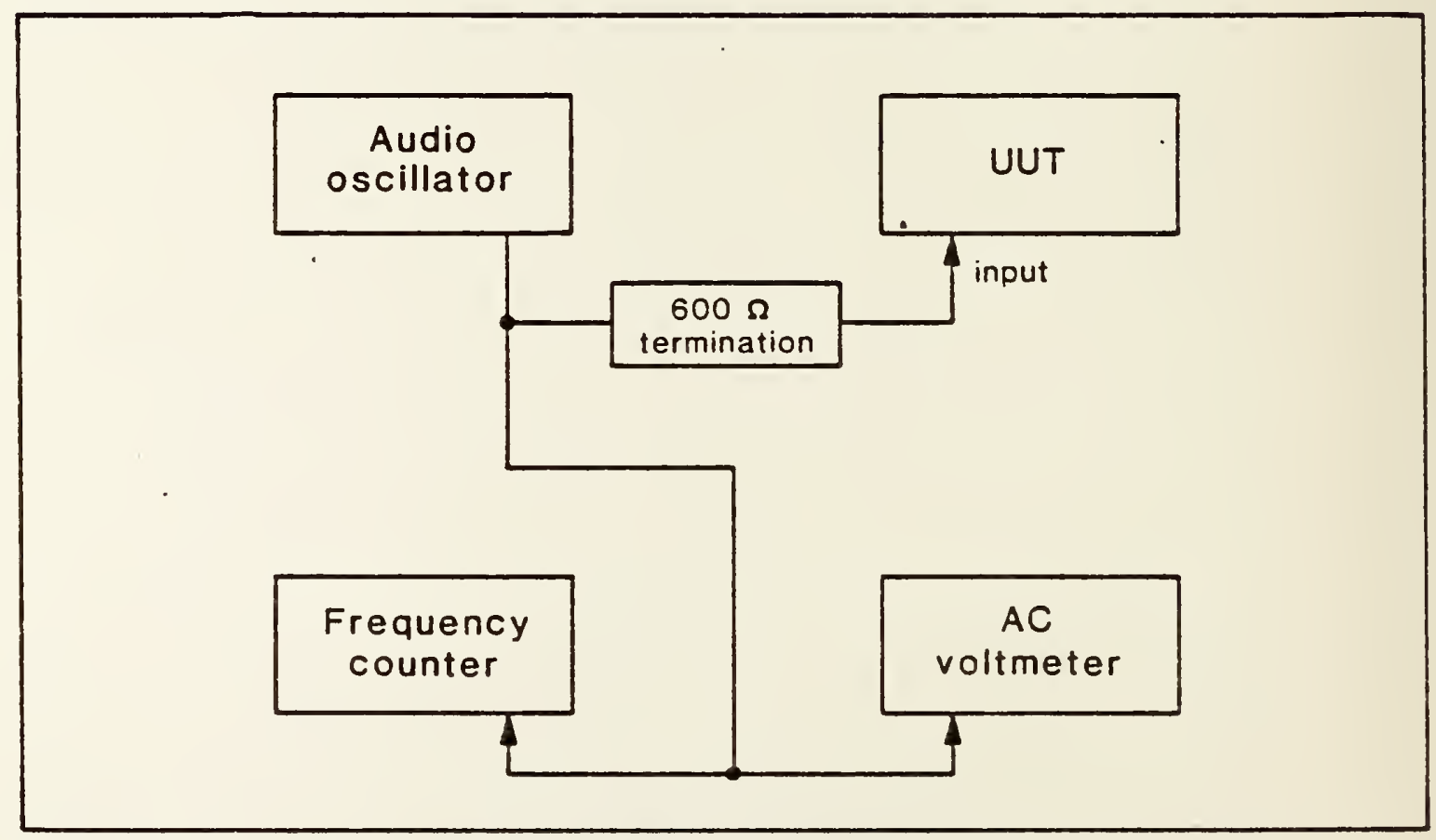

Fig. 10.2.6.1 Test setup for measuring the low pass filter $(30 \mathrm{kHz})$ response.

2. Set the controls on the $A C$ voltmeter as follows:

Function

Mode

Range
AC VOLTS

HIGH ACCURACY

AUTO 
3. Set the frequency of the audio oscillator to $30 \mathrm{kHz}$ as indicated by the frequency counter. Adjust the amplitude of the audio oscillator such that the voltmeter indicates nominally $1.0 \mathrm{~V}$ ac. Read and record on the data sheet the actud voltage level.

4. Set the controls on the UUT as follows:

$\begin{array}{ll}\text { Filters (all) } & \text { OFF } \\ \text { Ratio } & \text { OFF }\end{array}$

5. Select the dB RATIO on the UUT and, if provided, depress the PUSH TO SET 0 $\mathrm{dB}$ REF and set the LIN/LOG mode to LOG mode.

6. Select the $30 \mathrm{kHz}$ filter on the UUT.

7. Adjust the frequency of the audio oscillator such that the display on the UUT indicates $-3.0 \mathrm{~dB}$.

8. Read and record on the data sheet the frequency indicated on the frequency meter.

9. Set the frequency to $300 \mathrm{kHz}$ as indicated on the frequency meter.

10. If necessary, readjust the output amplitude of the audio oscillator such that the AC voltmeter indicates the same voltage level as was obtained in step 3 , above.

11. Read and record on the data sheet the displiay indicated on the UUT. If the UUT is capable of displaying voltage levels in $\mathrm{dB}$, record the value indicated. If the UUT is not capable of displaying the voltage level in $d B$, calculate and record the rolloff for one decade change in frequency in $d B$, using:

Rolloff $(\mathrm{dB})=20 \log$ (Indicated Voltage / Input Voltage)

Where: the Input Voltage is that voltage indicated on the voltmeter (step 10), and

the Indicated Voltage is that voltage read on the UUT (step 11). 
10.2.6.2 LOW PASS FILTER

Specification:

$3 \mathrm{~dB}$ at $80 \mathrm{kHz}$ accurate to within $\pm 4 \mathrm{kHz}$ and a rolloff at least $60 \mathrm{~dB} /$ decade (18 dB/octave).

Equipment:

Items

Audio Oscillator

AC Voltmeter

Frequency Counter

600 ohm Feedthrough Termination, $\pm 1 \%$

\section{Procedure:}

1. Connect the equipment as shown below
Model

TEK FG504T, or equivalent Fluke $8506 \mathrm{~A}$, or equivalent HP 5316A, or equivalent

TEK 011-0092-00, or equivalent

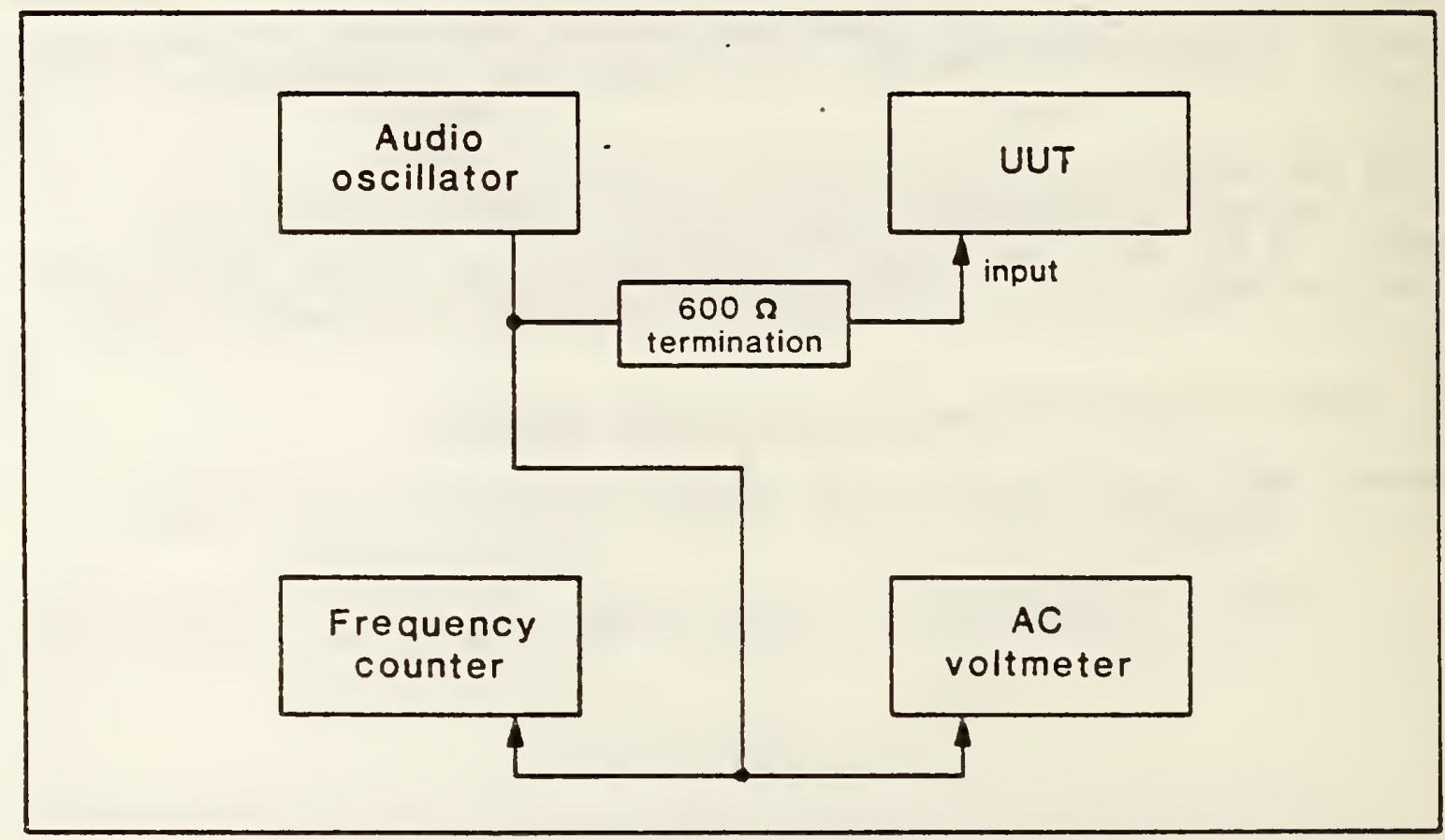

Fig. 10.2.6.2. Test setup for measuring the low pass filter $(80 \mathrm{kHz})$ response.

2. Set the controls on the $A C$ voltmeter as follows:

Function

Mode

Range
AC VOLTS

HIGH ACCURACY

AUTO 
3. Set the frequency of the audio oscillator to $80 \mathrm{kHz}$ as indicated by the frequency counter. Adjust the amplitude of the audio oscillator such that the voltmeter indicates nominally $1.0 \mathrm{~V}$ ac ( $\mathrm{rms})$. Read and record on the data sheet the actual voltage level.

4. Set the controls on the UUT as follows:

$\begin{array}{ll}\text { Filters (a11) } & \text { OFF } \\ \text { Ratio } & \text { OFF }\end{array}$

5. Select the dB RATIO on the UUT and, if provided, depress the PUSH TO SET $O$ $\mathrm{dB}$ REF and set the LIN/LOG mode to LOG mode.

6. Select the $80 \mathrm{kHz}$ filter on the UUT.

7. Adjust the frequency of the audio oscillator such that the display on the UUT indicates $-3.0 \mathrm{~dB}$.

8. Read and record on the data sheet the frequency indicated on the frequency meter.

9. Set the frequency to $800 \mathrm{kHz}$ as indicated on the frequency meter.

10. If necessary, readjust the output amplitude of the audio oscillator such that the $A C$ voltmeter indicates the same voltage level as was obtained in step 3, above.

11. Read and record on the data sheet the display indicated on the UUT. If the UUT is capable of displaying voltage levels in $\mathrm{dB}$, record the value indicated. If the UUT is not capable of displaying the voltage level in $\mathrm{dB}$, calculate and record the rolloff for one decade change in frequency in $\mathrm{dB}$, using:

Rolloff $(d B)=20 \log$ (Indicated Voltage / Input Voltage)

Where: the Input Voltage is that voltage indicated on the voltmeter (step 10), and

the Indicated Voltage is that voltage read on the UUT (step 11). 


\subsubsection{HIGH PASS FILTER}

Specification:

$3 \mathrm{~dB}$ at $400 \mathrm{~Hz}$ accurate to within $\pm 40 \mathrm{~Hz}$ and a rolloff at least $60 \mathrm{~dB} /$ decade (18 dB/octave).

Equipment:

Items

Audio Oscillator

AC Voltmeter

Frequency Counter

$600 \mathrm{ohm}$ Feedthrough Termination, $\pm 1 \%$

\section{Procedure:}

1. Connect the equipment as shown below

\section{Mode 1}

$10 \mathrm{~Hz}$ to $1 \mathrm{MHz}$

TEK FG504T, or equivalent Fluke $8506 \mathrm{~A}$, or equivalent HP 5316A, or equivalent TEK 011-0092-00, or equivalent

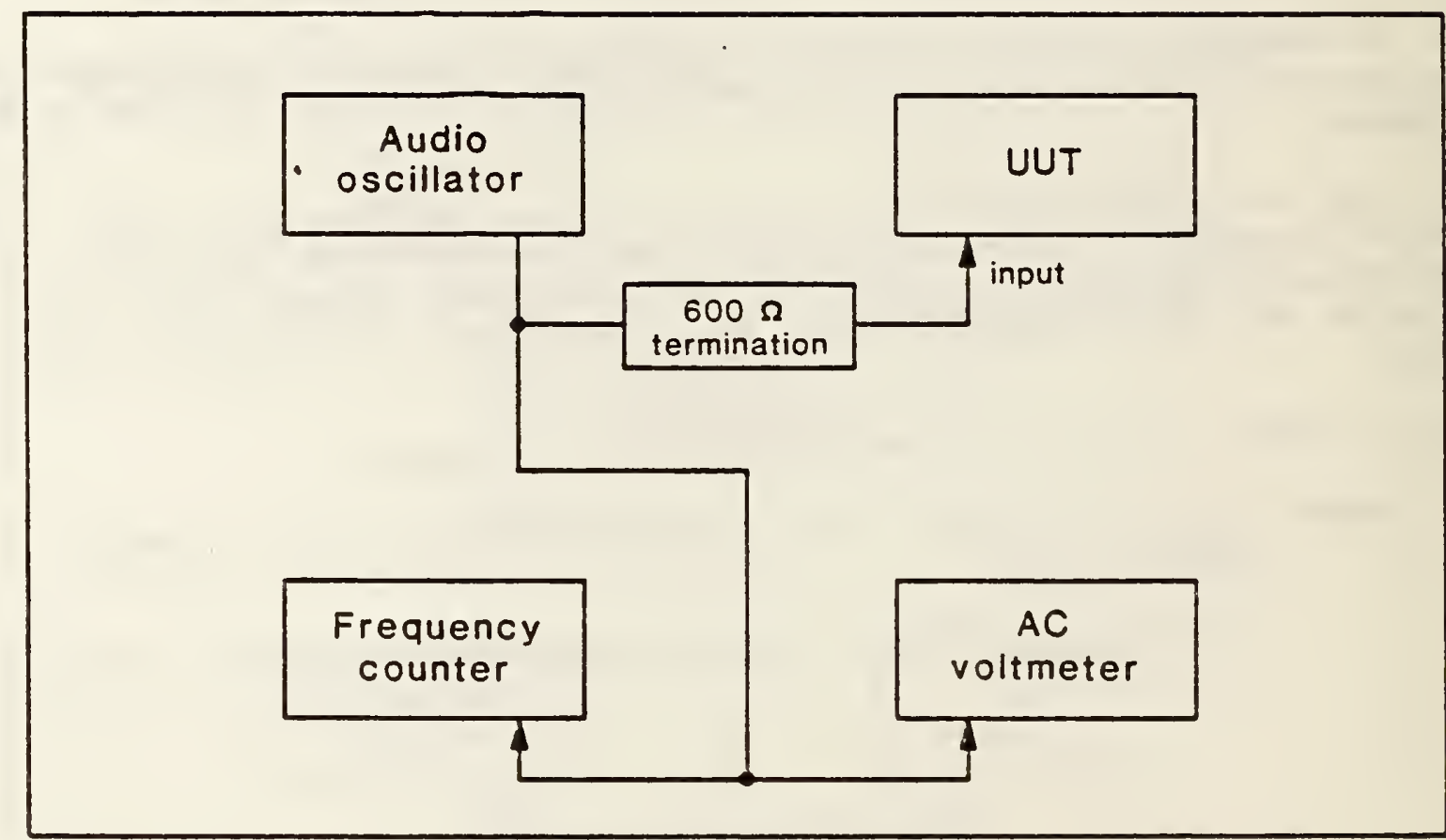

Fig. 10.2.6.3 Test setup for measuring the high pass filter $(400 \mathrm{~Hz}$ ) response.

2. Set the controls on the $A C$ voltmeter as follows:

Function

Mode

Range
AC VOLTS

HIGH ACCURACY

AUTO 
3. Set the frequency of the audio oscillator to $400 \mathrm{~Hz}$ as indicated by the frequency counter. Adjust the amplitude of the audio oscillator such that the voltmeter indicates nominally $1.0 \mathrm{~V}$ ac (rms). Read and record on the data sheet the actual voltage level.

4. Set the controls on the UUT as follows:

$\begin{array}{ll}\text { Filters (a11) } & \text { OFF } \\ \text { Ratio } & \text { OFF }\end{array}$

5. Select the dB RATIO on the UUT and, if provided, depress the PUSH TO SET O $d B$ REF and set the LIN/LOG mode to LOG mode.

6. Select the $400 \mathrm{~Hz}$ filter on the UUT.

7. Adjust the frequency of the audio oscillator such that the display on the UUT indicates $-3.0 \mathrm{~dB}$.

8. Read and record on the data sheet the frequency indicated on the frequency meter.

9. Set the frequency to $40 \mathrm{~Hz}$ as indicated on the frequency meter.

10. If necessary, readjust the output amplitude of the audio oscillator such that the digital voltmeter indicates the same voltage level as was obtained in step 3, above.

11. Read and record on the data sheet the display indicated on the UUT. If the UUT is capable of displaying voltage levels in $d B$, record the value indicated. If the UUT is not capable of displaying the voltage level in $d B$, calculate and record the rolloff for one decade change in frequency in $d B$, using:

Rolloff $(d B)=20 \log$ (Indicated Voltage / Input Voltage)

Where: the Input Voltage is that voltage indicated on the voltmeter (step 10), and

the Indicated Voltage is that voltage read on the UUT (step 1I). 


\subsection{LINE FREQUENCY REJECTION}

Specification:

The high pass filter shall reject the line frequency interference by at least $40 \mathrm{~dB}$.

Equipment:

Items

Range

Mode 1

Audio Oscillator

AC Voltmeter

$10 \mathrm{~Hz}$ to $1 \mathrm{MHz}$

Frequency Counter

$600 \mathrm{ohm}$ Feedthrough Termination, $\pm 1 \%$

TEK FG504T, or equivalent

Fluke $8506 \mathrm{~A}$, or equivalent

HP $5316 \mathrm{~A}$, or equivalent

TEK 011-0092-00, or equivalent

\section{Procedure:}

1. Connect the equipment as shown below

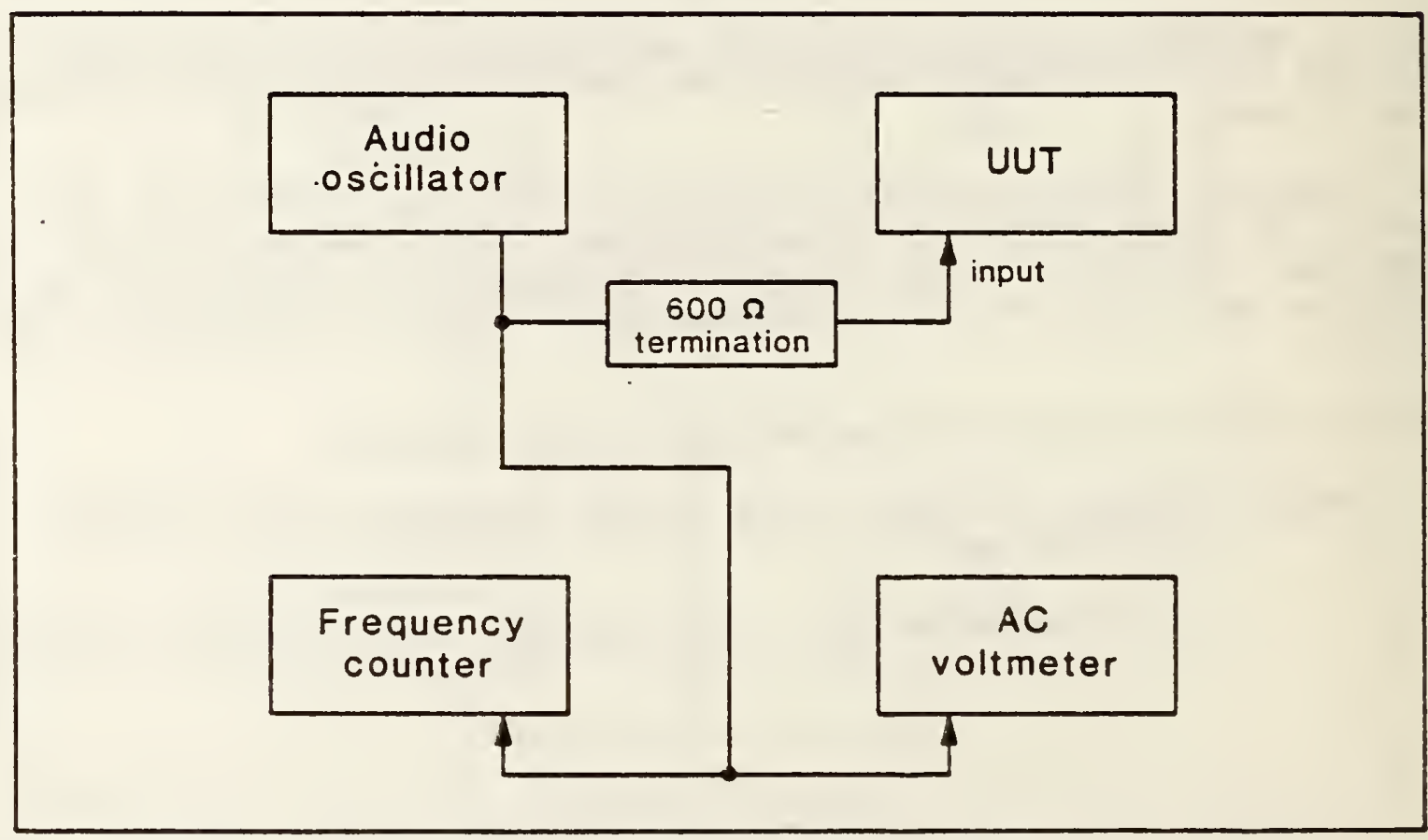

Fig. 10.2.6.3.1. Test setup for measuring the 1 ine frequency rejection.

2. Set the controls on the $A C$ voltmeter as follows:

Function

Mode

Range
AC VOLTS

HIGH ACCURACY

AUTO 
3. Set the frequency of the audio oscillator to $60 \mathrm{~Hz}$ as indicated by the frequency counter. Adjust the amplitude of the audio oscillator such that the voltmeter indicates nominally $1.0 \mathrm{~V}$ ac (rms). Read and record on the data sheet the actual voltage level.

4. Set the controls on the UUT as follows:

$$
\begin{array}{ll}
\text { Filters (all) } & \text { OFF } \\
\text { Ratio } & \text { OFF }
\end{array}
$$

5. If provided, select the dB RATIO on the UUT and depress the PUSH TO SET O $\mathrm{dB}$ REF and set the LIN/LOG mode to LOG mode.

6. Select the High Pass Filter on the UUT.

7. Read and record on the data sheet the display indicated on the UUT. If the UUT is capable of displaying voltage levels in $\mathrm{dB}$, record the value indicated. If the UUT is not capable of displaying the voltage level in $d B$, calculate and record the rejection of the High Pass Filter at $60 \mathrm{~Hz}$, in $\mathrm{dB}$, using:

Rejection $(d B)=20 \log$ (Indicated Voltage / Input Voltage)

Where: the Input Voltage is that voltage indicated on the voltmeter (step 3), and

the Indicated Voltage is that voltage read on the UUT (step 7). 


\subsubsection{MODE SELECTION}

Specification:

The front panel shall include controls to select mode of operation (distortion, SINAD or voltmeter).

\section{Procedure:}

1. Assure that the front panel includes controls to select the mode of operation (distortion, SINAD or voltmeter). Note on data sheet if this condition is met. 
10.2.8 COMMON MODE REJECTION RATIO (CMRR)

\section{Specification:}

For a common mode signal of $<1$ volt rms, the common mode rejection ratio in the frequency range from $50 \mathrm{~Hz}$ to $800 \mathrm{~Hz}$, shall be greater than $40 \mathrm{~dB}$.

\section{Equipment:}

\section{Items}

Audio Oscillator

AC Calibrator

Spectrum Analyzer

Coupling Transformer

\section{Procedure:}

1. Connect the equipment as shown below.

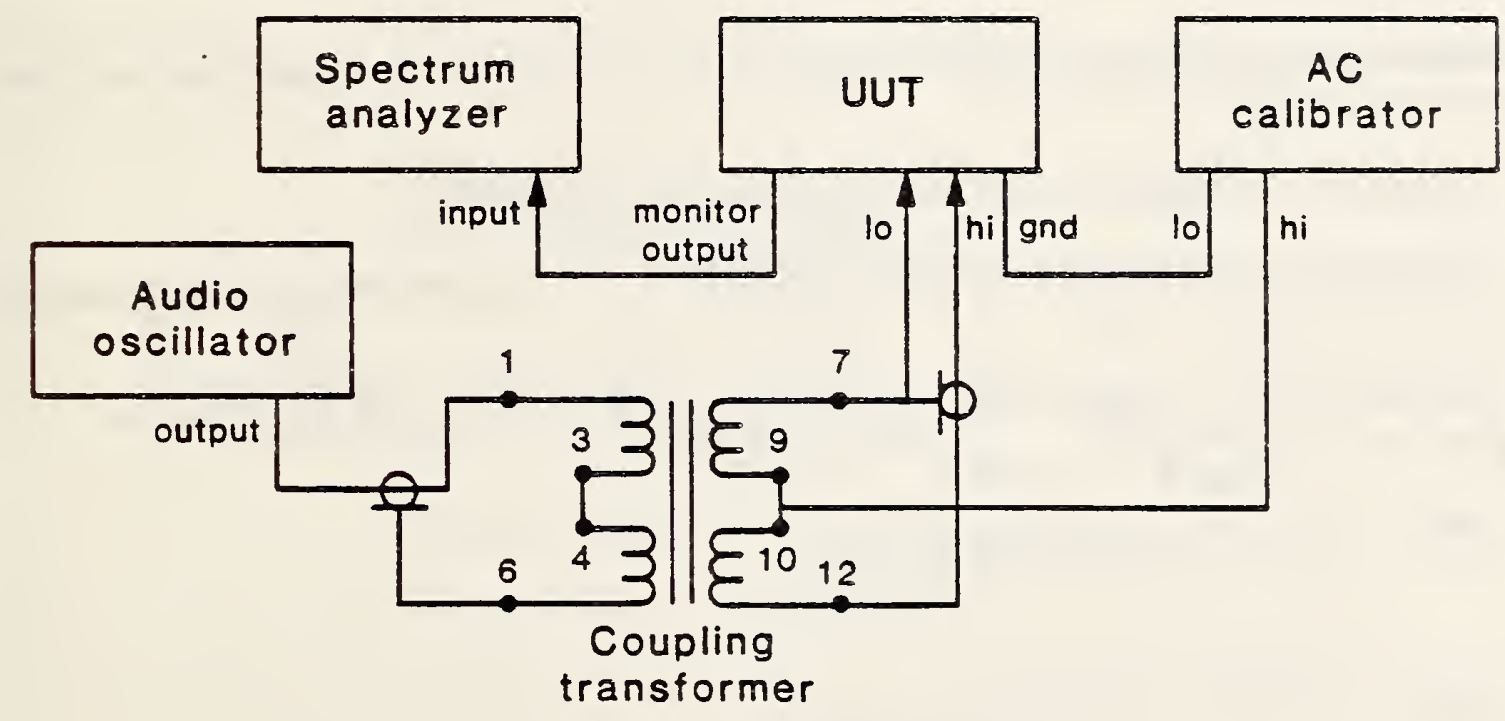

Fig. 10.2.8. Test setup for measuring the common mode rejection ratio.

2. Set the controls of the UUT as follows:

Function

Range

Filters (all)
AC VOLTS LEVEL

AUTO RANGE

OFF
Mode I

HP2040 or equivalent

Fluke $5200 \mathrm{~A}$ or equivalent

HP3585A or equivalent

UTC-LS-34 or equivalent 
3. Set the controls of the audio oscillator as follows:

Frequency

Output Level
NOMINAL $5 \mathrm{kHz}$

NOMINAL $100 \mathrm{mv}$ *

* Note: The unit under test $c$ an be used as the indicator for the audio oscillator nominal output level.

4. Set the controls of the $A C$ calibrator as follows:

$\begin{array}{ll}\text { Frequency } & 50 \mathrm{~Hz} \\ \text { Voltage } & 1 \mathrm{VOLT}\end{array}$

5. Set the controls of the spectrum analyzer as follows:

$\begin{array}{ll}\text { Sweep start } & 0 \mathrm{~Hz} \\ \text { Sweep stop } & \text { AS NEEDED } \\ \text { Display } & \text { VOLTS } \\ \text { Amplitude } & \text { AUTORANGE } \\ \text { Sweep Rate } & \text { TWO STEPS SLOWER THAN AUTOMATIC }\end{array}$

6. Record the reading on the UUT as V6.

7. Measure the peak amplitude of the $5 \mathrm{kHz}$ signal on the spectrum analyzer and record as $V_{7}$.

8. Measure the peak amplitude of the $50 \mathrm{~Hz}$ signal on the spectrum analyzer and record as $V_{8}$.

9. Change the frequency of the $A C$ calibrator to $800 \mathrm{~Hz}$.

10. Measure the peak amplitude of the $800 \mathrm{~Hz}$ signal on the spectrum analyzer and record as $V_{9}$.

11. Calculate the common mode rejection ratio for the $100 \mathrm{mv}$ range as follows:

$$
\begin{aligned}
& \text { CMRR at } 50 \mathrm{~Hz}=20 \log \frac{V_{7}}{\left(V_{6}\right)\left(V_{8}\right)} \\
& \text { CMRR at } 800 \mathrm{~Hz}=20 \log \frac{V_{7}}{\left(V_{6}\right)\left(V_{9}\right)}
\end{aligned}
$$




\subsubsection{OVERLOAD PROTECTION}

\section{Specification:}

The instrument shall be protected to at least a rms value of 175 volts and shall be capable of performing to all specfications after being subjected to an overload voltage up to 175 volts rms.

Equipment:

\section{ITEM}

AC Calibrator

Power Amplifier
RANGE

$175 V$ MODEL

Fluke $5200 \mathrm{~A}$ or equivalent Fluke $5205 \mathrm{~A}$ or equivalent

\section{Procedure:}

1. Connect the equipment as shown below. NOTE: Extreme caution must be used when the power amplifier is operational.

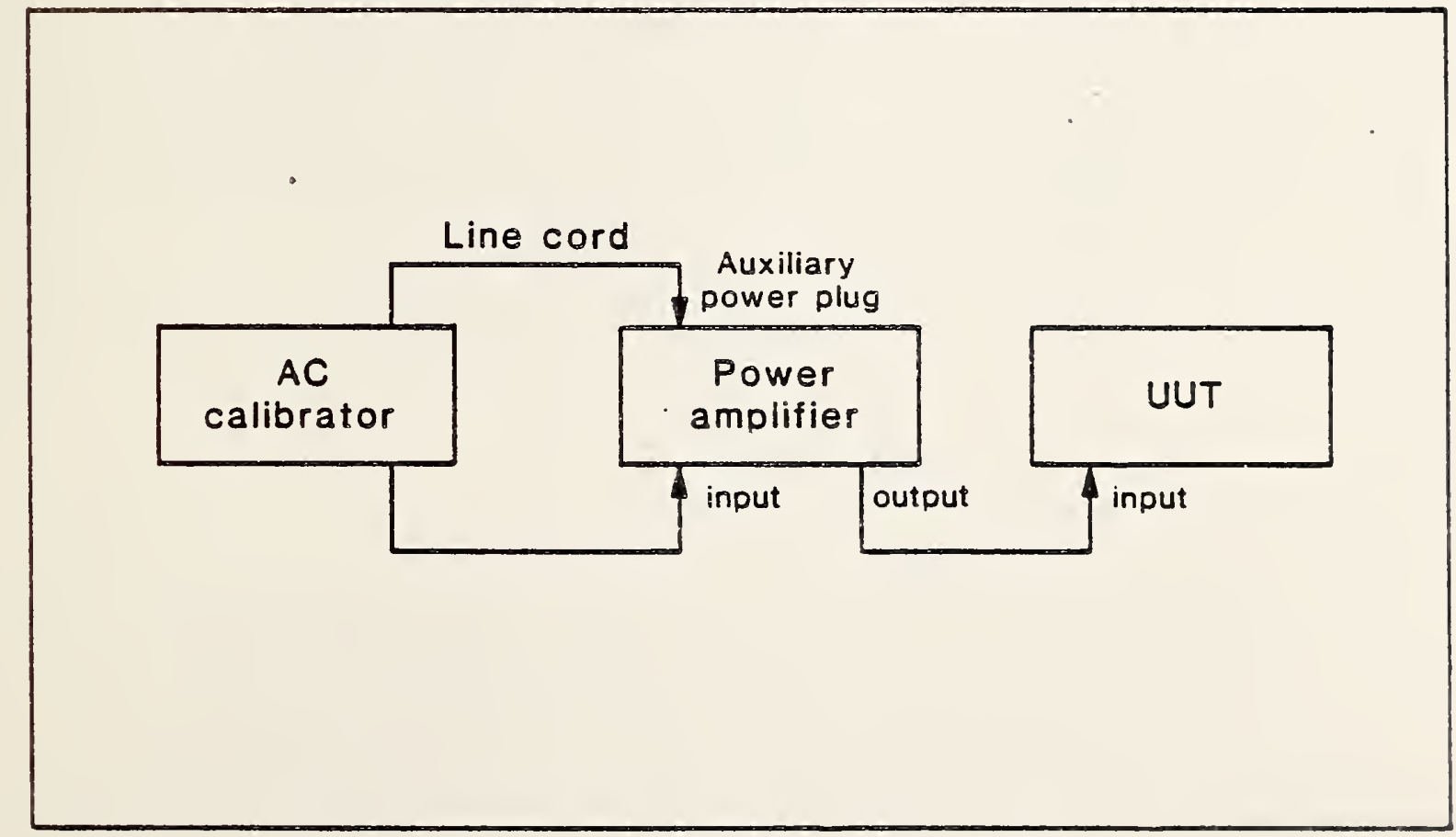

Fig. 10.2.9. Test setup for measuring overload protection.

2. Set the controls on the UUT as follows:

Range

Function
AUTORANGE

AC VOLTS 
3. Set the controls on the $A C$ calibrator as follows:

$\begin{array}{ll}\text { Amplitude } & 175 \mathrm{~V} \\ \text { Frequency } & 60 \mathrm{~Hz}\end{array}$

4. Maintain a 175 volt rms, $60 \mathrm{~Hz}$ level to the input of the UUT for 2 minutes.

5. Deenergize the calibrator and perform all test procedures for specification conformance. 


\section{Specification:}

The equipment shall be capable of setting a measurement made in $d B$ and $d B m$ as a zero reference. The control to set the $d B$ reference shall be located on the front panel.

\section{Procedure:}

Assure that the UUT has a control on the front panel to set a zero $d B$ reference level. Note and record on the data sheet whether or not this condition is met. 


\subsubsection{BANDWIDTH}

Specification:

The $3 \mathrm{~dB}$ bandwith of the equipment shall be at least $300 \mathrm{kHz}$.

Equipment:

ITEMS

AC Calibrator

Power Amplifier

Procedure:

1. Connect the equipment as shown below
RANGE

$100 \mathrm{MV}$ to $10 \mathrm{~V}$

$10 \mathrm{~V}$ to $130 \mathrm{~V}$

MODEL

Fluke $5200 \mathrm{~A}$ or equivalent Fluke $5205 \mathrm{~A}$ or equivalent

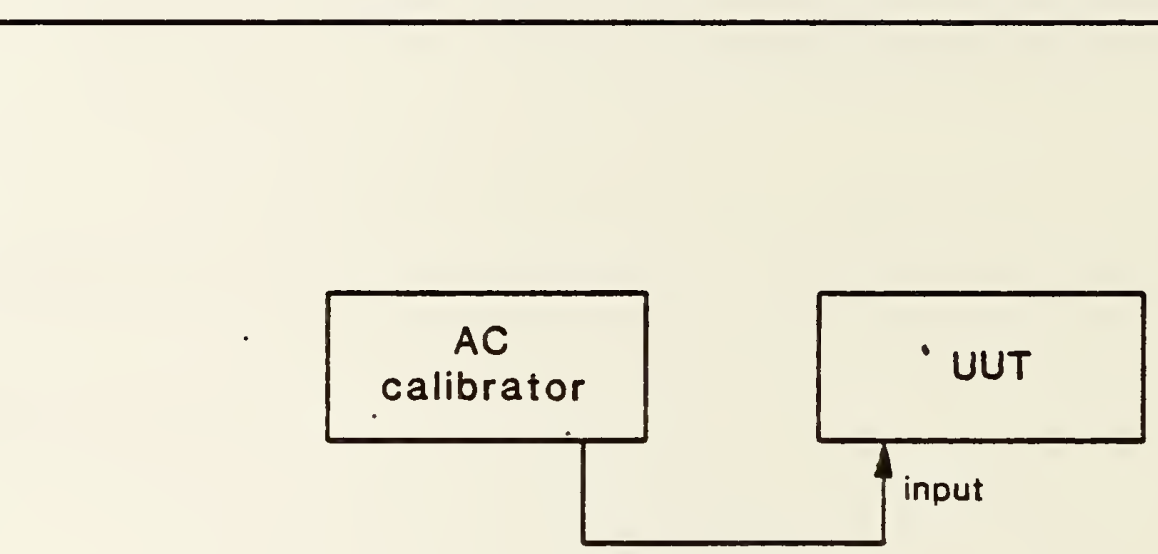

Fig. 10.2.11A Test setup for measuring the bandwidth (upper cutoff frequency) of the UUT for input levels up to 100 volts rms.

2. Set the controls of the unit under test as follows:

Filters (all)

Function

Ratio

Range
OFF

AC VOLTS

$\mathrm{dB}$

AUTORANGE 
3. Set the controls of the $A C$ calibrator as follows:

$\begin{array}{ll}\text { Voltage } & 100 \mathrm{mV} \\ \text { Frequency } & 1 \mathrm{kHz}\end{array}$

4. Set the zero $d B$ reference button.

5. Change the frequency of the $A C$ calibrator to $300 \mathrm{kHz}$.

6. Note and record the display indication on the UUT.

7. Repeat steps 3 thru 6 for $A C$ calibrator levels of $1 \mathrm{~V}$ and $10 \mathrm{~V}$.

8. Reconnect the equipment as shown below. NOTE: Extreme caution must be used when the power amplifier is operational.

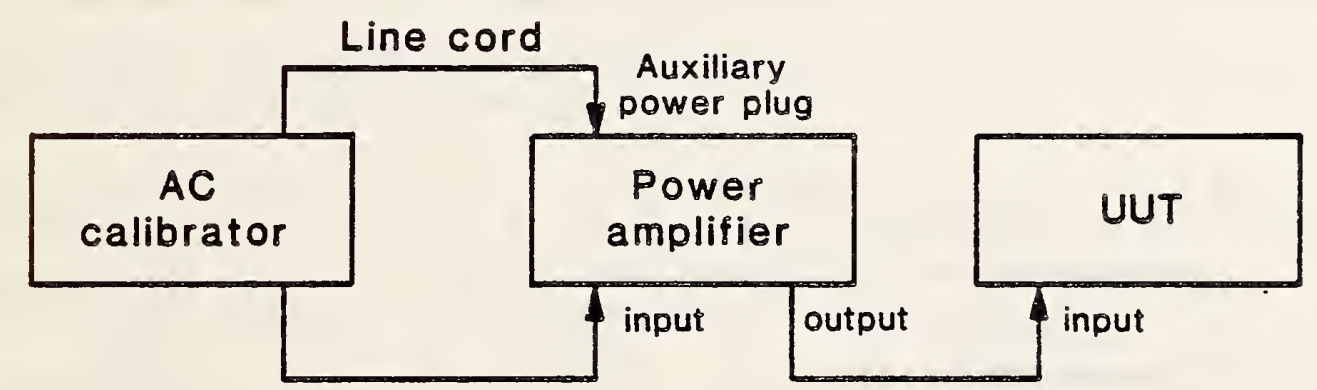

Fig. 10.2.11B Test setup for measuring the bandwidth (upper cutoff frequency) of the UUT for input levels above 100 volts rms.

9. Repeat steps 3 thru 6 for an output level of $130 \mathrm{~V}$ rms from the power amplifier. 


\subsubsection{INPUT IMPEDANCE}

\section{Specification:}

The input impedance in the distortion mode shall be $100 \mathrm{k}: 2$ accurate to within $\pm 2 \%$ shunted by less than 300 picofarads.

Equipment:

ITEMS

Digital LCR meter

Isolation Transformer

Three-wire-female to two-wire-male adapter

Procedure:

1. Connect the equipment as shown below
MODEL

HP4262A or equivalent

Topaz $91002-22$ or equivalent Order by description

l. Connect the equipment as shown below

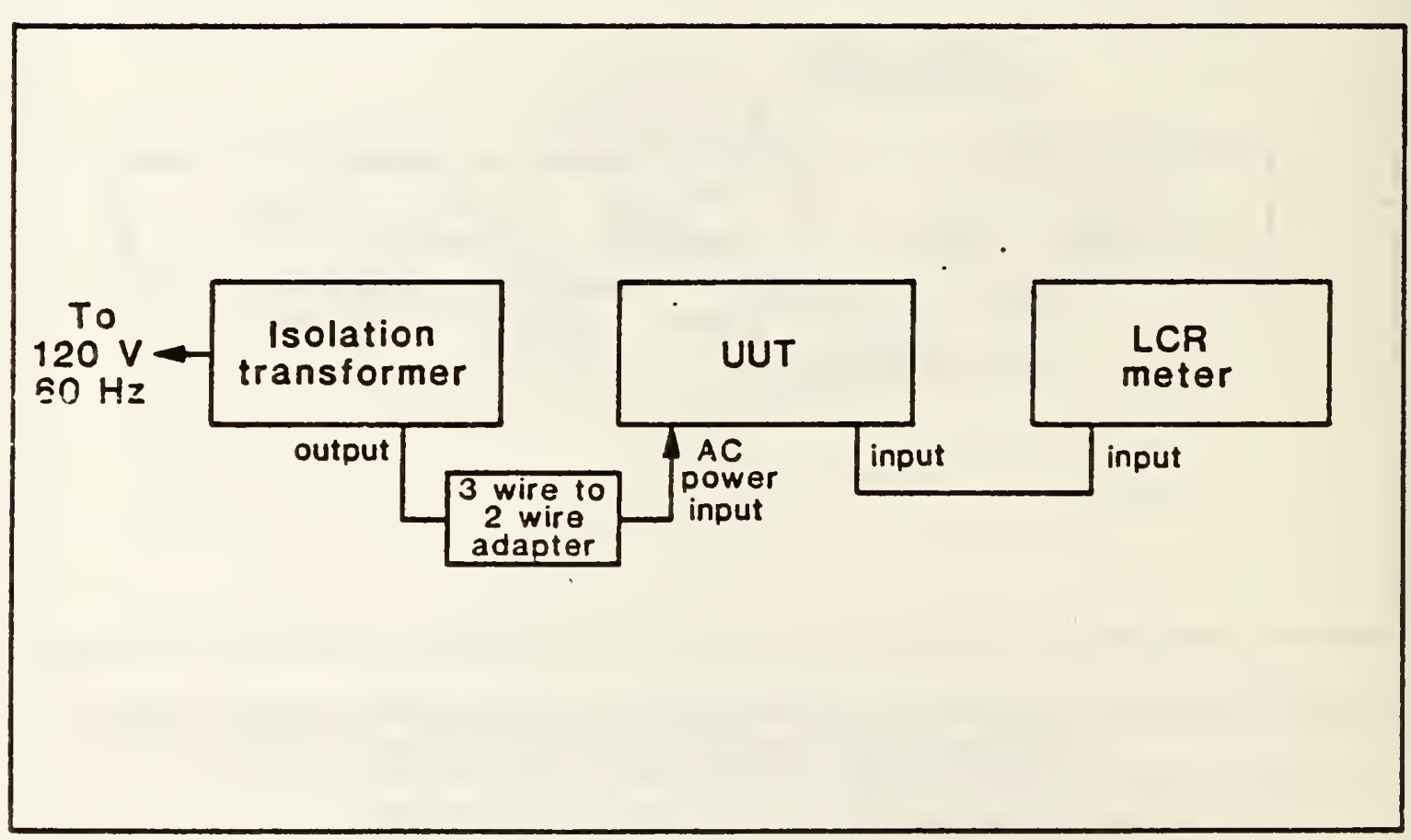

Fig. 10.2.12. Test setup for measuring input impedance.

Note: This procedure requires that the chassis of the UUT be ungrounded with respect to earth ground. Assure that adequate safety precautions are observed. 
2. Set the controls on the UUT as follows:

$\begin{array}{ll}\text { Function } & \text { OISTORTION MEASUREMENT } \\ \text { Range } & \text { AUTORANGE }\end{array}$

3. Set the controls on the LCR meter as follows:

$\begin{array}{ll}\text { OC Bias } & \text { OFF } \\ \text { Circuit Mode } & \text { PRL } \\ \text { Function } & \text { C } \\ \text { Test Signal } & 1 \mathrm{kHz} \\ \text { LCR Range } & \text { AUTO } \\ \text { OQ Range } & \text { AUTO } \\ \text { Trigger } & \text { INT }\end{array}$

4. Disconnect the BNC cable to the input of the UUT.

5. Read and record on the data sheet the value of the cable capacitance as indicated by the LCR meter.

6. Reconnect the BNC cable to the input of the UUT.

7. Read and record on the data sheet the value of the sum of the cable and input capacitance indicated in the LCR display.

8. Subtract the value of the capacitance obtained in step 5 from the value of the capacitance obtained in step 7. Record this difference on tine data sheet.

9. Press"the R/ESR button on the LCR meter.

10. Read and record on the data sheet the value of the input resistance indicated on the LCR display. 
10.2.13 FUNDAMENTAL FREQUENCY LOCKING

Specification:

There shall be an indication on the front panel as to when the distortion analyzer is locked on the fundamental component of the input signal.

\section{Procedure:}

Assure that the UUT is provided with a front panel indication as to when the UUT is locked on the fundamental. If the UUT does not have a dedicated indicator of frequency locking but uses some other indirect front panel indication such as a display of frequency this can be observed and noted in the OISTORTION MEASUREMENT ACCURACY $(10.3 .4)$ test procedure. Note and record whether this condition exists. 


\subsubsection{FUNDAMENTAL FREQUENCY RANGE}

\section{Specification:}

The equipment shall cover the fundamental frequency range from $20.0 \mathrm{~Hz}$ to $100.0 \mathrm{kHz}$.

\section{Equipment:}

Manufacturer's manual for UUT.

\section{Procedure:}

Read the manual for the UUT and note whether the specifications indicate a fundamental frequency range from $20.0 \mathrm{~Hz}$ to $100 \mathrm{kHz}$. Note and record on the data sheet whether the above range is indicated. Note: The distortion and SINAD test procedures exercise the UUT over the $20.0 \mathrm{~Hz}$ to $100 \mathrm{kHz}$ range. 


\subsubsection{INPUT LEVEL RANGE}

\section{Specifications:}

The minimum input level range for distortion and SINAD measurements shall be from 100.0 millivolts rms to 130.0 volts rms.

Equipment:

Manufacturer's manual for UUT.

\section{Procedure:}

Read the manual for the UUT and note whether the specifications indicate an input level range of 100.0 millivolts rms to 130 volts rms for distortion and SINAD measurements. Note and record on the data sheet whether the UUT is specified to operate within the above levels. Note: The distortion and SINAD test prcedures exercise the UUT over the 100.0 millivolt to 130 volt $r$ ange. 


\subsubsection{DISTORTION MEASUREMENT RANGE}

\section{Specification:}

The equipment's distortion measurement range shall cover, within specified accuracy, the range from $0.1 \%(-60 \mathrm{~dB})$ to $50 \%(-6 \mathrm{~dB})$.

\section{Procedure:}

The test procedure for the above (10.3.3) specification is included in part of the test procedure outlined for 10.3 .4 by measuring the accuracy over the range from $-60 \mathrm{~dB}$ to $-6 \mathrm{~dB}$. 


\subsubsection{DISTORTION MEASUREMENT ACCURACY}

\section{Specification:}

The accuracy of the distortion measurement across the full bandwidth and voltage range shall be within the following:

Fundamental Frequency Range

$20 \mathrm{~Hz}-20 \mathrm{kHz}$

$20 \mathrm{kHz}-50 \mathrm{kHz}$

$50 \mathrm{kHz}-100 \mathrm{kHz}$
Accuracy

$\pm 1 \mathrm{~dB}$

$\pm 2 \mathrm{~dB}$

$\pm 3 d B,-4 d B$

10.3.4 Part 1. Distortion Measurement with Two Sine Waves

Equipment:

ITEM

Low-Distortion Oscillator Audio Oscillator

AC Voltmeter

$600 \Omega$ Resistor (2)

Power Amplifier

Spectrum Analyzer
RANGE

$20 \mathrm{~Hz}$ to $100 \mathrm{kHz}$

$40 \mathrm{~Hz}$ to $300 \mathrm{kHz}$

$20 \mathrm{~Hz}$ to $300 \mathrm{kHz}$

MODEL

Tektronix SG5010 or equivalent HP204D or equivalent

Fluke $8506 \mathrm{~A}$ or equivalent see appendix $F$ Fluke $5205 \mathrm{~A}$ or equivalent HP3585A or equivalent

\section{Procedure:}

1. Connect the equipment to the UUT as shown below

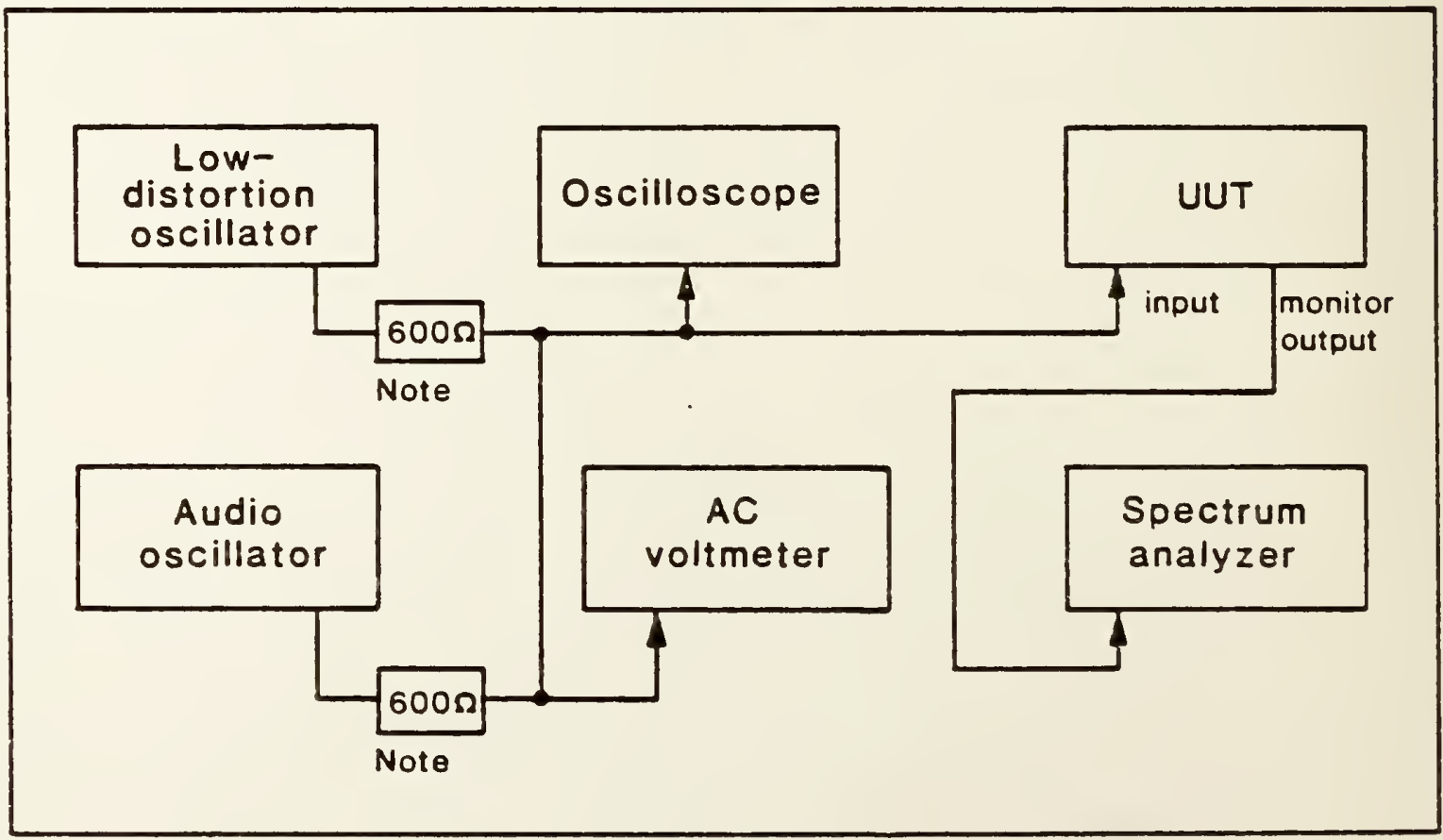

Fig. 10.3.4A Test setup for measuring distortion accuracy with sine wave signals. Note, the $600 \Omega$ series resistors may be omitted if the oscillators have an output impedance of 600 ohms or greater. 
2. Set the controls of the UUT as follows:

$\begin{array}{ll}\text { Range } & \text { AUTORANGE MODE } \\ \text { Function } & \text { DISTORTION } \\ \text { Display mode } & \text { dB (log) } \\ \text { Filters (al1) } & \text { OFF } \\ \text { Detection mode } & \text { RMS }\end{array}$

3. Set the controls of the voltmeter as follows:

$\begin{array}{ll}\text { Function } & \text { AC VOLTS } \\ \text { ilode } & \text { HIGH ACCURACY } \\ \text { Range } & \text { AUTO }\end{array}$

4. Refer to the data sheet table 10.3.4A for setting the frequencies, amplitude, and attenuation levels of the oscillators. Repeat steps 5 through 11 inclusive for each line of data.

5. Set the frequency of the low-distortion oscillator and audio oscillator to the indicated frequencies.

6. Set the output level of the audio oscillator to a minimum.

7. Set the output level of the low-distortion oscillator so that the voltmeter reads the nominal amplitude level given in the table. Note the level setting on the low-distortion osciliator and record the actual reading on the $A C$ volitmeter.

8. Set the low-distortion oscillator to a minimum output level and adjust the audio oscillator to give the same voltmeter reading obtained in step 7 .

9. Change the attenuator setting on the audio oscillator to attenuate to the ac voltmeter level recorded in the table.

10. Reset the low-distortion oscillator to the same level noted in step 7.

11. Read and record the display of the UUT.

The following four steps (12 through 15) are intended to test the RESPONSE TIME (10.2.5).

12. Repeat the measurement of the second line of table 10.3.4A ( i.e. $20 \mathrm{~Hz}$, $0.1 \mathrm{~V}, 40 \mathrm{~Hz}, 60 \mathrm{~dB}$ ) and note the distortion value indicated by the UUT.

13. Remove the signal cable from the input of the UUT.

14. Reconnect the signal cable and time the UUT to display the level noted in step 12.

15. Record the time on data sheet 10.2.5. 
The following 4 steps (16 through 18 ) are intended to test the FUNDAMENTAL REJECTION (10.3.7).

16. Connect the spectrum analyzer to the UUT monitor output and switch the function of the UUT to DISTORTION.

17. Set the controls of the spectrum analyzer as follows:

$\begin{array}{ll}\text { Sweep Start } & 0 \mathrm{~Hz} \\ \text { Sweep Stop } & \text { AS NEEDED } \\ \text { Display } & \text { LOG } 10 \mathrm{~dB} / \text { DIV } \\ \text { Amplitude } & \text { AUTORANGE } \\ \text { Sweep Rate } & \text { TWO STEPS SLOWER THAN AUTOMATIC }\end{array}$

18. Refer to the data sheet table 10.3.7 for setting the frequencies, amplitude, and attenuation levels of the oscillators. Repeat steps 5 through 10 inclusive and record the peak amplitude in $\mathrm{dB}$ of the two frequencies indicated on the spectrum analyzer for each line of data.

19. Set the function of the UUT back to DISTORTION.

20. Reconnect the equipment to the UUT using the power amplifier as shown below. NOTE, extreme caution must be used when the power amplifier is operational.

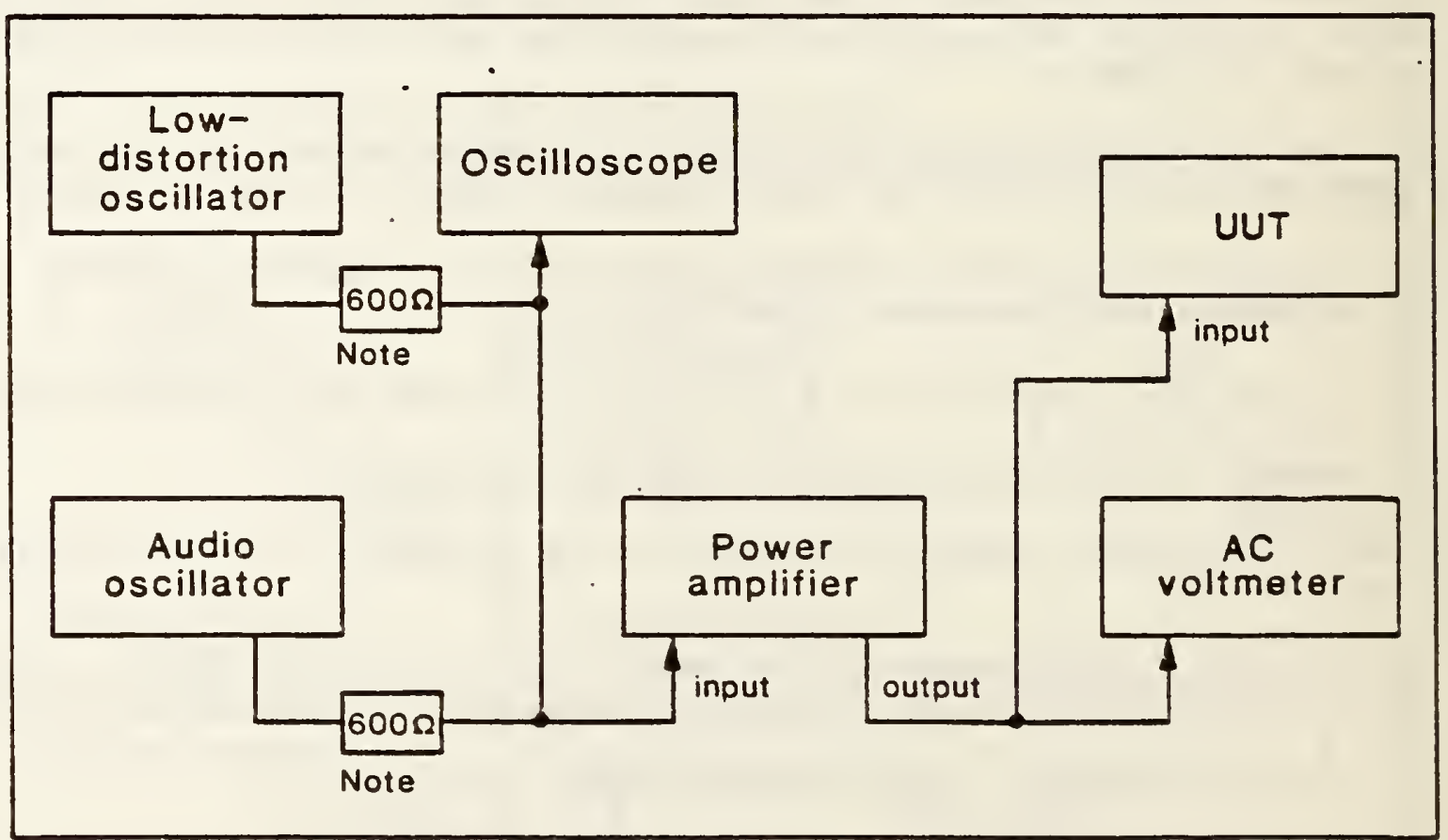

Fig. 10.3.4B. Test setup for measuring distortion accuracy with sine wave sianals above 10 volts. Note, the $600 \Omega$ series resistors may be omitted if the oscillators have an output impedance of 600 ohms or greater.

21. Refer to the data sheet table 10.3.4B for setting frequencies, amplitude, and attenuation levels of the oscillators. Repeat steps 5 through 11 inclusive for each line of data. B-40 
10.3.4 Part 2. Distortion Measurment with a 3:1 Crest Factor Signal Equipment:

\section{ITEM}

Arbitrary Waveform Generator Spectrum Analyzer

488 Controller

3:1 Crest Factor program

Low Pass Filter

100: I Attenuator Probe

Power Amplifier
RANGE

$20 \mathrm{~Hz}$ to $300 \mathrm{kHz}$

$20 \mathrm{~Hz}$ to $300 \mathrm{kHz}$

$20 \mathrm{~Hz}$ to $300 \mathrm{kHz}$

$3 \mathrm{~dB}$ at $200 \mathrm{kHz}$

$10 \mathrm{~V}$ to $130 \mathrm{~V}$
MODEL

Wavetek 275 or equivalent HP3585A or equivalent Hp9836 or equivalent ARB-15, see append ix $D$ see appendix $E$ Tektronix P6007 or equiv Fluke 5205A or equiv.

\section{Procedure:}

1. Connect the equipment to the UUT as shown below:

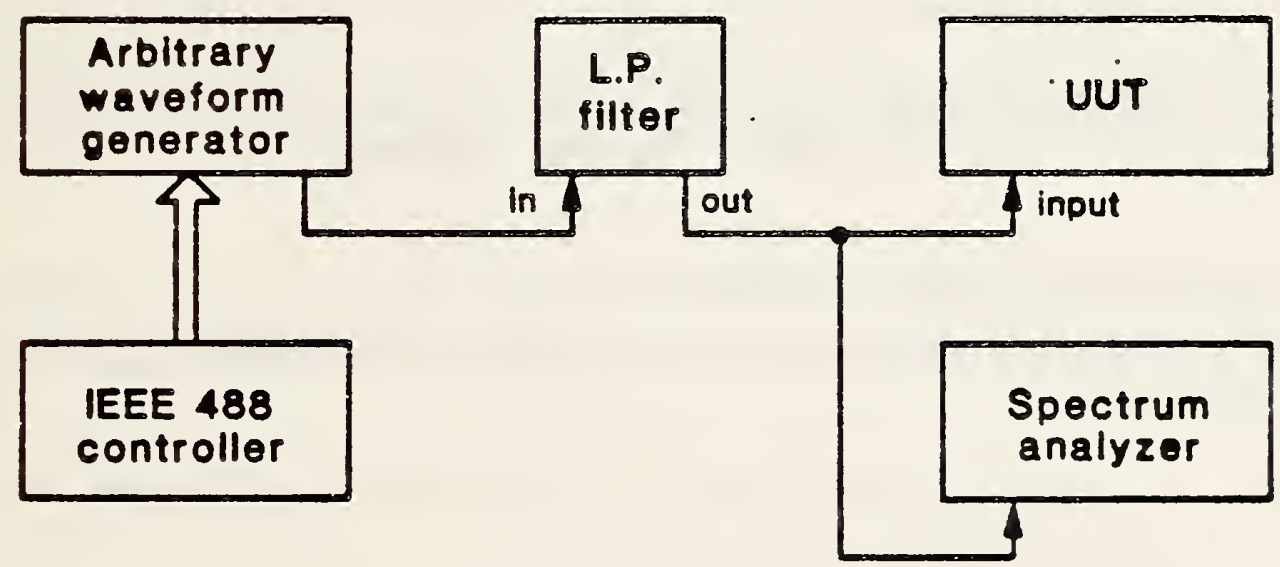

Fig. 10.3.4C. Test setup for measuring distortion accuracy with signals that have a $3: 1$ crest factor. 
2. Set the controls of the UUT as follows:

$\begin{array}{ll}\text { Range } & \text { AUTORANGE } \\ \text { Function } & \text { DISTORTION } \\ \text { Display Mode } & \text { dB (log) } \\ \text { Filters (ali) } & \text { OFF } \\ \text { Detection Mode } & \text { RMS }\end{array}$

3. Set the controls of the spectrum analyzer as follows:

$\begin{array}{ll}\text { Sweep Start } & 0 \mathrm{~Hz} \\ \text { Sweep Stop } & \text { AS NEEDED } \\ \text { Display } & 5 \text { dB/DIV } \\ \text { Amplitide } & \text { AUTORANGE } \\ \text { Level Indication } & \text { VOLTS } \\ \text { Sweep Rate } & \text { TWO STEPS LONGER THAN AUTOMATIC } \\ \text { Input Connection } & 1 \mathrm{M} \text { ohm INPUT }\end{array}$

4. Load the program, ARB-15 into the 488 controller and run the program.

5. Refer to the data sheet table 10.3.4C for setting the frequencies and amplitudes of the generator. Repeat steps 6 through 11 inclusive for each frequency and amplitude indicated.

6. Set the frequency of the arbitrary waveform generator to the indicated frequency.

7. Using the spectrum analyzer readings adjust the amplitude of the arbitrary waveform generator to give the nominal desired fundamental amplitude within 10 percent.

8. Read and record the actual fundamental amplitude.

9. Read and record all the harmonics with amplitudes greater than $2 \%$ of the fundamental amplitude.

10. Calculate the root sum square (rss) of the harmonic amplitudes recorded in step 9.

11. Record the distortion indicated on the UUT. 
12. Reconnect the equipment to the UUT as shown below. Note: Use extreme caution when the power amplifier is operational.

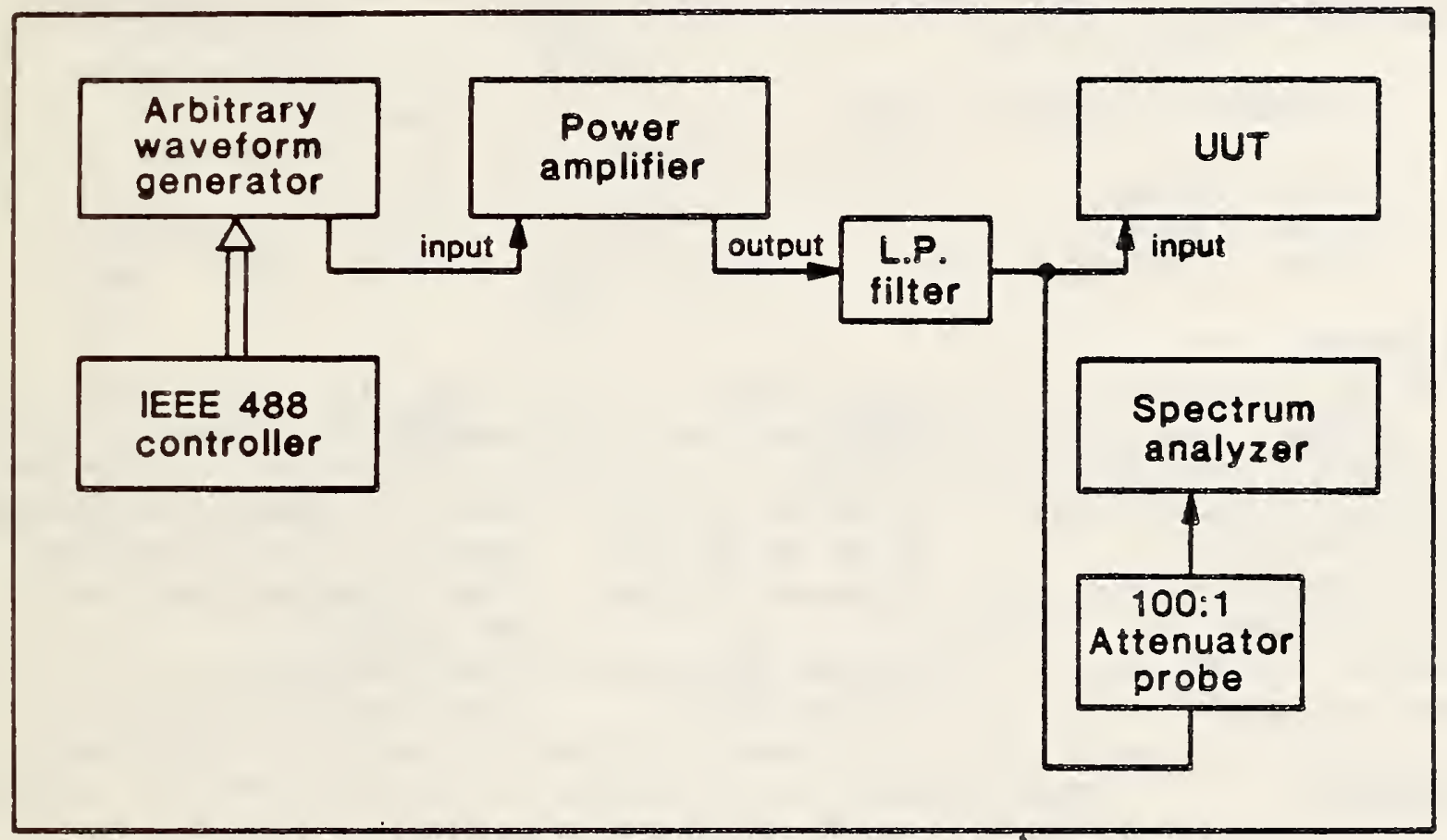

Fig. 10.3.4D. Test setup for measuring distortion accuracy of signals with a 3:1 crest factor and peak amplitudes above 10 volts.

13. Refer to the data sheet table 10.3.40 for setting the frequency and amplitude of the generator. Repeat steps 6 through 11 inclusive for each line of data. 


\subsubsection{SINAD MEASUREMENT ACCURACY}

Specification:

The accuracy of the SINAD measurement shall be within the same accuracy as specified in para. 10.3.4.

Fundamental Frequency Range

$20 \mathrm{~Hz}-20 \mathrm{kHz}$

$30 \mathrm{kHz}-50 \mathrm{kHz}$

$50 \mathrm{kHz}-100 \mathrm{kHz}$
Accuracy

$\pm 1 \mathrm{~dB}$

$\pm 2 d B$

$\pm 3 d B,-4 d B$

Equipment:

ITEMS

Low-Distortion Oscillator No ise Generator

AC Voltmeter

$600 \Omega$ Resistor (2)

Low Pass Filter

Power Amplifier
RANGE

$20 \mathrm{~Hz}$ to $100 \mathrm{kHz}$

$20 \mathrm{~Hz}$ to $300 \mathrm{kHz}$

$20 \mathrm{~Hz}$ to $300 \mathrm{kHz}$

$3 \mathrm{~dB}$ at $200 \mathrm{kHz}$

$10 \mathrm{~V}$ to $130 \mathrm{~V}$
MODEL

Tektronix SG5010 or equivalent Wavetek 132 or equivalent Fluke $8506 \mathrm{~A}$ or equivalent see appendix $F$ see appendix $E$ Fluke $5205 \mathrm{~A}$ or equivalent

\section{Procedure:}

1. Connect the equipment to the UUT as shown below

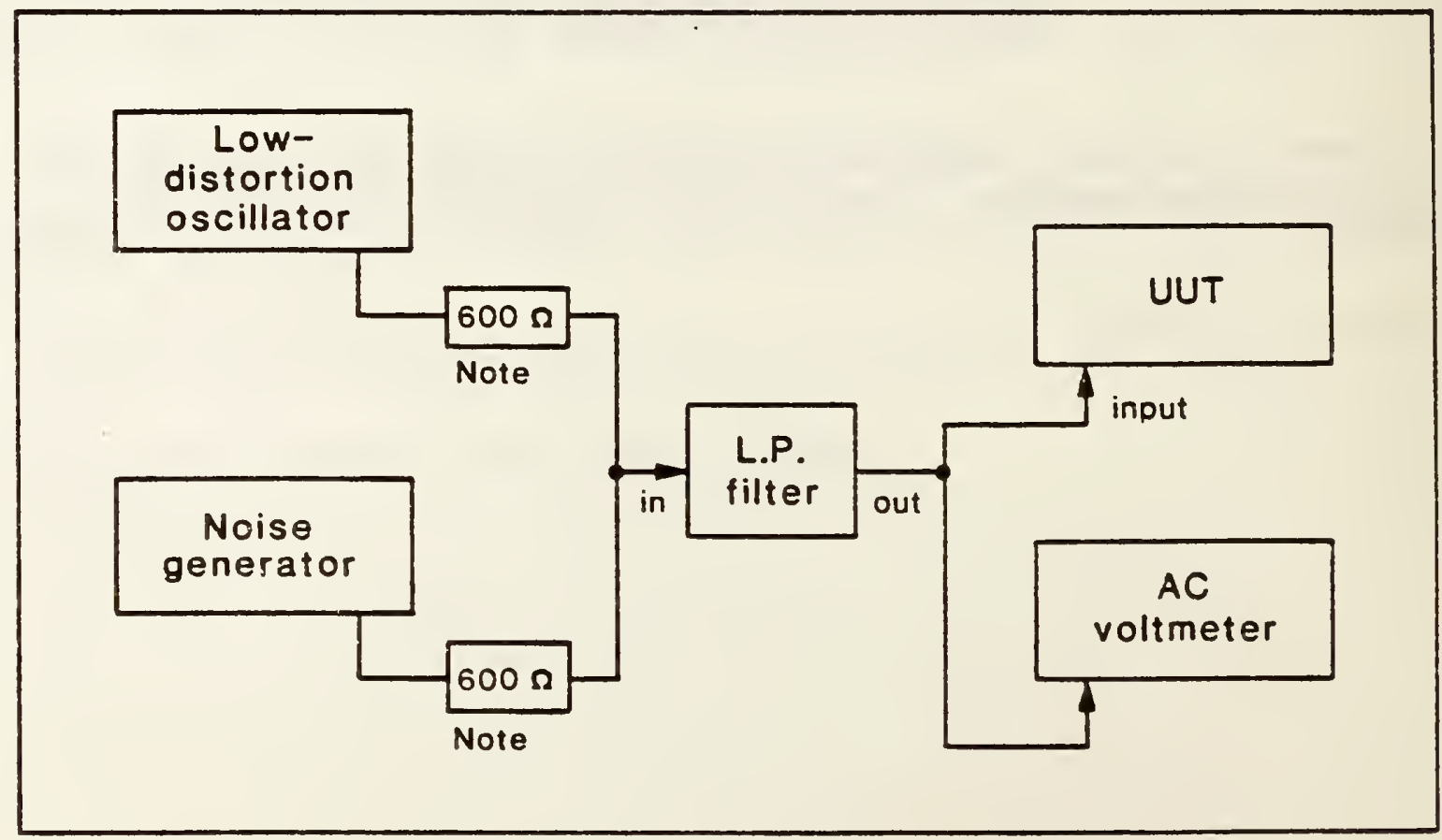

Fig. 10.3.6A. Test setup for measuring SINAD accuracy. Note, the $600 \Omega$ series resistors may be omitted if the oscillators have an output impedance of 600 ohms or greater. 
2. Set the controls of the UUT as follows:

$\begin{array}{ll}\text { Range } & \text { AUTORANGE MODE } \\ \text { Function } & \text { SINAD } \\ \text { Display mode } & \text { dB (log) } \\ \text { Filters (all) } & \text { OFF } \\ \text { Detection mode } & \text { AVERAGE }\end{array}$

3. Set the controls of the voltmeter as follows:

$\begin{array}{ll}\text { Function } & \text { AC VOLTS } \\ \text { Mode } & \text { HIGH ACCURACY } \\ \text { Range } & \text { AUTO }\end{array}$

4. Refer to the data sheet table 10.3.6A for setting the amplitude of the noise generator, the frequency of the low-distortion oscillator, and the combined amplitude of both generators. Repeat steps 5 through 9 inclusive for each line of data.

5. Set the frequency of the low-distortion oscillator as indicated.

6. Set the output of the low-distortion oscillator to a minimum.

7. Set the output level of the noise generator to the level indicated in the table. Use the voltmeter to establish the required level.

8. Increase the output amplitude of the low-distortion oscillator to obtain the combined amplitude indicated in the table. Again use the voltmeter to establish the required level.

9. Read and record the SINAD indication on the UUT. 
10. Reconnect the UUT as shown below. NOTE: Extreme caution must be used when the power amplifier is operational.

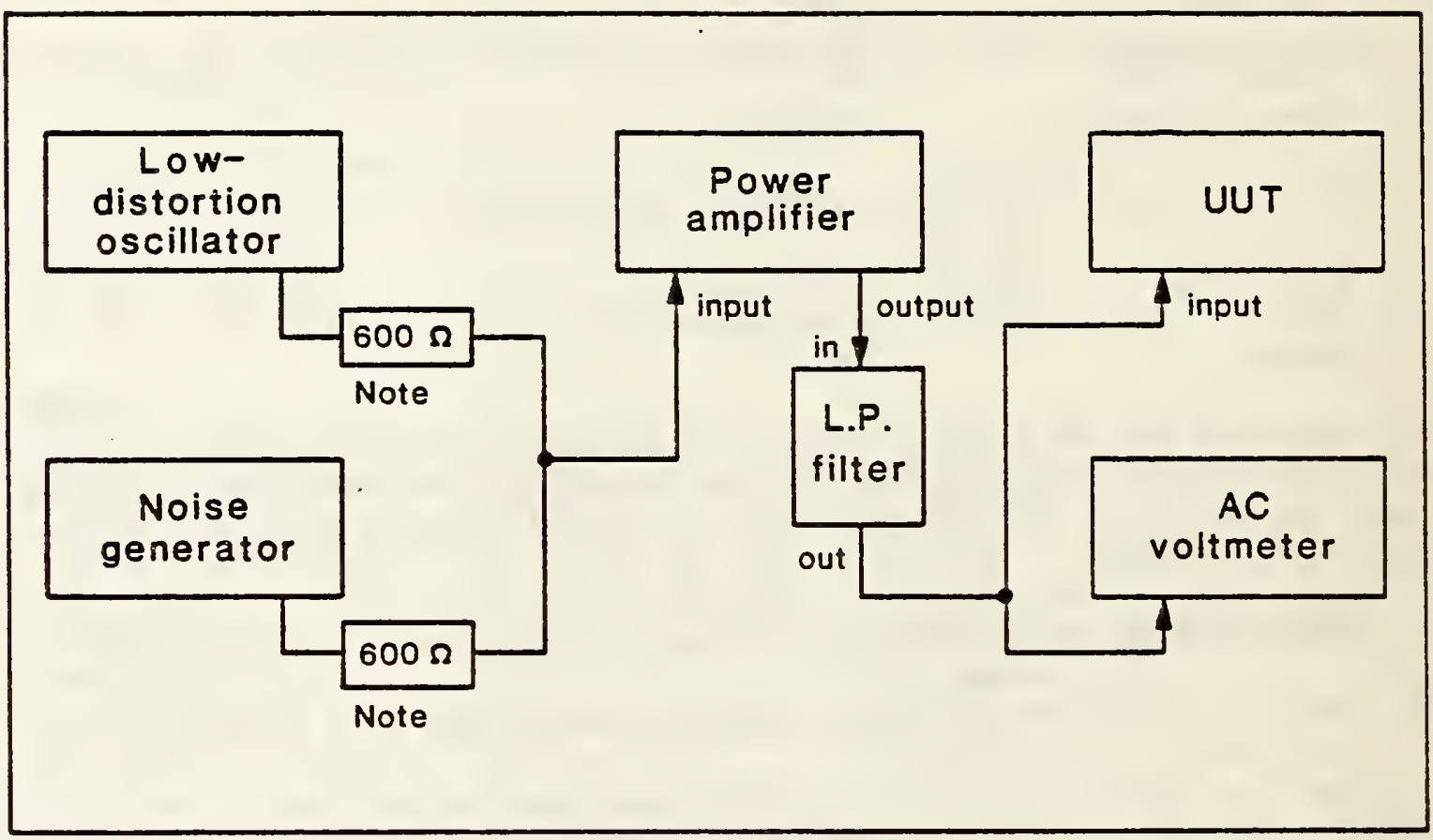

Fig. 10.3.6B. Test setup for measuring SINAD accuracy with signals above 10 volts. Note, the 600 series resistors may be omitted if the oscillators have an output impedance of 600 ohms or greater.

11. Refer to the data sheet table 10.3.6B for setting the amplitude of the noise generator, the frequency of the low-distortion oscillator, and the combined amplitude of both generators. Repeat steps 5 through 9 inclusive for each line of data. 


\subsubsection{FUNDAMENTAL REJECTION}

Specification:

The distortion analyzer shall reject the fundamental component of the input signal by at least $10 \mathrm{~dB}$ below the total harmonic distortion and noise level.

Procedure:

The test procedure for this specification is contained in the test procedure for DISTORTION MEASUREMENT ACCURACY $(10.3 .4)$ steps 16 through 18. 


\subsubsection{MEASUREMENT MODE}

Specification:

The equipment shall display distortion in $\mathrm{dB}$ and percent and SINAD in $\mathrm{dB}$. Measurement mode shall be selectable by front panel control.

\section{Procedure:}

1. Assure that the UUT displays distortion in $d B$ and percent and that the measurement mode is selectable by a front panel control. Note on the data sheet if this condition is met. 


\section{Specification:}

Without using any filters, for both rms and average response, the total distortion + noise introduced by the equipment across the entire voltage range shall be less than $-65 \mathrm{~dB}(.056 \%)$ across the entire bandwidth of the equipment.

\section{Equipment:}

\section{ITEM}

Low-Distortion Oscillator AC Voltmeter

Low Pass Filter
RANGE

$20 \mathrm{~Hz}$ to $100 \mathrm{kHz}$ $100 \mathrm{mV}$ to $130 \mathrm{~V}$ $3 \mathrm{~dB}$ at $200 \mathrm{kHz}$

\section{MODEL}

Tektronix SG5010 or equivalent Fluke $8506 \mathrm{~A}$ or equivalent see appendix $E$

\section{Procedure:}

1. Connect the equipment as shown below

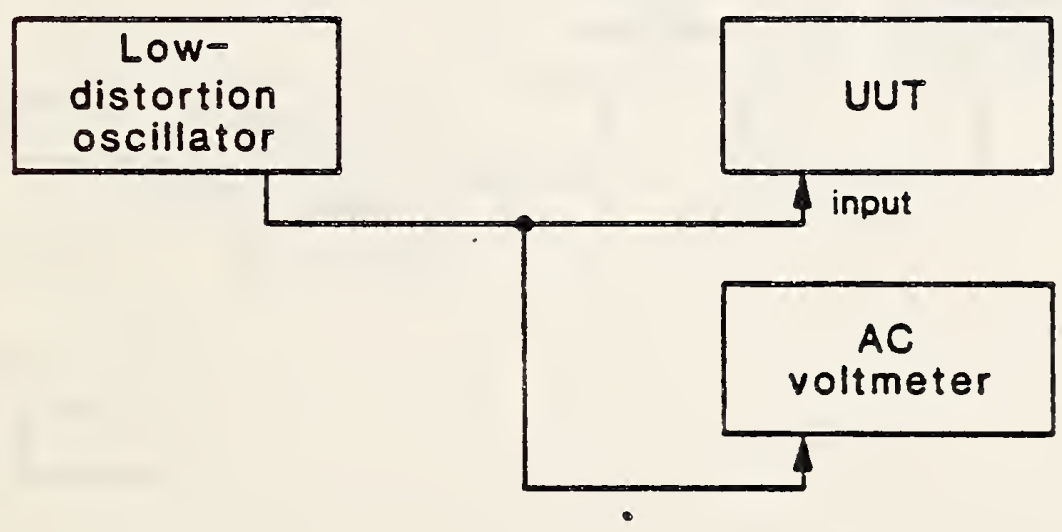

Fig. 10.3.9A. Test setup for measuring residual distortion and noise. 
2. Set the UUT controls as follows:

ON/OFF Switch

Function

Display Mode

Filters (all)

Range Mode
ON

DISTORTION

$\mathrm{dB}(\log )$

OFF

AUTORANGE

3. Refer to the data sheet table 10.3.9A for setting the frequency and amplitude of the low-distortion oscillator. Repeat steps 4 and 5 inclusive for each line of data.

4. Set the frequency and amplitude of the low-distortion oscillator to the indicated values.

5. Read and record the value displayed on the UUT.

6. Reconnect the equipment as shown below. NOTE: Use extreme caution when the power amplifier is operational.

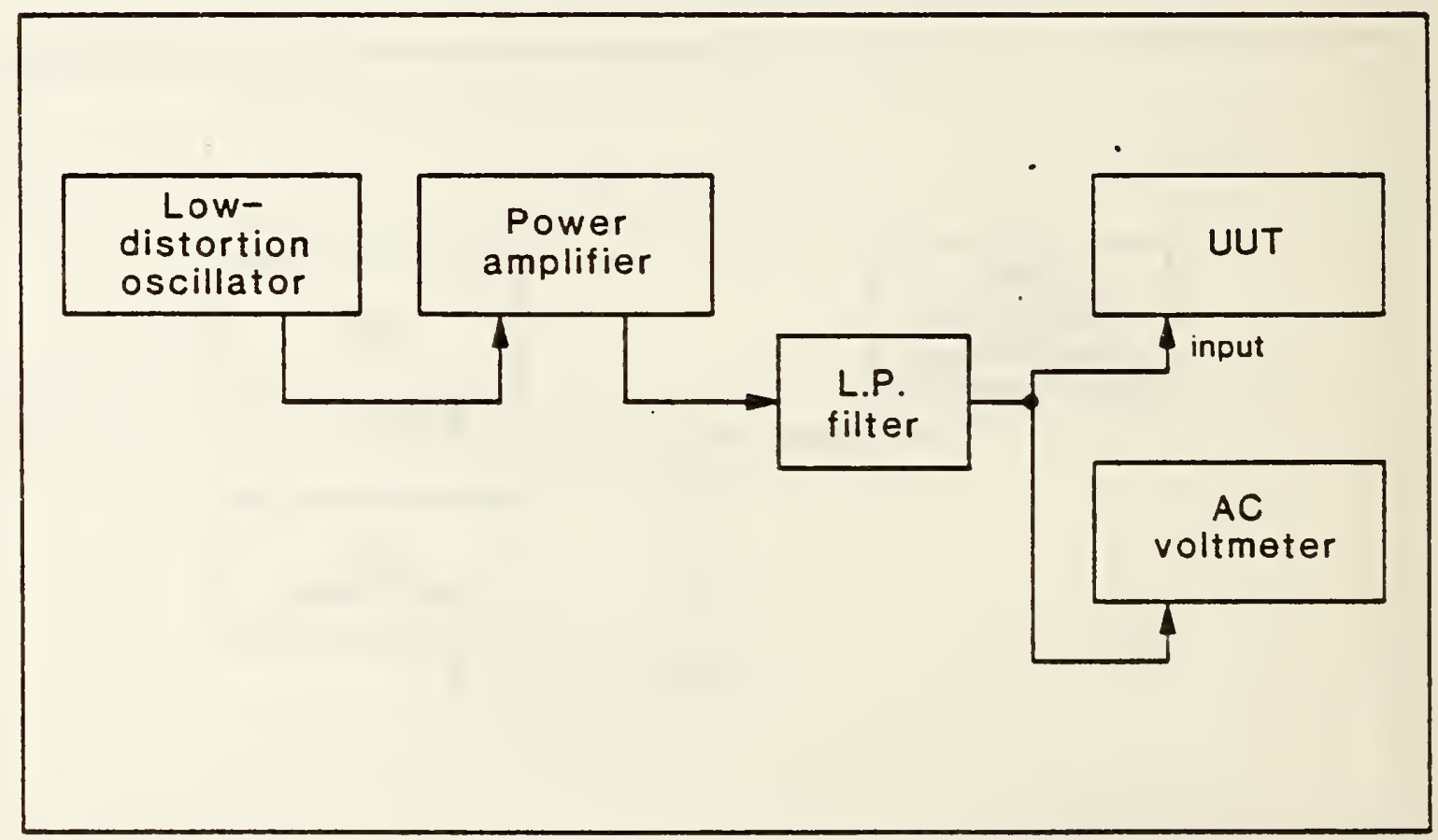

Fig. 10.3.9B. Test setup for measuring residual distortion and noise at input levels above 10 volts.

7. Refer to the data sheet table 10.3.9B for setting the amplitude and frequency to the UUT.

8. Repeat steps 4 and 5 inclusive for each line of data. 


\section{Specification:}

There shall be on the panel an indication to indicate when the input signal is not within the accuracies as specified in para 10.3.4.

\section{Procedure:}

Assure that there is a digital indication on the front panel to indicate when the input signal is not within the range to maintain the accuracies specified in para 10.3.4. Note on the data sheet if this condition is met. 
10.4.1 VOLTAGE RANGE

Specification:

The minimum range of the $A C$ voltmeter shall be from 100 militivolts true rms to 130 volts true rms.

\section{Equipment:}

Manufacturer's manual for UUT.

\section{Procedure:}

Read the manuals for the UUT and note whether the AC yoltmeter range covers the limits specified and whether the measurement method is based on true rms type detection. 
10.4.2 VOLTMETER ACCURACY

\section{Specification:}

The $A C$ voltmeter shall be accurate over the entire range as specified in para. 10.4 .1 , to within $\pm 2 \%$ of the reading in the fundamental frequency $r$ ange of $20 \mathrm{~Hz}$ to $20 \mathrm{kHz}$, and $\pm 4 \%$ in the fundamentai frequency range from $20 \mathrm{kHz}$ to 100 $\mathrm{kHz}$.

\section{Equipment:}

ITEMS

RANGE

MODEL

AC Calibrator $\quad 1 \mathrm{mV}$ to $100 \mathrm{VAC}$ (rms) Fluke $5200 \mathrm{~A}$ or equivalent

Procedure:

1. Connect the equipment as shown below

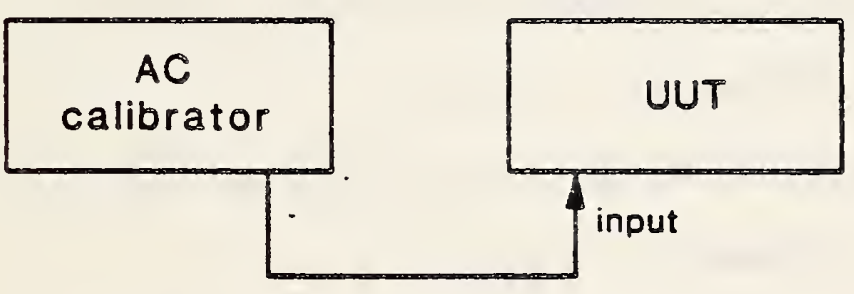

Fig. 10.4.2. Test setup for measuring voltmeter accuracy.

Warning: High voltages are employed in this test procedure. Assure that all equipment is properly grounded and that ail applicable safety procedures are followed. 
2. Set the controls on the UUT as follows:

$\begin{array}{ll}\text { Function } & \text { AC VOLTMETER MODE } \\ \text { Filters (a11) } & \text { OFF } \\ \text { Range } & \text { AUTO }\end{array}$

3. Set the frequency of the meter calibrator to $20 \mathrm{~Hz}$.

4. Set the voltage output of the meter calibrator to $0.100 \mathrm{~V} A C$ (rms).

5. Read and record on the data sheet the voltage measured by the UUT.

6. Set the voltage output of the meter calibrator to $1.000 \mathrm{VAC}$ (rms).

7. Read and record on the data sheet the voltage measured by the UUT.

8. Set the voltage output of the meter calibrator to $10.00 \mathrm{VAC}$ (rms).

9. Read and record on the data sheet the voltage measured by the UUT.

10. Set the voltage output of the meter calibrator to $100.0 \mathrm{~V} A C$ (rms).

11. Read and record on the data sheet the voltage measured by the UUT.

12. Set the frequency of the meter calibrator to $60 \mathrm{~Hz}$.

13. Repeat steps 4 through 11, inclusive.

14. Set the frequency of the meter calibrator to $400 \mathrm{~Hz}$.

15. Repeat steps 4 through 11 , inclusive.

16. Set the frequency of the meter calibrator to $1000 \mathrm{~Hz}$.

17. Repeat steps 4 through 11 , inclusive.

18. Set the frequency of the meter calibrator to $5 \mathrm{kHz}$.

19. Repeat steps 4 through 11, inclusive.

20. Set the frequency of the meter calibrator to $10 \mathrm{kHz}$.

21. Repeat steps 4 through 11, inclusive.

22. Set the frequency of the meter calibrator to $20 \mathrm{kHz}$.

23. Repeat steps 4 through 11 , inclusive.

24. Set the frequency of the meter calibrator to $50 \mathrm{kHz}$.

25. Repeat steps 4 through 11, inclusive.

26. Set the frequency of the meter calibrator to $100 \mathrm{kHz}$. 
27. Repeat steps 4 through 11 inclusive.

28. Repeat the measurement in step 4 and note the level on the UUT display.

29. Change the calibrator to 100 volts.

30. Change the calibrator back to 0.1 volts and measure the time for the display to settle to the value noted in step 28.

31. Record the response time on data sheet 10.2.5.

32. Set the voltage output of the calibrator to zero, turn off, and disconnect the equipment. 


\subsubsection{MEASUREMENT MODE}

Specification:

The equipment shall display level in rms volts, millivolts and $\mathrm{dBm}$ (into 600 ohms). Measurement mode shall be selectable by front panel control.

\section{Procedure:}

1. Assure that the UUT displays level in rms volts and $\mathrm{dBm}$ (into 600 ohms) and that the measurement mode is selectable by a front panel control. Note on the data sheet if this condition is met. 
10.4.4 LEVEL OVERRANGE INDICATION

Specification:

There shall be on the front panel an indication to indicate when the input signal is not within the accuracies as specified in para. 10.4.2.

\section{Procedure:}

Assure that there is a digital indication on the front panel to indicate when the input signal is not within the range to maintain the accuracies as specified in para. 10.4.2. Note on the data sheet if this condition is met. 


\section{APPENDIX C \\ SPECIFICATION PERFORMANCE \\ DATA SHEETS AND TABLES \\ FOR USE WITH TEST PROCEDURES \\ IN APPENDIX B}


Specification Performance

Data Sheet

Bid Sample ID No.

\begin{tabular}{|c|c|c|c|c|c|}
\hline $\begin{array}{l}\text { Reference } \\
\text { Paragraph }\end{array}$ & $\begin{array}{l}\text { Specification } \\
\text { Description }\end{array}$ & $\begin{array}{l}\text { Measurement Data, } \\
\text { Observations, Notes, etc. }\end{array}$ & $\frac{\text { Acceptable }}{\text { Min. }}$ & $\frac{\text { Limits }}{\text { Max. }}$ & Units \\
\hline 10.1 & Operation & & & & \\
\hline 10.1 .1 & $\begin{array}{l}\text { Distortion } \\
\text { Measurement }\end{array}$ & . & & & \\
\hline 10.2 .1 & Display & & & & \\
\hline 10.2 .1 .1 & $\begin{array}{l}\text { Display } \\
\text { Resolution }\end{array}$ & & $\begin{array}{l}0.1 \\
100\end{array}$ & -- & $\begin{array}{l}d B, \% \\
\text { counts }\end{array}$ \\
\hline 10.2 .2 & $\begin{array}{l}\text { Input } \\
\text { Connector }\end{array}$ & • & & & \\
\hline 10.2 .3 & $\begin{array}{l}\text { Monitor Output } \\
\text { Connector }\end{array}$ & $\begin{array}{c}\text { Use Tables } \\
10.2 .3 A \\
\text { and } \\
10.2 .3 B\end{array}$ & & & \\
\hline 10.2 .3 .1 & $\begin{array}{l}\text { Output } \\
\text { Impedance } \\
\text { 5) Voltage V1 } \\
\text { 7) Voltage V2 } \\
\text { 9) Cal. Output } \\
\text { Impedance }\end{array}$ & & $\begin{array}{l}-- \\
-- \\
570\end{array}$ & $\begin{array}{l}-- \\
-- \\
630\end{array}$ & $\begin{array}{l}\text { Volts } \\
\text { Volts } \\
\text { Ohms }\end{array}$ \\
\hline
\end{tabular}


Specification Performance

Data Sheet

Bid Sample ID No.

\begin{tabular}{|c|c|c|c|c|c|}
\hline $\begin{array}{l}\text { Reference } \\
\text { Paragraph }\end{array}$ & $\begin{array}{l}\text { Specification } \\
\text { Description }\end{array}$ & $\begin{array}{l}\text { Measurement Data, } \\
\text { Observations, Notes, etc. }\end{array}$ & $\frac{\text { Accept }}{\text { Min. }}$ & $\frac{\text { Limits }}{\operatorname{Max} .}$ & Units \\
\hline 10.2 .4 & Detection & & & & \\
\hline 10.2 .5 & $\begin{array}{l}\text { Response } \\
\text { Time }\end{array}$ & $\begin{array}{l}\text { [Performed in steps } 28- \\
30 \text { of } 10.4 .2 \text { and steps } \\
12-15 \text { of } 10.3 .4 \text { ] }\end{array}$ & 10 & & Seconds \\
\hline 10.2 .6 & Filters & & 3 & & Filters \\
\hline 10.2 .6 .1 & $\begin{array}{l}\text { Low-Pass } \\
\text { Filter } \\
\text { 3) Voltmeter } \\
\text { Reading } \\
\text { 8) -3 dB Freq. } \\
\text { 11) Rolloff }\end{array}$ & - & 28 & $\begin{array}{r}32 \\
-60\end{array}$ & $\begin{array}{c}. \\
\text { Volis } \\
\mathrm{kHz} \\
\mathrm{dB}\end{array}$ \\
\hline 10.2 .6 .2 & $\begin{array}{l}\text { Low-Pass } \\
\text { Filter } \\
\text { 3) Voltmeter } \\
\text { Reading } \\
\text { 8) -3 dB Freq. } \\
\text { 11) Rolloff }\end{array}$ & & 75 & $\begin{array}{r}84 \\
-60\end{array}$ & $\begin{array}{c}\text { Volts } \\
\mathrm{kHz} \\
\mathrm{dB}\end{array}$ \\
\hline
\end{tabular}


Specification Performance

Data Sheet

Bid Sample ID No.

\begin{tabular}{|c|c|c|c|c|c|}
\hline $\begin{array}{l}\text { Reference } \\
\text { Paragraph }\end{array}$ & $\begin{array}{l}\text { Specification } \\
\text { Description }\end{array}$ & $\begin{array}{l}\text { Measurement Data, } \\
\text { Observations, Notes, etc. }\end{array}$ & $\frac{\text { Accept }}{\text { Min. }}$ & $\frac{\text { Limits }}{\operatorname{Max}}$ & Units \\
\hline 10.2 .6 .3 & $\begin{array}{l}\text { High-Pass } \\
\text { Filter } \\
\text { 3) Voltmeter } \\
\text { Reading } \\
\text { 8) -3 dB Freq. } \\
\text { 11) rolloff }\end{array}$ & & $\begin{array}{c}360 \\
--\end{array}$ & $\begin{array}{l}440 \\
-60\end{array}$ & $\begin{array}{c} \\
\text { Volts } \\
\mathrm{Hz} \\
\mathrm{dB}\end{array}$ \\
\hline 10.2 .6 .3 .1 & $\begin{array}{l}\text { Line Freq. } \\
\text { Rejection } \\
\text { 3) Voltmeter } \\
\text { Reading } \\
\text { 7) Rolloff }\end{array}$ & - & -- & -40 & $\begin{array}{c}\text { Volts } \\
\text { dB }\end{array}$ \\
\hline 10.2 .7 & $\begin{array}{l}\text { Mode } \\
\text { Selection }\end{array}$ & & & & \\
\hline 10.2 .8 & $\begin{array}{l}\text { Common-Mode } \\
\text { Rejection } \\
\text { Ratio } \\
\text { 6) Voltage V6 } \\
\text { 7) Voltage V7 } \\
\text { 8) Voltage V8 } \\
\text { 9) Voltage V9 } \\
\text { 10) Calc. CMRR } \\
\text { @ } 50 \mathrm{~Hz} \\
\text { 10) Calc. CMRR } \\
\text { a } 800 \mathrm{~Hz}\end{array}$ & & $\begin{array}{l}-- \\
-- \\
-- \\
-- \\
40 \\
40\end{array}$ & $\begin{array}{l}-- \\
-- \\
-- \\
-- \\
--\end{array}$ & $\begin{array}{c}\text { Volts } \\
\text { Volts } \\
\text { Volts } \\
\text { Volts } \\
\mathrm{dB} \\
\mathrm{dB}\end{array}$ \\
\hline
\end{tabular}


Specification Performance

Data Sheet

Bid Sample ID No.

\begin{tabular}{|c|c|c|c|c|c|}
\hline $\begin{array}{l}\text { Reference } \\
\text { Paragraph }\end{array}$ & $\begin{array}{l}\text { Specification } \\
\text { Description }\end{array}$ & $\begin{array}{l}\text { Measurement Data, } \\
\text { Observations, Notes, etc. }\end{array}$ & $\frac{\text { Accept }}{\text { Min. }}$ & $\frac{\text { Limits }}{\text { Máx. }}$ & Units \\
\hline 10.2 .9 & $\begin{array}{l}\text { Overload } \\
\text { Protection }\end{array}$ & & 175 & & $V \mathrm{~ms}$ \\
\hline 10.2 .10 & $\begin{array}{l}\text { Relative } \\
\mathrm{dB} \text { Reference }\end{array}$ & & & & \\
\hline 10.2 .11 & $\begin{array}{l}\text { Bandwidth } \\
\text { 6) } 100 \mathrm{mV} \\
\text { 7) } 1 \mathrm{v} \\
\text { 7) } 10 \mathrm{v} \\
\text { 9) } 100 \mathrm{v}\end{array}$ & • & & $\begin{array}{l}-3 \\
-3 \\
-3 \\
-3\end{array}$ & $\begin{array}{l}d B \\
d B \\
d B \\
d B\end{array}$ \\
\hline 10.2 .12 & $\begin{array}{l}\text { Input } \\
\text { Impedance } \\
\text { 5) Cable Cap } \\
\text { 7) Cable t } \\
\text { Input Cap } \\
\text { 8) Input Cap } \\
\text { 10) Resistance }\end{array}$ & & $\begin{array}{l}-- \\
-- \\
-- \\
98 k\end{array}$ & $\begin{array}{l}-- \\
-- \\
-- \\
102 k\end{array}$ & $\begin{array}{l}\text { pF } \\
\text { pF } \\
\text { pF } \\
\text { Ohms }\end{array}$ \\
\hline 10.2 .13 & $\begin{array}{l}\text { Fund amental } \\
\text { Frequency } \\
\text { Locking }\end{array}$ & & & & \\
\hline 10.3 .1 & $\begin{array}{l}\text { Fund amental } \\
\text { Frequency } \\
\text { Range }\end{array}$ & & 20 & $100 \mathrm{k}$ & Hertzz \\
\hline
\end{tabular}


Specification Performance

Data Sheet

Bid Sample ID No.

\begin{tabular}{|c|c|c|c|c|c|}
\hline $\begin{array}{l}\text { Reference } \\
\text { Paragraph }\end{array}$ & $\begin{array}{l}\text { Specification } \\
\text { Description }\end{array}$ & $\begin{array}{l}\text { Measurement Data, } \\
\text { Observations, Notes, etc. }\end{array}$ & $\frac{\text { Accept ab }}{\text { Min. }}$ & $\frac{\text { le Limits }}{\text { Max. }}$ & Units \\
\hline 10.3 .2 & $\begin{array}{l}\text { Input Level } \\
\text { Range }\end{array}$ & & 0.1 & 130 & volts \\
\hline 10.3 .3 & $\begin{array}{l}\text { Distortion } \\
\text { Measurement } \\
\text { Range }\end{array}$ & & $\begin{array}{l}0.1 \\
-60\end{array}$ & $\begin{array}{l}50 \\
-6\end{array}$ & $\begin{array}{l}\% \\
d B\end{array}$ \\
\hline 10.3 .4 & $\begin{array}{l}\text { Distortion } \\
\text { Measurement } \\
\text { Accuracy }\end{array}$ & $\begin{array}{l}\text { Use Tables } \\
10.3 .4 A, 10.3 .4 B \\
10.3 .4 C, 10.3 .4 D\end{array}$ & & & \\
\hline 10.3 .6 & $\begin{array}{l}\text { SINAD } \\
\text { Measurement } \\
\text { Accuracy }\end{array}$ & $\begin{array}{l}\text { Use Tables } \\
\text { 10.3.6A, 10.3.6B }\end{array}$ & & & \\
\hline 10.3 .7 & $\begin{array}{l}\text { Fundamental } \\
\text { Rejection }\end{array}$ & $\begin{array}{l}\text { Use Table } \\
10.3 .7\end{array}$ & & & \\
\hline 10.3 .8 & $\begin{array}{l}\text { Measurement } \\
\text { Mode }\end{array}$ & & & & \\
\hline 10.3 .9 & $\begin{array}{l}\text { Residual } \\
\text { Distortion \& } \\
\text { Noise }\end{array}$ & $\begin{array}{l}\text { Use Tables } \\
10.3 .9 \mathrm{~A} \text {, and } \\
10.3 .9 \mathrm{~B}\end{array}$ & & & \\
\hline 10.3 .10 & $\begin{array}{l}\text { Level } \\
\text { Under/Over } \\
\text { Range Indic. }\end{array}$ & & & & \\
\hline 10.4 .1 & $\begin{array}{l}\text { Voltage } \\
\text { Range }\end{array}$ & & & & \\
\hline
\end{tabular}


Specification Performance

Data Sneet

Bid Sample ID No.

\begin{tabular}{|c|c|c|c|c|c|}
\hline $\begin{array}{l}\text { Reference } \\
\text { Paragraph }\end{array}$ & $\begin{array}{l}\text { Specification } \\
\text { Description }\end{array}$ & $\begin{array}{l}\text { Measurement Data, } \\
\text { Observations, Notes, etc. }\end{array}$ & $\frac{\text { Accept }}{\text { Min. }}$ & $\frac{\text { le Limits }}{\text { Max. }}$ & Units \\
\hline 10.4 .2 & 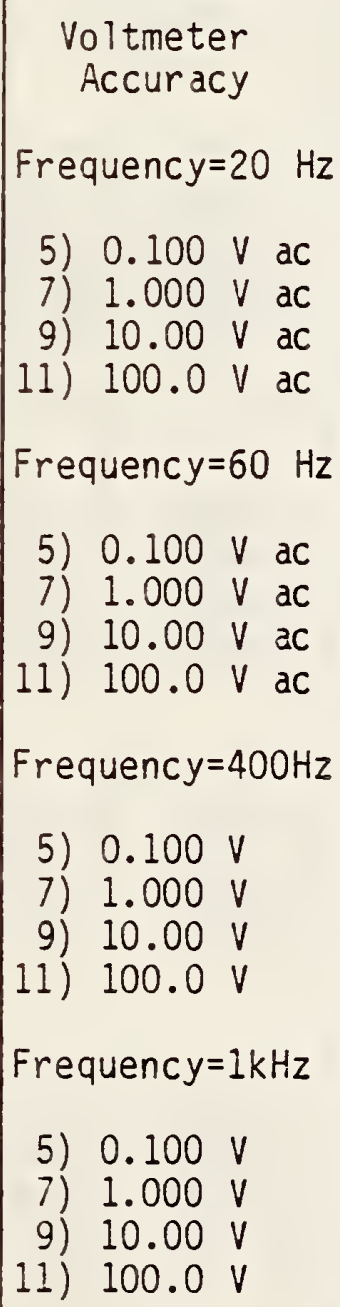 & & $\begin{array}{l}0.09800 \\
0.98000 \\
9.80000 \\
98.0000 \\
\\
0.09800 \\
0.98000 \\
9.80000 \\
98.0000 \\
\\
\\
0.09800 \\
0.98000 \\
9.80000 \\
98.0000 \\
\\
0.09800 \\
0.98000 \\
9.3000 \\
98.0000\end{array}$ & $\begin{array}{l}0.10200 \\
1.02000 \\
10.2000 \\
102.000 \\
\\
0.10200 \\
1.02000 \\
10.2000 \\
102.000 \\
\\
0.10200 \\
1.02000 \\
10.2000 \\
102.000\end{array}$ & $\begin{array}{l}\text { Volts } \\
\text { volts } \\
\text { volts } \\
\text { Volts } \\
\text { Volts } \\
\text { volts } \\
\text { volts } \\
\text { volts } \\
\\
\text { volts } \\
\text { volts } \\
\text { volts } \\
\text { volts }\end{array}$ \\
\hline
\end{tabular}


Specification Performance

Data Sheet

Bid Sample ID No.

\begin{tabular}{|c|c|c|c|c|c|}
\hline $\begin{array}{l}\text { Reference } \\
\text { Paragraph }\end{array}$ & $\begin{array}{l}\text { Specification } \\
\text { Description }\end{array}$ & $\begin{array}{l}\text { Measurement Data, } \\
\text { Observations, Notes, etc. }\end{array}$ & $\frac{\text { Accepta }}{\text { Min. }}$ & $\frac{\text { le Limits }}{\text { Max. }}$ & Units \\
\hline $\begin{array}{c}10.4 .2 \\
\text { Cont. }\end{array}$ & 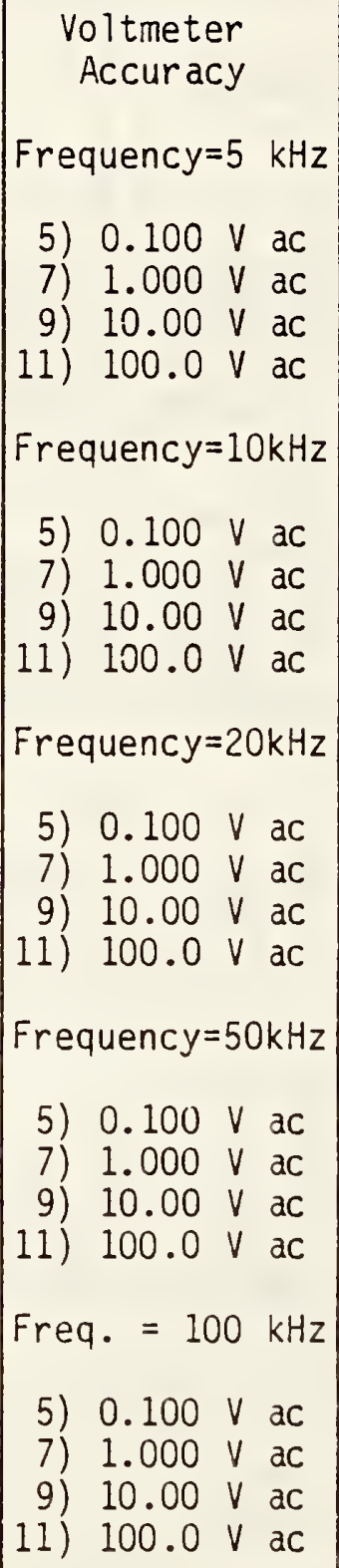 & & $\begin{array}{l}0.09800 \\
0.98000 \\
9.80000 \\
98.0000 \\
\\
0.09800 \\
0.98000 \\
9.80000 \\
98.0000 \\
\\
0.09800 \\
0.98000 \\
9.80000 \\
98.0000 \\
\\
0.09600 \\
0.96000 \\
9.60000 \\
96.0000 \\
\\
\\
0.09600 \\
0.96000 \\
9.60000 \\
96.0000\end{array}$ & $\begin{array}{r}0.10200 \\
1.02000 \\
10.2000 \\
102.000 \\
\\
0.10200 \\
1.02000 \\
10.2000 \\
102.000 \\
\\
0.10200 \\
1.02000 \\
10.2000 \\
102.000 \\
\\
0.10400 \\
1.04000 \\
10.4000 \\
104.000 \\
\\
0.10400 \\
1.04000 \\
10.4000 \\
104.000\end{array}$ & $\begin{array}{l}\text { Volts } \\
\text { Volts } \\
\text { Volts } \\
\text { Volts } \\
\text { Volts } \\
\text { Volts } \\
\text { Volts } \\
\text { Volts } \\
\\
\text { Volts } \\
\text { Volts } \\
\text { Volts } \\
\text { Volts } \\
\\
\text { Volts } \\
\text { Volts } \\
\text { Volts } \\
\text { Volts } \\
\\
\text { Volts } \\
\text { Volts } \\
\text { Volts } \\
\text { Volts }\end{array}$ \\
\hline
\end{tabular}


Specification Performance

Data Sheet

Bid Sample ID No.

\begin{tabular}{|c|c|c|c|c|}
\hline $\begin{array}{l}\text { Reference } \\
\text { Paragraph }\end{array}$ & $\begin{array}{l}\text { Specification } \\
\text { Description }\end{array}$ & $\begin{array}{l}\text { Measurement Data, } \\
\text { Observations, Notes, etc. }\end{array}$ & \begin{tabular}{c|c} 
Acceptable Limits \\
Min.
\end{tabular} & Units \\
\hline 10.4 .3 & $\begin{array}{l}\text { Measurement } \\
\text { Mode }\end{array}$ & & & \\
\hline 10.4 .4 & $\begin{array}{c}\text { Level } \\
\text { Overange } \\
\text { Indication }\end{array}$ & & & \\
\hline
\end{tabular}


Table 10.2.3.A. Monitor Output Connector, Part 1 (Sine Wave Signals)

\begin{tabular}{|c|c|c|c|c|c|c|}
\hline \multicolumn{2}{|c|}{ AC Calibrator } & \multirow{3}{*}{ 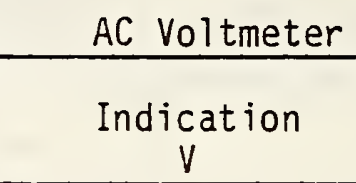 } & \multirow{3}{*}{$\begin{array}{c}\text { Normalized } \\
\text { Indication } \\
\%\end{array}$} & \multicolumn{3}{|c|}{ Acceptable Limits } \\
\hline Freq. & Ampl. & & & Deviation & & \\
\hline & & & & & Min V & Max V \\
\hline 20 & 0.1 & - & - & \pm 10 & .05 & 5 \\
\hline $1 k$ & 0.1 & $\ldots+\ldots$ & $\operatorname{Ref}=0$ & $\operatorname{Ref}=0$ & .05 & 5 \\
\hline $100 k$ & 0.1 & 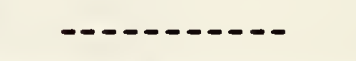 & - & \pm 10 & .05 & 5 \\
\hline 20 & 1 & 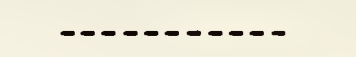 & - & \pm 10 & .05 & 5 \\
\hline $1 \mathrm{k}$ & 1 & - & $\operatorname{Ref}=0$ & Ref $=0$ & .05 & 5 \\
\hline $100 k$ & - 1 & $\ldots$ & - - & \pm 10 & .05 & 5 \\
\hline 20 & 10 & - & - & \pm 10 & .05 & 5 \\
\hline $1 k$ & 10 & - & $\operatorname{Re} f=0$ & $\operatorname{Ref}=0$ & .05 & 5 \\
\hline $100 \mathrm{k}$ & 10 & - & - & \pm 10 & .05 & 5 \\
\hline 20 & 100 & 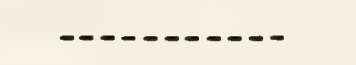 & 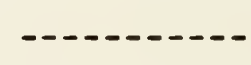 & \pm 10 & .05 & 5 \\
\hline $1 \mathrm{k}$ & 100 & - & $\operatorname{Re} f=0$ & $\operatorname{Ref}=0$ & .05 & 5 \\
\hline $100 k$ & 100 & $-\ldots$ & $-\ldots-\ldots$ & \pm 10 & .05 & 5 \\
\hline 20 & 130 & 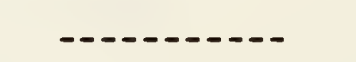 & - & +10 & .05 & 5 \\
\hline $1 k$ & 130 & - & $\operatorname{Ref}=0$ & $\operatorname{Re} f=0$ & .05 & 5 \\
\hline $100 \mathrm{k}$ & 130 & - & - & \pm 10 & .05 & 5 \\
\hline
\end{tabular}


Table 10.2.3.8. Monitor Output Connector, Part 2 (3:1 Crest Factor Signals)

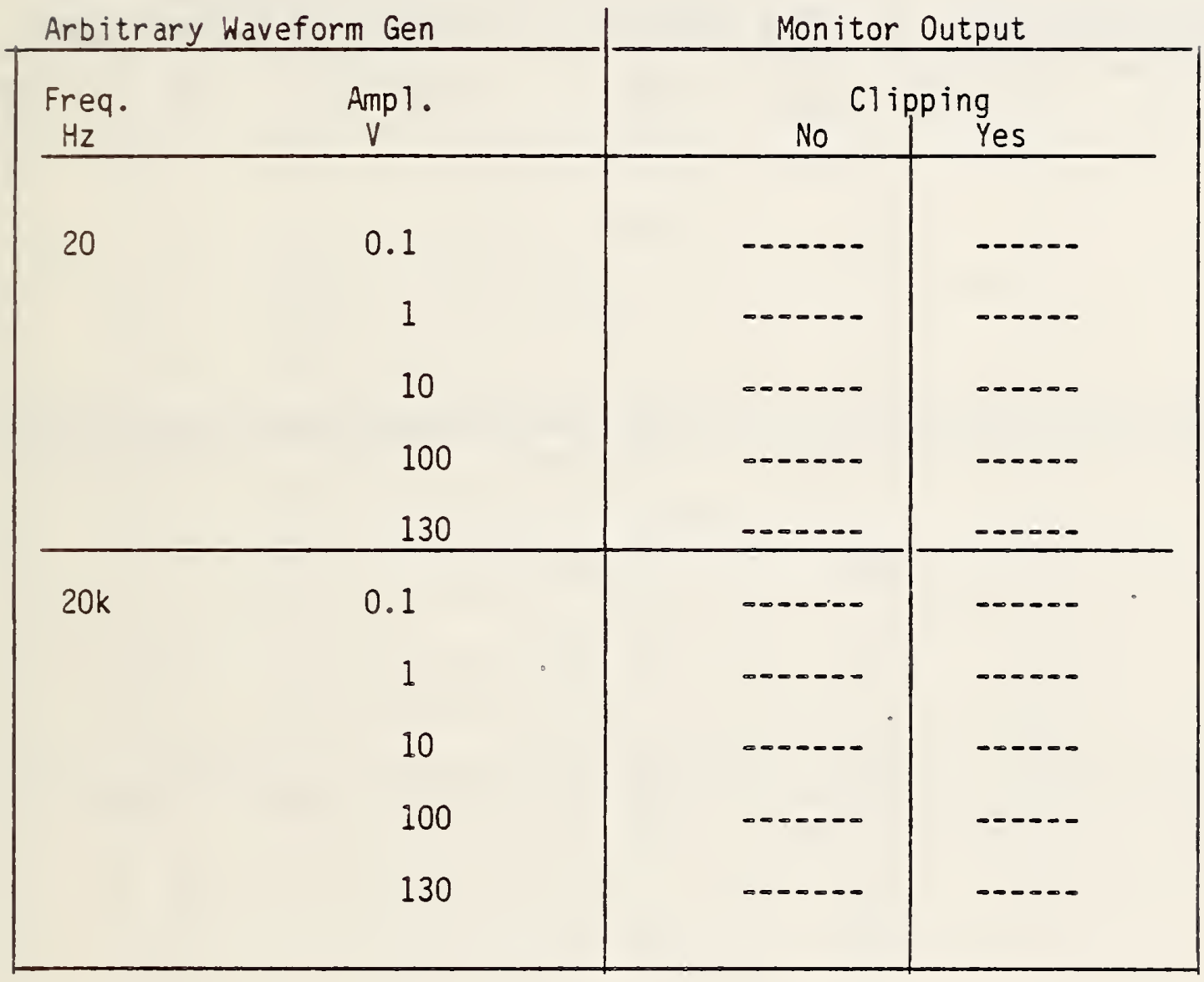


Table 10.3.4A. Distortion Measurement Accuracy, Part 1 (Sine Wave Signals up to loV rms)

\begin{tabular}{|c|c|c|c|c|c|c|c|}
\hline \multicolumn{3}{|c|}{ Low-Distortion Oscillator } & \multicolumn{2}{|c|}{ Audio Oscillator } & \multirow{2}{*}{$\begin{array}{l}\text { UUT Indication } \\
\begin{array}{c}\text { Distortion } \\
\mathrm{dB}\end{array}\end{array}$} & \multicolumn{2}{|c|}{ Accept. Limits } \\
\hline $\begin{array}{l}\text { Freq. } \\
\mathrm{Hz}\end{array}$ & Nom. Amp 1. & Meas. Amp l. & $\begin{array}{l}\text { Freq. } \\
\mathrm{Hz}\end{array}$ & $\begin{array}{c}\text { Attn. } \\
\mathrm{dB}\end{array}$ & & $\underset{\mathrm{d} 8}{\operatorname{Min}}$ & $\begin{array}{c}\text { Max. } \\
d B\end{array}$ \\
\hline 20 & $\begin{array}{c}0.1 \\
1 \\
10 \\
\end{array}$ & -..... & 40 & $\begin{array}{l}10 \\
60 \\
10 \\
60 \\
10 \\
\end{array}$ & - & $\begin{array}{r}9 \\
59 \\
9 \\
59 \\
9 \\
\end{array}$ & $\begin{array}{l}11 \\
61 \\
11 \\
61 \\
11 \\
\end{array}$ \\
\hline 200 & $\begin{array}{r}0.1 \\
1 \\
10\end{array}$ & & 600 & $\begin{array}{l}10 \\
60 \\
10 \\
60 \\
10 \\
60 \\
\end{array}$ & (1) & $\begin{array}{r}9 \\
59 \\
9 \\
59 \\
9 \\
59 \\
\end{array}$ & $\begin{array}{l}11 \\
61 \\
11 \\
61 \\
11 \\
61 \\
\end{array}$ \\
\hline $2 k$ & 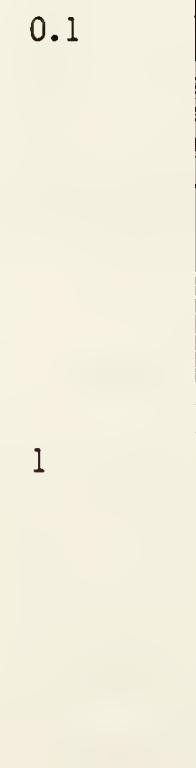 & - & 更 & $\begin{array}{l}10 \\
20 \\
30 \\
40 \\
50 \\
60 \\
10 \\
60 \\
10 \\
20 \\
30\end{array}$ & (1) & $\begin{array}{r}9 \\
19 \\
29 \\
39 \\
49 \\
59 \\
9 \\
59 \\
9 \\
19 \\
29\end{array}$ & $\begin{array}{l}11 \\
21 \\
31 \\
41 \\
51 \\
61 \\
11 \\
61 \\
11 \\
21 \\
31\end{array}$ \\
\hline
\end{tabular}


Table 10.3.4A. Distortion Measurement Accurcy, Part 1

(Continued)

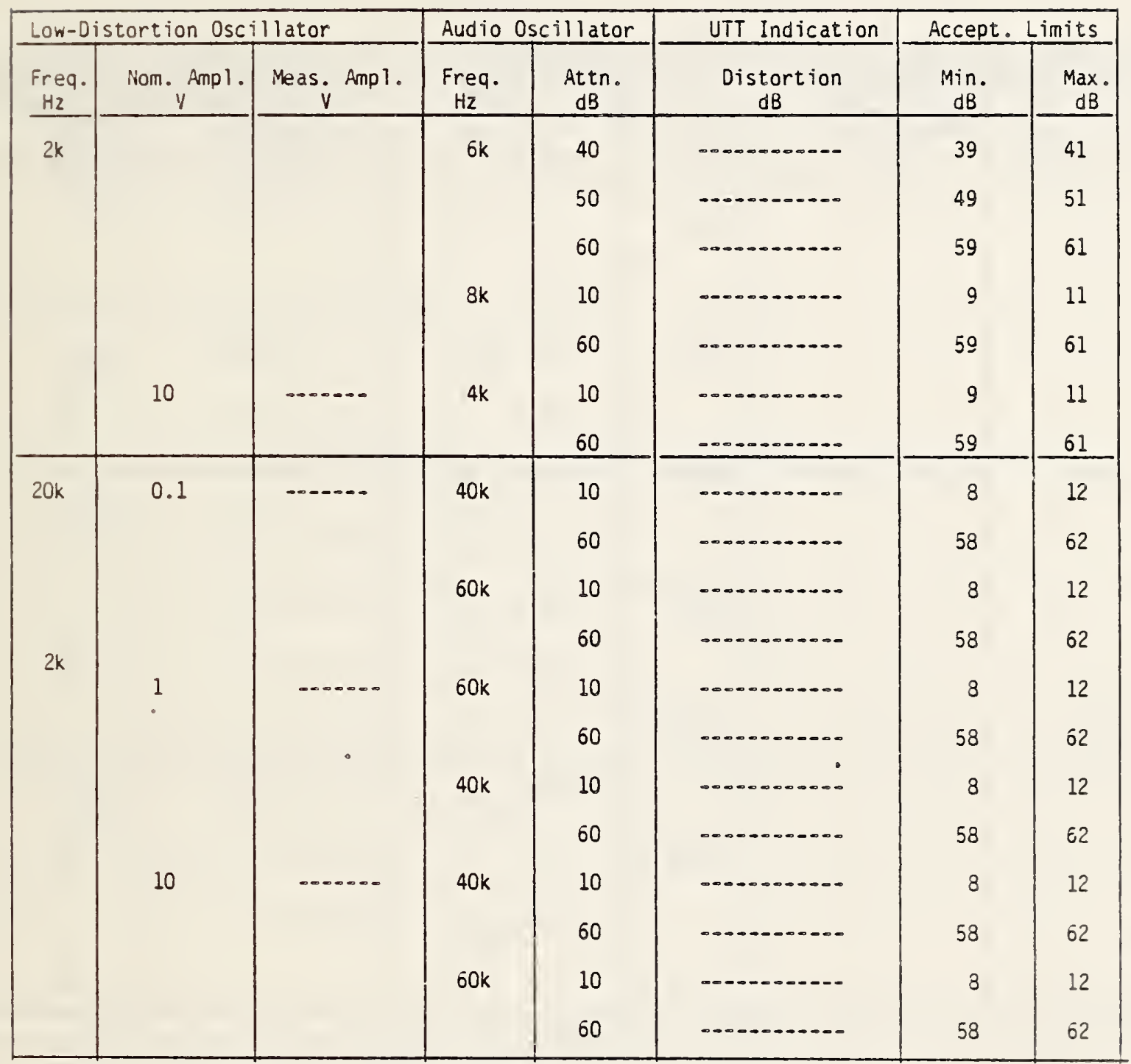


Table 10.3.4A. Distortion Measurement Accuracy, Part 1 (Continued)

\begin{tabular}{|c|c|c|c|c|c|c|c|}
\hline \multicolumn{3}{|c|}{ Low-Distortion 0scillator } & \multicolumn{2}{|c|}{ Audio 0scillator } & \multirow{2}{*}{$\begin{array}{c}\text { UUT Indication } \\
\begin{array}{c}\text { Distortion } \\
\mathrm{dB}\end{array}\end{array}$} & \multicolumn{2}{|c|}{ Accept. Limits } \\
\hline $\begin{array}{c}\text { Freq. } \\
\mathrm{Hz}\end{array}$ & Nom. Amp l. & Meas. Ampl. & $\begin{array}{c}\text { Freq. } \\
\mathrm{Hz}\end{array}$ & $\begin{array}{l}\text { Attn. } \\
\mathrm{dB}\end{array}$ & & $\underset{d B}{\operatorname{Min} .}$ & $\operatorname{Max}$. \\
\hline \multirow[t]{13}{*}{$100 k$} & 0.1 & $\cdots+\cdots$ & $200 k$ & 10 & $\cdots+\cdots$ & 6 & 13 \\
\hline & & & & 60 & $\cdots \ldots-\cdots$ & 56 & 63 \\
\hline & & & $300 \mathrm{k}$ & 10 & $\ldots \ldots$ & 6 & 13 \\
\hline & & & & 60 & ------ & 56 & 63 \\
\hline & 1 & $\ldots \ldots$ & $300 \mathrm{k}$ & 10 & $-\cdots-\cdots$ & 6 & 13 \\
\hline & & & & 60 & $-\cdots--$ & 56 & 63 \\
\hline & & & $200 k$ & 10 & $\cdots \cdots$ & 6 & 13 \\
\hline & & & & 60 & $\cdots \cdots \cdots$ & 56 & 63 \\
\hline & 10 & ------- & $200 \mathrm{k}$ & 10 & 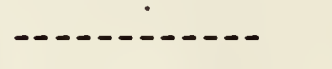 & 6 & 13 \\
\hline & & & & 60 & $\ldots+\ldots$ & 56 & 63 \\
\hline & & & $300 k$ & 10 & $------\cdots--$ & 58 & 13 \\
\hline & & & & 60 & $\ldots \ldots \ldots$ & 6 & 63 \\
\hline & & & & & & 56 & 13 \\
\hline
\end{tabular}


Table 10.3.4B. Distortion Measurement Accuracy, Part 1 (Sine Wave Signals Above $10 \vee \mathrm{rms}$ )

\begin{tabular}{|c|c|c|c|c|c|c|c|}
\hline \multirow{2}{*}{\multicolumn{3}{|c|}{ 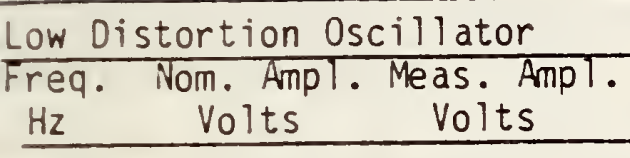 }} & \multicolumn{2}{|c|}{ Audio Oscillator } & \multirow{2}{*}{$\begin{array}{c}\text { UUT Indication } \\
\text { Distortion } \\
\mathrm{dB}\end{array}$} & \multicolumn{2}{|c|}{ Accep. Limits } \\
\hline & & & $\begin{array}{c}\text { Frea- } \\
\mathrm{Hz}\end{array}$ & $\begin{array}{l}\text { Attn. } \\
\mathrm{dB}\end{array}$ & & $\begin{array}{c}\text { Min. } \\
\mathrm{dB}\end{array}$ & $\begin{array}{l}\text { Max. } \\
\mathrm{dB}\end{array}$ \\
\hline \multirow[t]{2}{*}{20} & 100 & --- & 40 & 10 & $-\cdots$ & 9 & 11 \\
\hline & & & & 60 & $-\cdots$ & 59 & 61 \\
\hline \multirow[t]{2}{*}{200} & 100 & --- & 600 & 10 & $=--$ & 9 & 11 \\
\hline & & & & 60 & --- & 59 & 61 \\
\hline \multirow[t]{4}{*}{$2 k$} & 100 & --- & $4 k$ & 10 & $\cdots$ & 9 & 11 \\
\hline & & & & 60 & $\ldots$ & 59 & 61 \\
\hline & & & $6 k$ & 10 & $-\cdots$ & 9 & 11 \\
\hline & & & . & 50 & $-\cdots$ & .59 & 61 \\
\hline \multirow[t]{4}{*}{$20 k$} & 100 & $\therefore$ & $40 k$ & 10 & $\cdots$ & 8 & 12 \\
\hline & & & & 60 & $\ldots$ & 58 & 62 \\
\hline & & & $60 k$ & 10 & --- & 8 & 12 \\
\hline & & & & 60 & $-\cdots$ & 58 & 62 \\
\hline \multirow[t]{4}{*}{$100 \mathrm{k}$} & 100 & --- & $200 k$ & 10 & $-\cdots$ & 6 & 13 \\
\hline & & & & 60 & $-\cdots$ & 56 & 63 \\
\hline & & & $300 k$ & 10 & $-\cdots$ & 6 & 13 \\
\hline & & & & 60 & & 56 & 63 \\
\hline
\end{tabular}


Table 10.3.4C Distortion Measurement Accuracy, Part 2

( 3 to 1 Crest Factor Signals Up to 1 volt)

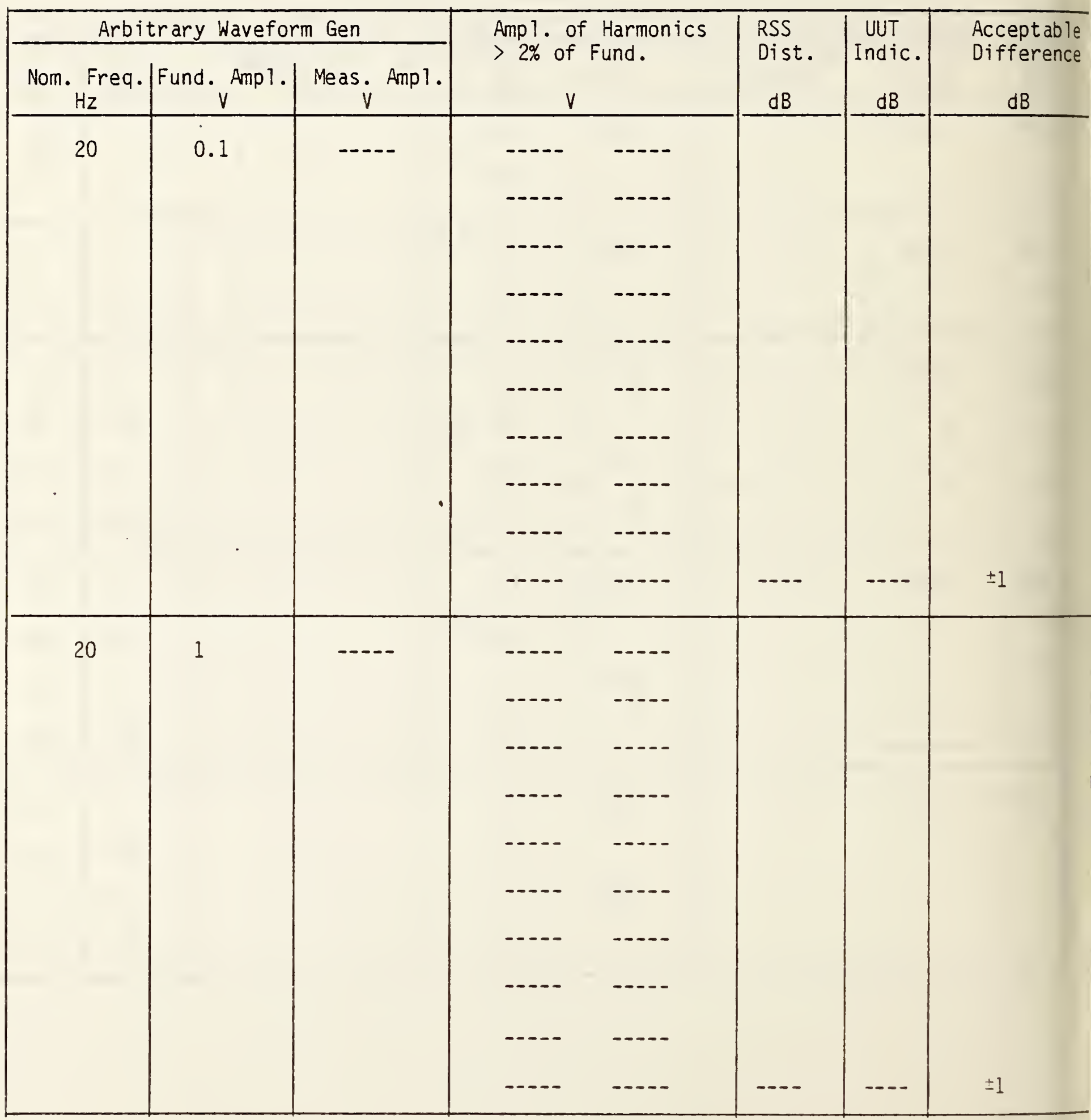


Table 10.3.4C. Distortion Measurement Accuracy, Part 2 (Continued)

Arbitrary Waveform Gen

Nom. Freq. Fund. Ampl. $\mathrm{Hz}$

200
Meas. Ampl. $\checkmark$
Amp 1. of Harmonics

$>2 \%$ of Fund.

$V \quad d B$
RSS

Dist

-
$d B$

\begin{tabular}{|c|c|}
\hline UUT & Acceptable \\
Indic. & Difference
\end{tabular}

$-\cdots$

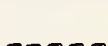
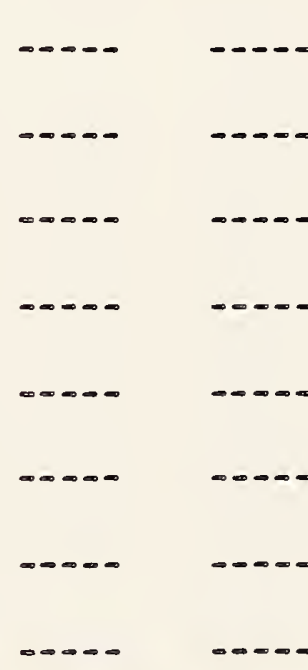

$-\infty-\infty$

200

1
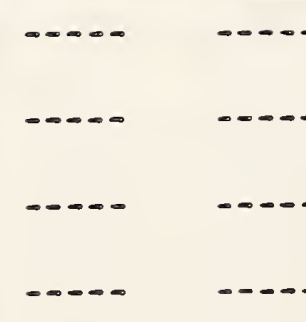

$+$

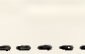

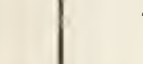
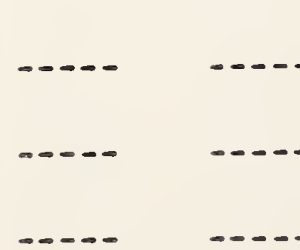
Table 10.3.4C Distortion Measurement Accuracy, Part 2 (Cont inued)

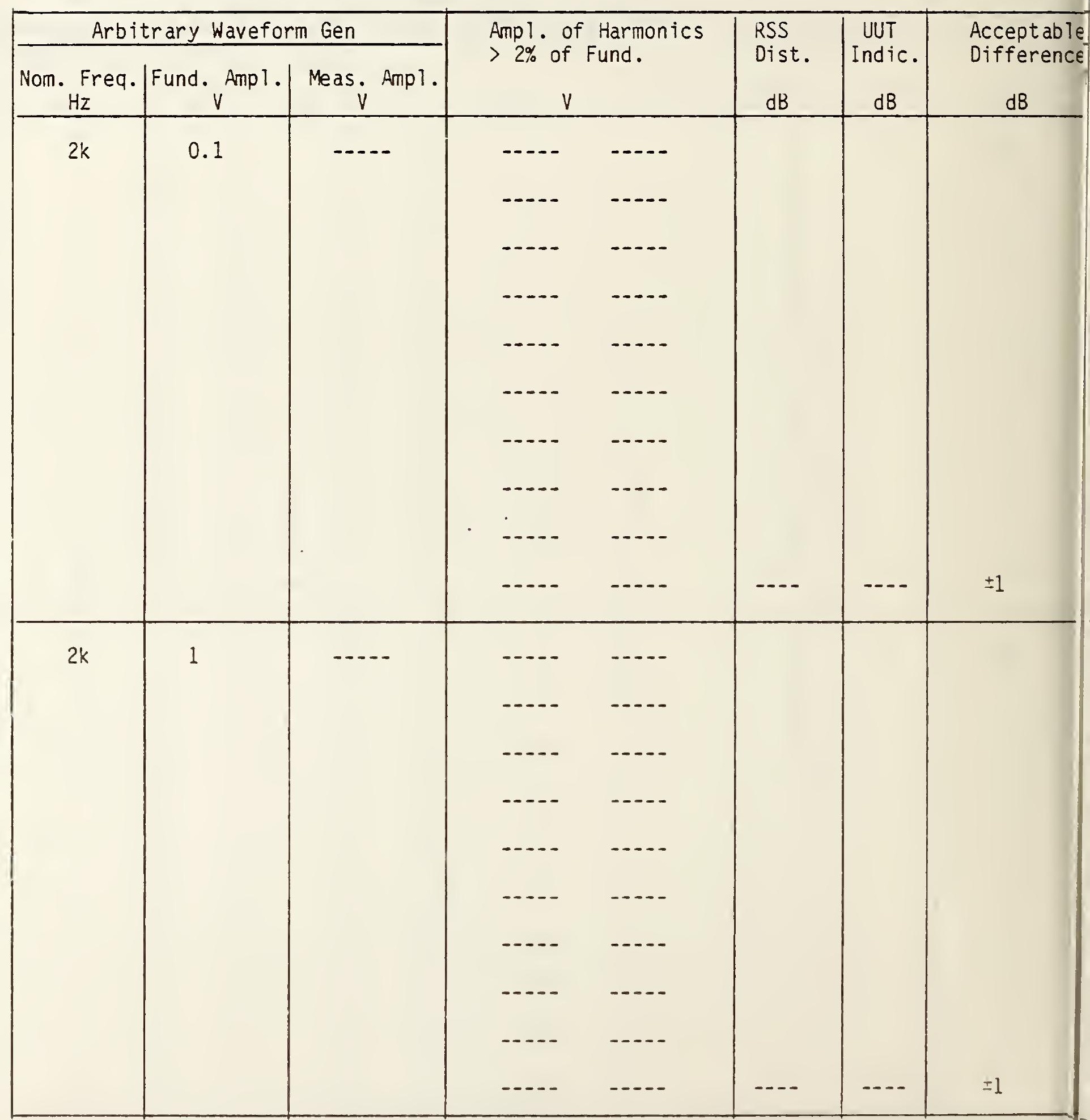


Table 10.3.4D Distortion Measurement Accuracy, Part 2 ( 3 to 1 Crest Factor Signals above 1 voit)

\section{Arbitrary Waveform Gen}

Nom. Freq. Fund. Ampl. $\mathrm{Hz}$ 20 $\checkmark$
Meas. Amp l.

\begin{tabular}{|c|}
$V$ \\
\hline 10
\end{tabular}

\section{0}

Amp 1. of Harmonics $>2 \%$ of Fund.

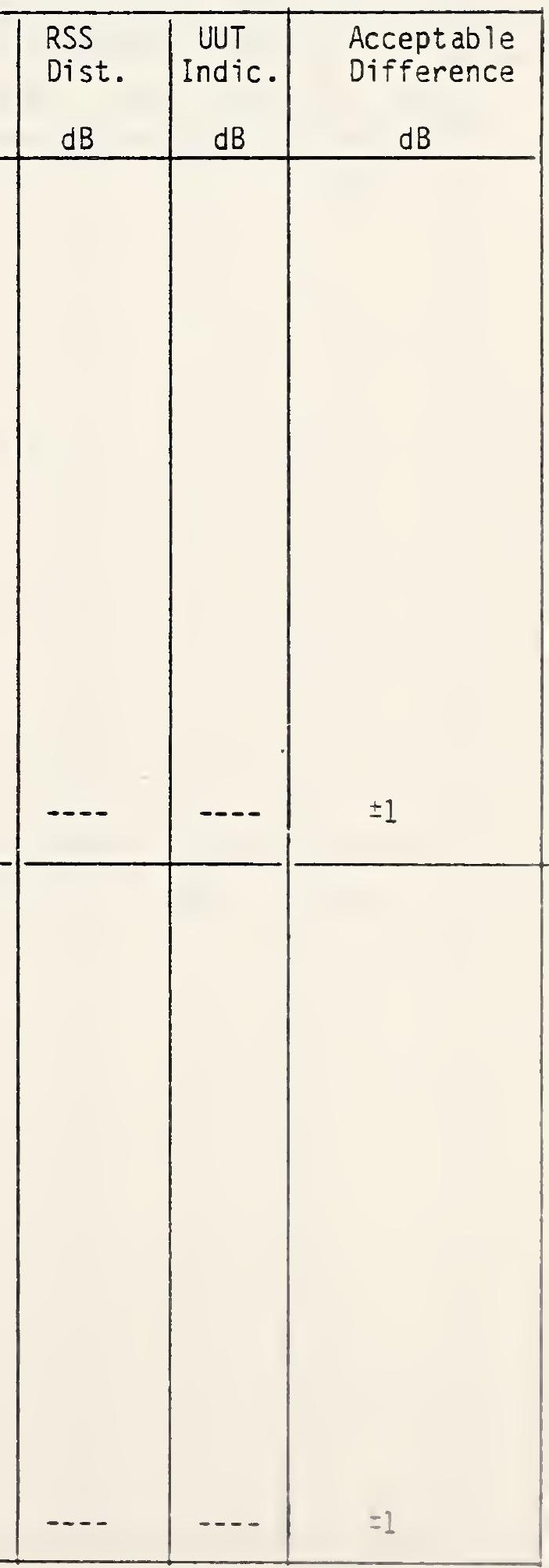


Table 10.3.40 Distortion Measurement Accuracy, Part 2 (Cont inued)

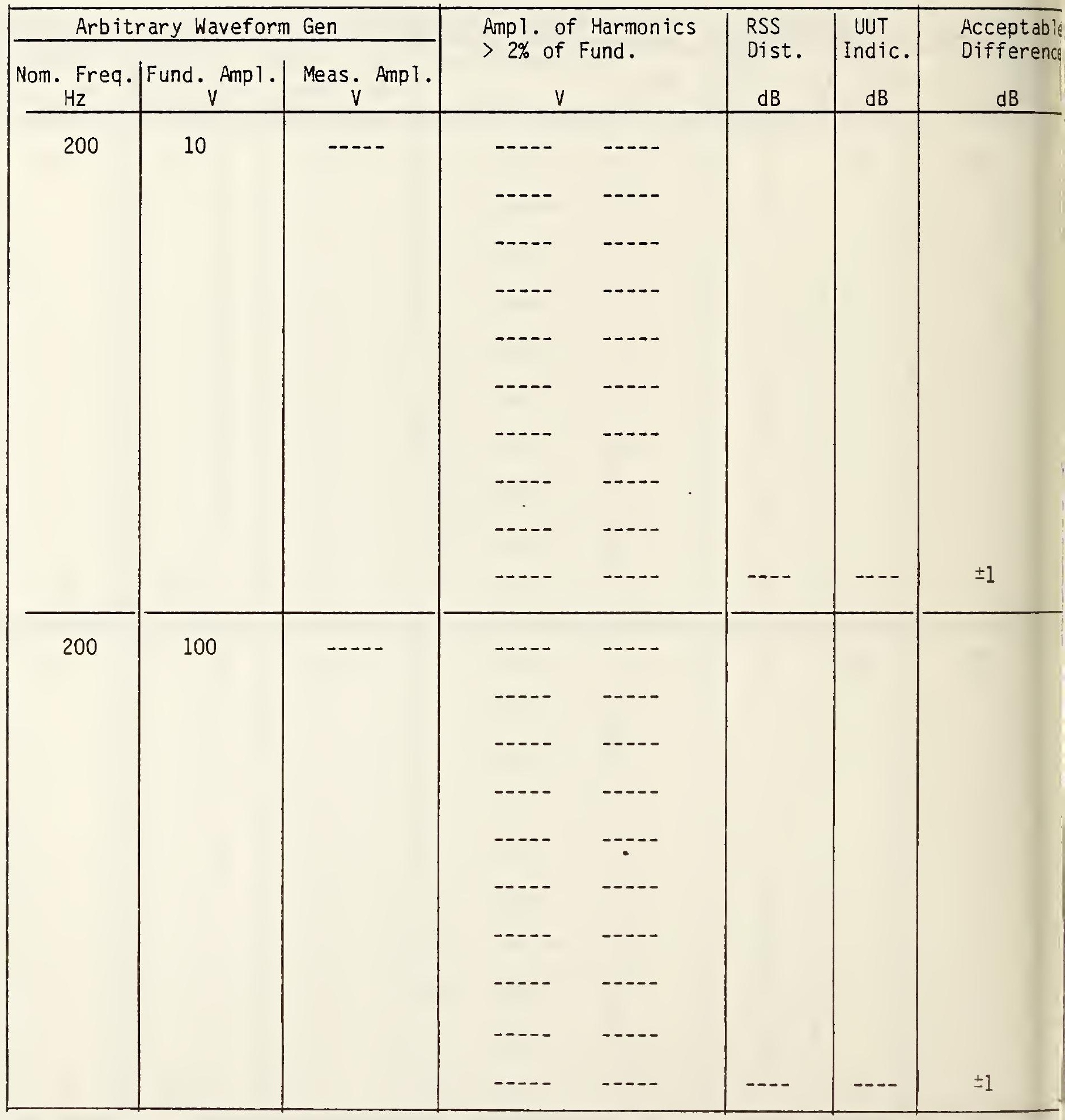


Table 10.3.40 Distortion Measurement Accuracy, Part 2 (Continued)

\begin{tabular}{|c|c|c|c|c|c|c|}
\hline \multicolumn{3}{|c|}{ Arbitrary Waveform Gen } & \multirow{2}{*}{$\begin{array}{c}\text { Ampl. of Harmonics } \\
>2 \% \text { of Fund } \\
V\end{array}$} & \multirow{2}{*}{$\begin{array}{l}\text { RSS } \\
\text { Dist. } \\
\text { dB }\end{array}$} & \multirow{2}{*}{$\begin{array}{c}\text { UUT } \\
\text { Indic. } \\
\mathrm{dB}\end{array}$} & \multirow{2}{*}{$\begin{array}{c}\text { Acceptable } \\
\text { Difference } \\
\mathrm{dB} \\
\end{array}$} \\
\hline $\begin{array}{c}\text { Freq. Nom. } \\
\mathrm{Hz}\end{array}$ & Fund. Amp 1. & ${ }_{i}$ Meas Ampl. & & & & \\
\hline $2 k$ & 10 & $-\cdots$ & 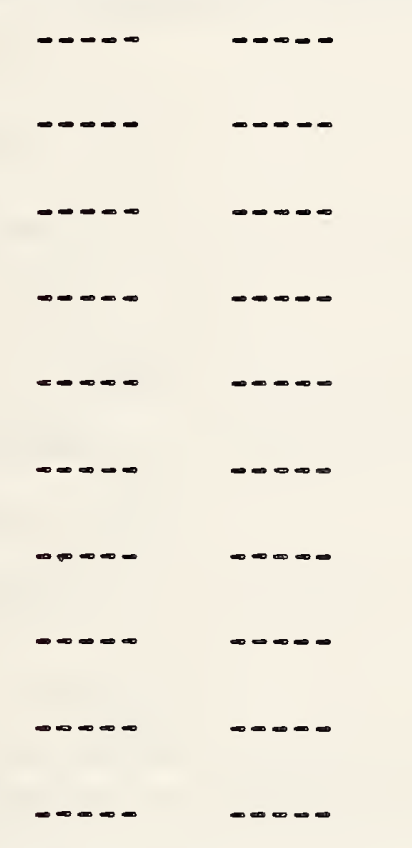 & --- & $-\infty$ & \pm 1 \\
\hline $2 k$ & 100 & 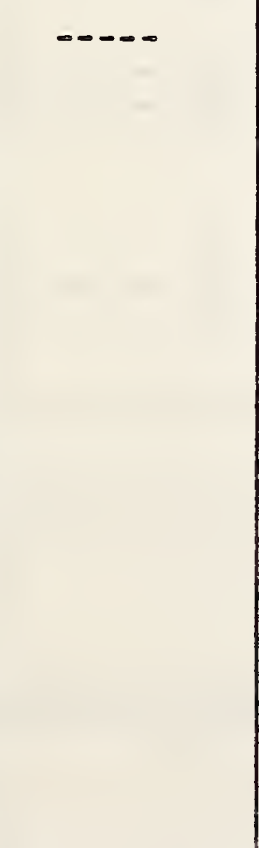 & 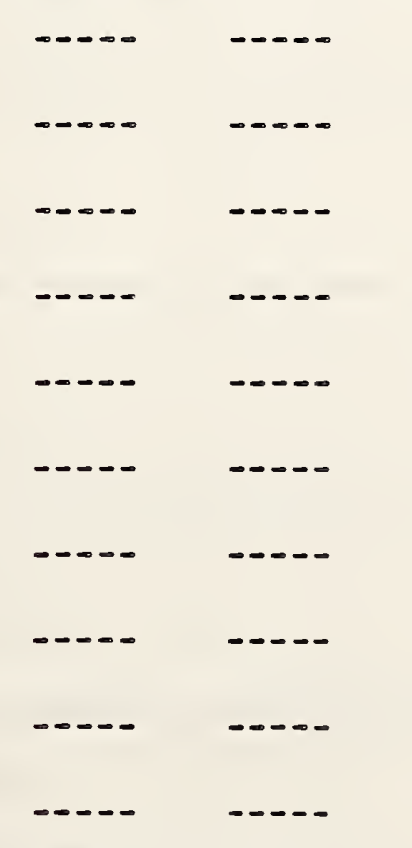 & --- & $-\ldots$ & \pm 1 \\
\hline
\end{tabular}


Table 10.3.6A SINAD Measurement Accuracy

(Combined Signal Amplitudes Up to 10 volts)

\begin{tabular}{|c|c|c|c|c|c|}
\hline No ise Gen. & Low-Dist. Oscil. & No ise Gen./Low-Dist. Oscil. & UUT & \multicolumn{2}{|c|}{ Acceptable Limits } \\
\hline$\underset{V}{\operatorname{Amp}} 1$. & $\begin{array}{c}\text { Freq. } \\
\mathrm{Hz}\end{array}$ & $\begin{array}{c}\text { Combined Ampl. } \\
\mathrm{V}\end{array}$ & $\begin{array}{c}\text { Indic. } \\
\mathrm{dB}\end{array}$ & $\begin{array}{c}\text { Min. } \\
\mathrm{dB}\end{array}$ & $\begin{array}{c}\operatorname{Max} \\
d B\end{array}$ \\
\hline \multirow[t]{4}{*}{0.01} & \multirow[t]{4}{*}{20} & 0.316 & --- & 29 & 31 \\
\hline & & 1.00 & --- & 39 & 41 \\
\hline & & 3.16 & --- & 49 & 51 \\
\hline & & 10.0 & --- & 59 & 61 \\
\hline \multirow[t]{4}{*}{0.1} & \multirow[t]{4}{*}{20} & 0.316 & --- & 9 & 11 \\
\hline & & 1.00 & $-\cdots$ & 19 & 21 \\
\hline & & 3.16 & --- & 29 & 31 \\
\hline & & 10.0 & --- & 39 & 41 \\
\hline \multirow[t]{2}{*}{1.0} & \multirow[t]{2}{*}{20} & 3.16 & ---- & 9 & 11 \\
\hline & & 10.0 & --- & 19 & 21 \\
\hline \multirow[t]{2}{*}{0.01} & \multirow[t]{2}{*}{200} & 0.1 & --- & 19 & 21 \\
\hline & & 3.16 & ---- & 49 & 51 \\
\hline \multirow[t]{2}{*}{0.1} & \multirow[t]{2}{*}{200} & 1.0 & --- & 19 & 21 \\
\hline & & 10.0 & --- & 39 & 41 \\
\hline \multirow[t]{2}{*}{1.0} & \multirow[t]{2}{*}{200} & 3.16 & -..- & 9 & 11 \\
\hline & & 10.0 & --- & 19 & 21 \\
\hline \multirow[t]{3}{*}{0.01} & \multirow[t]{3}{*}{$2 k$} & 0.316 & -..- & 29 & 31 \\
\hline & & 3.16 & --- & 49 & 51 \\
\hline & & 10.0 & --.- & 59 & 61 \\
\hline
\end{tabular}


Table 10.3.6A SINAD Measurement Accuracy (Continued)

\begin{tabular}{|c|c|c|c|c|c|}
\hline \multirow{2}{*}{$\begin{array}{l}\text { No ise Gen. } \\
\text { Ampl. } \\
\text { V }\end{array}$} & \multirow{2}{*}{$\begin{array}{l}\text { Low-Dist. Oscil. } \\
\text { FREQ. } \\
\text { Hz }\end{array}$} & \multirow{2}{*}{$\begin{array}{l}\text { Noise Gen./Low-Dist. Oscil. } \\
\text { Combined Ampl. } \\
V\end{array}$} & \multirow{2}{*}{ 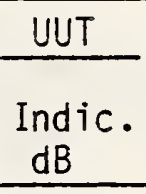 } & \multicolumn{2}{|c|}{ Acceptable Limits } \\
\hline & & & & $\begin{array}{c}\text { Min. } \\
\mathrm{dB} \\
\end{array}$ & $\begin{array}{c}\operatorname{Max} . \\
\mathrm{dB} \\
\end{array}$ \\
\hline \multirow[t]{3}{*}{0.1} & \multirow[t]{3}{*}{$2 k$} & 0.316 & $-\cdots$ & 9 & 11 \\
\hline & & 1.0 & --- & 19 & 21 \\
\hline & & 10.0 & ---- & 39 & 41 \\
\hline \multirow[t]{2}{*}{1.0} & \multirow[t]{2}{*}{$2 k$} & 3.16 & --- & 9 & 11 \\
\hline & & 10.0 & --- & 19 & 21 \\
\hline 0.01 & $20 k$ & 10.0 & 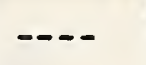 & 58 & 62 \\
\hline \multirow[t]{2}{*}{0.1} & \multirow[t]{2}{*}{$20 k$} & 0.316 & --- & 8 & 12 \\
\hline & & 10.0 & --- & 38 & 42 \\
\hline \multirow[t]{2}{*}{1.0} & \multirow[t]{2}{*}{$20 k$} & 3.16 & $\cdots$ & 8 & 12 \\
\hline & & 10.0 &.-- & 18 & 22 \\
\hline \multirow[t]{3}{*}{0.01} & \multirow[t]{3}{*}{$100 \mathrm{~K}$} & 0.316 & -..- & 26 & 33 \\
\hline & & 3.16 &.-- & 46 & 53 \\
\hline & & 10.0 & $\cdots$ & 56 & 63 \\
\hline \multirow[t]{3}{*}{0.1} & \multirow[t]{3}{*}{$100 \mathrm{~K}$} & 0.316 & 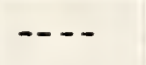 & 6 & i3 \\
\hline & & 3.16 & .... & 26 & 33 \\
\hline & & 10.0 & --- & 36 & 43 \\
\hline \multirow[t]{2}{*}{1.0} & \multirow[t]{2}{*}{$100 \mathrm{~K}$} & 3.16 & $\ldots$ & ó & 13 \\
\hline & & 10.0 & -.-- & 16 & 23 \\
\hline
\end{tabular}


Table 10.3.6B SINAD Measurement Accuracy

(Combined Signal Amplitudes Above 10 volts)

\begin{tabular}{|c|c|c|c|c|c|}
\hline Noise Gen. & Low-Dist. Oscil. & Noise Gen/Low-Dist. Oscil. & UUT & \multicolumn{2}{|c|}{ Acceptable Limits } \\
\hline Amp 1. & $\begin{array}{c}\text { Freq. } \\
\mathrm{Hz}\end{array}$ & $\begin{array}{c}\text { Combined Amp T. } \\
\mathrm{V}\end{array}$ & $\begin{array}{c}\text { Indication } \\
\mathrm{dB}\end{array}$ & $\begin{array}{c}\text { Min. } \\
d B\end{array}$ & $\begin{array}{l}\text { Max. } \\
\mathrm{dB}\end{array}$ \\
\hline 0.1 & 20 & 100 & $-\cdots$ & 59 & 61 \\
\hline 0.1 & 200 & 100 & --- & 59 & 61 \\
\hline 0.1 & $2 k$ & 31.6 & $\cdots$ & 49 & 51 \\
\hline 0.1 & $2 k$ & 100 & --- & 54 & 61 \\
\hline 1.0 & $2 \mathrm{k}$ & 31.6 & --- & 29 & 31 \\
\hline 1.0 & $2 k$ & 100 & -..- & 39 & 41 \\
\hline 0.1 & $20 \mathrm{k}$ & 100 & --- & 58 & 62 \\
\hline 0.1 & $100 \mathrm{k}$ & 100 & -.. & 56 & 63 \\
\hline 1.0 & $100 \mathrm{k}$ & 100 & --- & 36 & 43 \\
\hline
\end{tabular}


Table 10.3.7. Fundamental Rejection

\begin{tabular}{|c|c|c|c|c|c|c|c|c|}
\hline \multicolumn{3}{|c|}{ Low Distortion Oscillator } & \multicolumn{2}{|c|}{ Audio Oscil. } & \multicolumn{3}{|c|}{ Spectrum Analyzer } & \multirow{2}{*}{$\frac{\text { Accept. Limit }}{\text { Min. }}$ dB } \\
\hline $\begin{array}{c}\text { Freq. } \\
\mathrm{Hz}\end{array}$ & Non. Amp T. $_{i}$ & $\begin{array}{c}\text { Meas. Amp T. } \\
\text { v }\end{array}$ & $\begin{array}{c}\text { Freq. } \\
\mathrm{Hz}\end{array}$ & $\begin{array}{c}\text { Attn. } \\
\mathrm{dB}\end{array}$ & $\begin{array}{c}\begin{array}{c}L-D \text { USCT. } \\
\mathrm{dB}\end{array} \\
\end{array}$ & \begin{tabular}{|c|} 
Audio. OSCT \\
$\mathrm{dB}$
\end{tabular} & \begin{tabular}{|c|} 
Diff. \\
$d B$
\end{tabular} & \\
\hline 20 & 0.1 & --- & 40 & 60 & $\cdots$ & $-\cdots$ & --- & 10 \\
\hline 200 & 0.1 & --- & 600 & 60 & --- & $-\infty$ & --- & 10 \\
\hline $2 k$ & 0.1 & --- & $4 k$ & 60 & $\cdots$ & $-\infty$ & --- & 10 \\
\hline $20 k$ & 0.1 & ---- & $40 k$ & 60 & $-\infty$ & --- & --- & 10 \\
\hline $100 \mathrm{k}$ & 0.1 & $\cdots$ & $200 \mathrm{k}$ & 60 & $\infty$ & $-\infty$ & --- & 10 \\
\hline
\end{tabular}


Table 10.3.9A. Residual Distortion and Noise (Up to 10 Volts)

\begin{tabular}{|c|c|c|c|}
\hline \multicolumn{2}{|c|}{ Low-Distortion Oscillator } & \multirow{2}{*}{$\begin{array}{c}\text { UUT Indication } \\
\begin{array}{c}\text { Distortion } \\
\mathrm{dB}\end{array} \\
\end{array}$} & Accept. Limits \\
\hline $\begin{array}{l}\text { Freq. } \\
\mathrm{Hz}\end{array}$ & Nom. Amp 1. & & $\begin{array}{l}\text { Min. } \\
\mathrm{dB}\end{array}$ \\
\hline \multirow[t]{3}{*}{20} & 0.1 & 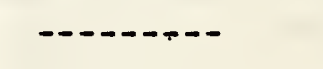 & 65 \\
\hline & 1 & $-\ldots$ & 65 \\
\hline & 10 & ------ & 65 \\
\hline \multirow[t]{3}{*}{200} & 0.1 & ------- & 65 \\
\hline & 1 & 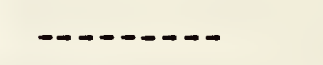 & 65 \\
\hline & 10 & - & 65 \\
\hline \multirow[t]{3}{*}{$2 k$} & 0.1 & ------ & 65 \\
\hline & 1 & -....... & 65 \\
\hline & 10 & $-\ldots$ & 65 \\
\hline \multirow[t]{3}{*}{$20 k$} & 0.1 & $\cdots+\cdots$ & 65 \\
\hline & 1 & $\cdots+\cdots$ & 65 \\
\hline & 10 & -........ & 65 \\
\hline \multirow[t]{3}{*}{$100 \mathrm{k}$} & 0.1 & ------ & 65 \\
\hline & 1 & $-\ldots-\ldots$ & 65 \\
\hline & 10 & 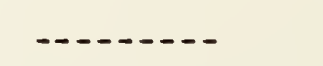 & 65 \\
\hline
\end{tabular}


Table 10.3.98. Residual Distortion and Noise (Above 10 Volts)

\begin{tabular}{|c|c|c|c|}
\hline \multicolumn{2}{|c|}{ Low-Distortion 0scillator } & UUT Indication & Accept. Limits \\
\hline $\begin{array}{l}\text { Freq. } \\
\mathrm{Hz}\end{array}$ & $\begin{array}{c}\text { Input Tevel to } \\
\text { UUT Nom. } \\
V\end{array}$ & $\begin{array}{c}\text { Distortion } \\
\mathrm{dB}\end{array}$ & $\begin{array}{l}\text { Min. } \\
\mathrm{dB}\end{array}$ \\
\hline 20 & 100 & 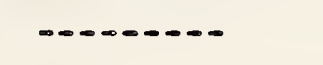 & $65 \mathrm{~dB}$ \\
\hline 200 & 100 & $0 .-0.0 .0$ & $65 \mathrm{~dB}$ \\
\hline $2 k$ & 100 & $\infty-\infty+\infty$ & $65 \mathrm{~dB}$ \\
\hline $20 \mathrm{k}$ & 100 & $0-\infty-0,0-\infty$ & $65 d B$ \\
\hline $100 k$ & 100 & $-0,-000000$ & $65 \mathrm{~dB}$ \\
\hline
\end{tabular}





\section{APPENDIX D \\ ARBITRARY WAVEFORM PROGRAM \\ FOR USE WITH WAVETEK 275 \\ SIGNAL GENERATOR}

$0-1$ 


\section{INITIALIZE WAVEFORM GENERATOR}

ON TIMEOUT 7,1 GOSUB No_wavetek! HANGS IF TIME $<0.20$ SEC Wavete $\mathrm{k}=709$

OUTPUT Wavetek;"P1G1S5.5E-6A5C6XBOXH", N_1, "I"

$$
P 1=1
$$

$$
\mathrm{G}=1
$$

$S=2.67 E-6$

! OUTPUT ON

! INTERNAL TRIGGER

$$
A=5
$$$$
\text { ! 5V P-P INTO } 50 \text { OHMS }
$$

$P \$=" O N "$. ! OUTPUT IS ON INDICATOR

$\mathrm{H} 1=0$ ! HARMONIC FREQUENCY

$\mathrm{H} 2=0$

Freq $=1000$

! HARMONIC AMPLITUDE

St artadd $=0$

! FREQUENCY $1000 \mathrm{HZ}$

Stop add $=\mathrm{N}-1$

! START ADDRESS IS 0

SET UP KEYS

ON KEY O LABEL "CALC DIST" GOSUB Distortion

ON KEY 1 LABEL "FUNCTION" GOSUB FUNC! SAMPLE NO. HARMONIC NO. AND AMPL

ON KEY 2 LABEL "FREQUENCY" GOSUB Freq! SET FREQUENCY

ON KEY 3 LABEL "AMPLITUDE" GOSUB AmpI! SET AMPLITUDE OF P-P VOLTAGE ON KEY 4 LABEL "ON/OFF" GOSUB On_off! SET OUTPUT ON/OFF

500

GOSUB Print status! DISPLAY DEFAULT STATUS

GOTO 430 ! WAIT HERE FOR KEY TO BE DEPRESSED 
PRINT "AMPLITUDE.........;

PRINT "NUMBER OF STEPS....";

PRINT "ON/OFF..........."P\$ 


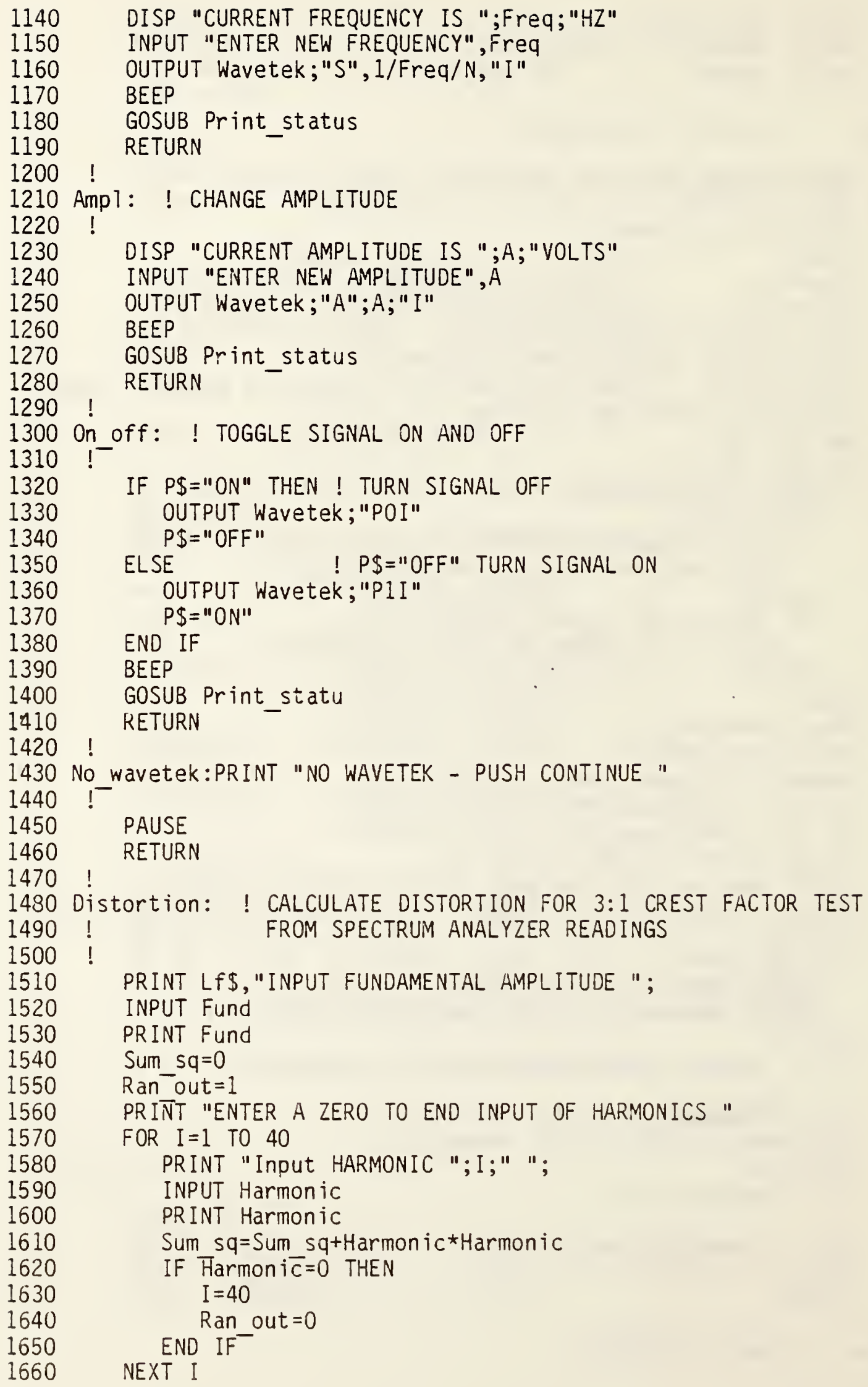


1670 IF Ran out THEN BEEP 400,1 No i se $=\bar{S} Q R$ (Sum $s q$ )

Tota $1=$ SQR (Sum ${ }^{-}$sq $+F$ und $*$ Fund)

1700

1710

1720 Dist $=20 *$ LGT (No ise/Total)

1730 !

IMAGE K, 40.2D, K, 40.2D, K

1740

PRINT USING 1720;"DISTORTION = ";Dist;" $d B=" ; 100 *$ Noise/Total;" \%"

1750

1760

RETURN

END 

APPENDIX E

LOW-PASS FILTER 

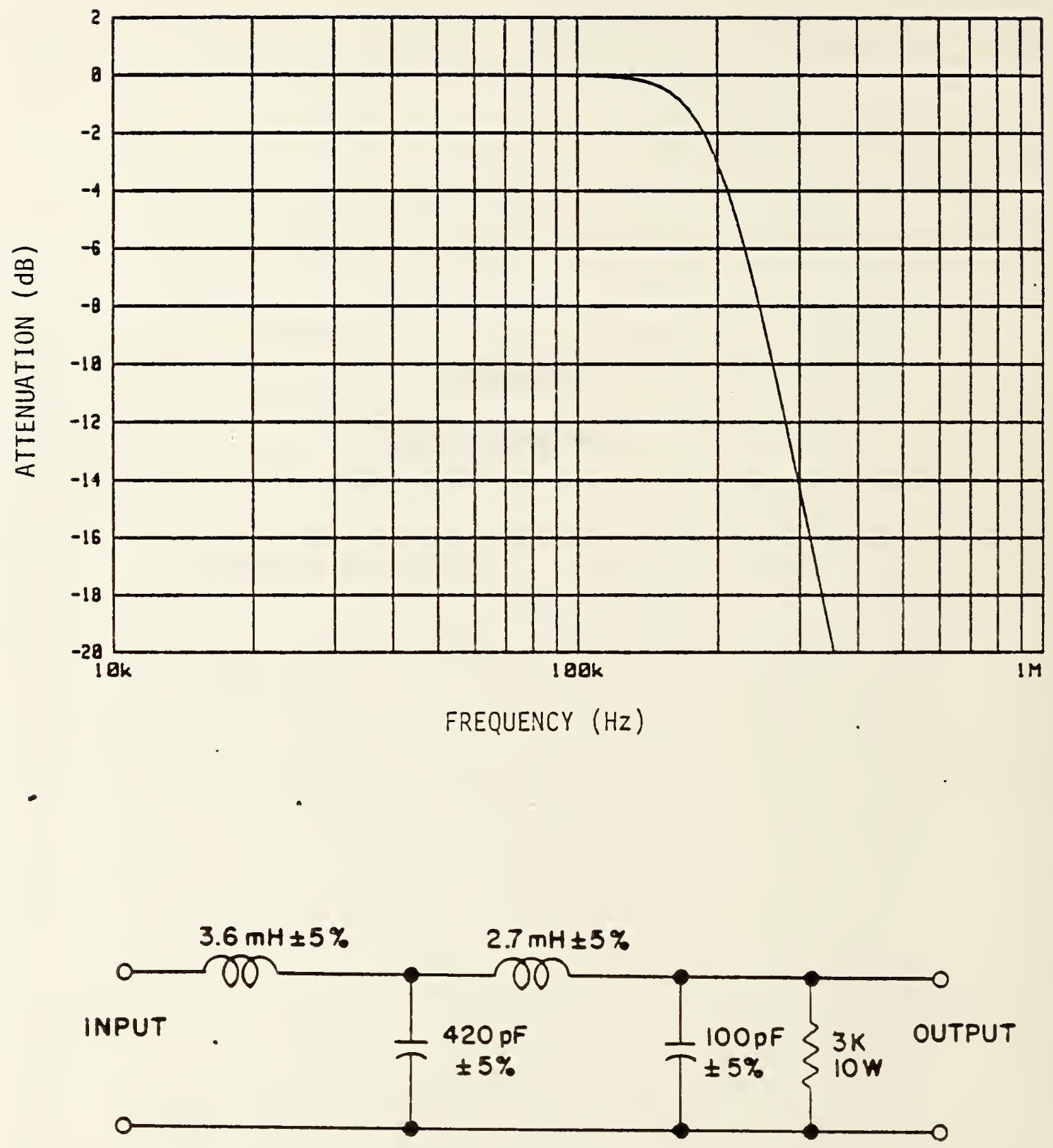

INDUCTORS: MIN $Q=70$, CURRENT RATING $=60 \mathrm{~mA}$

Fig. E.1 Frequency Response \& Schematic of Low-Pass Filter Used in Tests 10.3.? and 10.3.6. 


\section{APPENDIX $F$ \\ TEST EQUIPMENT LIST \\ FOR \\ TS-4084 ( ) / G \\ DISTORTION ANALYZER}


AC Calibrator

Power Amplifier

AC Voltimeter

Arbitrary Waveform Gen.

488 Controller

Active Filter

Low-Pass Filter

Oscilloscope

Audio Oscillator

600 ohm Feedthrough Term.

Frequency Counter

Spectrum Analyzer

Coupling Transformer

LCR meter

Isolation Transformer

3 Wire / 2 Wire Power Adapter

Low-Distortion Oscillator

$600 \therefore$ Resistors

100:1 Atten. Probe

Noise Generator
$100 \mathrm{mV}$ to $100 \mathrm{~V} \mathrm{ac}$

$100 \mathrm{~V}$ to $175 \mathrm{~V}$ ac

$10 \mathrm{mV}$ to $175 \mathrm{~V}$ ac

$20 \mathrm{~Hz}$ to $20 \mathrm{kHz}$

-.-.-

$20 \mathrm{~Hz}$ to $100 \mathrm{kHz}$

$-3 \mathrm{~dB} \approx 200 \mathrm{kHz}$

$20 \mathrm{~Hz}$ to $300 \mathrm{kHz}$

$10 \mathrm{~Hz}$ to $1 \mathrm{MHz}$

$$
\pm 1 \%
$$

$20 \mathrm{~Hz}$ to $1 \mathrm{MHz}$

$50 \mathrm{~Hz}$ to $100 \mathrm{kHz}$ $5 \mathrm{khz}$

-..-

$20 \mathrm{~Hz}$ to $100 \mathrm{kHz}$ $\pm 5 \% \quad 1 / 2$ watt

$20 \mathrm{~Hz}$ to $100 \mathrm{kHz}$
Fluke $5200 \mathrm{~A}$ or equiv.

Fluke 5205A or equiv.

Fluke $8506 \mathrm{~A}$ or equiv. Wavetek 275 or equiv. HP 9836 or equiv.

Wavetek 452 or equiv. See Appendix E

Tektronix 2445 or equiv. Tektronix F6504T or equiv.

Tektronix 011-0092-00 or equiv. HP 5316A or equiv.

HP 3585A or equiv.

UTC-LS-34 or equiv.

HP $4262 A$ or equiv.

Topaz 91002-22 or equiv. Order by Description

Tektronix SG 5010 or equiv. Order by Description or equiv. Tektronix. P6007 or equiv. Wavetek 132 or equiv. 
4. TITLE AND SUBTITLE

\section{ELECTRICAL PERFORMANCE TESTS FOR AUDIO DISTORTION ANALYZERS}

5. $A U T H O R(S)$

O.B. Laug, G.N. Stenbakken, and T. F. Leedy

6. PERFORMING ORGANIZATION (If joint or other than NBS, see instructions)

NATIONAL BUREAU OF STANDARDS

DEPARTMENT OF COMMERCE

WASHINGTON, D.C. 20234

9. SPONSORING ORGANIZATION NAME AND COMPLETE ADDRESS (Street, City. Stote, ZIP)

10. SUPPLEMENTARY NOTES

Document describes a computer program; SF-185, FIPS Software Summary, is attached.

11. ABSTRACT (A 200-word or less factual summary of most significant information. If document includes a significant bibliography or literature survey. mention it here)

Electrical performance test procedures for audio distortion analyzers were developed by the National Bureau of Standards for the U.S. Army Communications-Electronics Command. The report provides detailed, step-by-step test procedures that are based on specifications supplied by the Army for purposes of evaluating audio distortion analyzer bid samples. Examples of data sheets and tables are also provided for recording interim and final results.

The report discusses the philosoply of each measurement procedure with a view toward providing an understanding of the basic metrology required to perform the measurements. In addition, the sources of measurement error are discussed. The primary applications and basic principles of modern audio distortion analyzers are also presented.

12. KEY WORDS (Six to twelve entries: alphabetical order: capitalize only proper names; and separate key words by semicolons) audio distortion analyzer; distortion analyzer; distortion; distortion specification; and test procedures.

13. AVAILABILITY

Xx] Unlimited

For Official Distribution. Do Not Release to NTIS

$\square$ Order From Superintendent of Documents, U.S. Government Printing Office, Washington, D.C. 20402.

14. NO. OF

PRINTED PAGES

X* Order From National Technical Information Service (NTIS), Springfield, VA. 2216I

$\begin{aligned} & 157 \\ & \text { 15. Price } \\ & \$ 16.35\end{aligned}$




